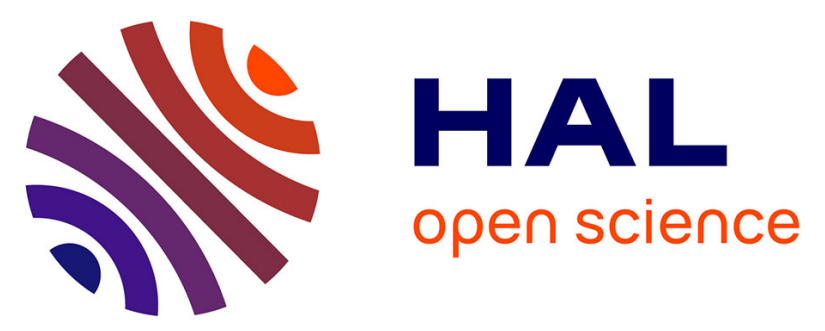

\title{
A semantic typology of location, existence, possession and copular verbs: areal patterns of polysemy in Mainland East and Southeast Asia
} Hilary Chappell, Shanshan Lü

\section{- To cite this version:}

Hilary Chappell, Shanshan Lü. A semantic typology of location, existence, possession and copular verbs: areal patterns of polysemy in Mainland East and Southeast Asia. Linguistics, 2021, 60 (1), pp.1 - 82. 10.1515/ling-2021-0219 . hal-03584141

\author{
HAL Id: hal-03584141 \\ https://hal.science/hal-03584141
}

Submitted on 22 Feb 2022

HAL is a multi-disciplinary open access archive for the deposit and dissemination of scientific research documents, whether they are published or not. The documents may come from teaching and research institutions in France or abroad, or from public or private research centers.
L'archive ouverte pluridisciplinaire HAL, est destinée au dépôt et à la diffusion de documents scientifiques de niveau recherche, publiés ou non, émanant des établissements d'enseignement et de recherche français ou étrangers, des laboratoires publics ou privés. 


\section{Hilary Chappell and Shanshan Lü*}

\section{A semantic typology of location, existence, possession and copular verbs: areal patterns of polysemy in Mainland East and Southeast Asia}

https://doi.org/10.1515/ling-2021-0219

Received August 15, 2019; accepted December 17, 2020; published online December 21, 2021

Abstract: This study is based on a sample of 116 languages from the Mainland East and Southeast Asian linguistic area. Its first objective is to examine four distinct synchronic patterns of areal polysemy, created by the semantic domains of copular, locative, existential and possessive verbs and the constructions they form. As a consequence, its second objective is to model the diachronic change underlying four language types identified on this basis from the data. We argue that there are three grammaticalization pathways which motivate the four synchronic patterns: Type III languages are distinguished by the grammaticalization chain: (PoSTURAL VERB $)>($ DwelL $)>$ LOCATIVE $>$ EXISTENTIAL $>$ PosSESSIVE, while the other two types, Type II and Type IV, show an opposing pathway: (Grasp) > Possessive > Existential. Type I and Type II languages additionally reveal a recurrent polysemy between LocATIVE and Copular verbs. On this basis, an implicational universal is adduced to the effect that no diachronic adjacency exists between LOCATIVE and POSSESSIVE constructions. Crucially, the intervening stage of an EXISTENTIAL construction provides the necessary bridging context for POSSESSIVE reanalysis in this first pathway, while POSSESSIVE verbs are formally distinct from LOCATIVEs in the second, bearing no diachronic relationship to them. The findings on the patterns of polysemy sharing reinforce the notion of a clear typological split between Tibeto-Burman languages on the one hand, and Sinitic, Kra-Dai, Hmong-Mien, and Austroasiatic on the other.

Keywords: existential and possessive verbs; locative; Mainland East and Southeast Asian linguistic area (MESEA); polysemy sharing; semantic typology

\footnotetext{
*Corresponding author: Shanshan Lü, Institute of Corpus Studies and Applications, Shanghai International Studies University, Office 142, Classroom Building 5, 1550 Wenxiang Rd., Songjiang Dist., 201620, Shanghai, China, E-mail: Iv_shanshan@live.cn. https://orcid.org/0000-00022801-7141

Hilary Chappell, Centre de recherches linguistiques sur l'Asie orientale (CRLAO), Ecole des Hautes Etudes en Sciences Sociales (EHESS), Paris, France, E-mail: hilary.chappell@ehess.fr
} 


\section{Introduction}

Over the past century, the relationship of existence and location to possession has been the subject of a vast field of research including studies in both linguistics and philosophy. Notable are Meillet's (1923) and Benveniste's (1960) seminal articles on be- and have- languages in Indo-European as well as Lyons $(1967,1968)$ on the derivation of existential and possessive constructions from locatives. This theme has subsequently been expanded into a crosslinguistic survey by Clark (1978) and taken up again in studies by Freeze (1992), Koch (2012), Bentley et al. (2015), among many others. In particular, Lyons and Clark were proponents of the influential viewpoint that possessors are animate locations and that, accordingly, possessive constructions are a subclass of locative-existential sentences. More recently the link between these semantic domains has been investigated in terms of predicative possession in Heine (1997a, 1997b), Stassen (2009), Creissels (2013), Chappell and Creissels (2019) and also in Mazzitelli (2015) and Myler (2016).

The first objective of the present study is a typological one to investigate the extent of polysemy as opposed to the use of distinct forms in the lexical fields carved out by copular, locative, existential and possessive verbs in languages of the Mainland East and Southeast Asian area (MESEA) in a purely synchronic perspective. To this end, the patterns for 'splitting' and 'sharing' of verbal forms are analyzed by using a sample of 116 languages from Sino-Tibetan, Hmong-Mien, Kra-Dai and Austroasiatic, leading to the establishment of four main language types. None of these languages is found to possess more than three distinct verbal forms, with the semantic domains split or fused in different ways. Furthermore, regardless of the language family, it proves to be an invariant in our sample that possessive and existential verbs share identical forms in each language, whereas no similar kind of syncretism for locative and possessive verbs to the exclusion of all others is in evidence. The locations for the 116 languages and the areal distribution for the four language types are illustrated in two accompanying maps.

The finding on the use of identical forms for existential and possessive verbs as a robust typological characteristic of MESEA supports the same observation made in Clark (1989), similarly reinforcing the finding based on a smaller sample of 71 languages, discussed in Chappell and Creissels (2019). Nonetheless, the latter has a different goal from the present paper in challenging Stassen's hypothesis that a majority of Asian languages make use of Topic Possessives to express predicative possession, and, to this end, presents an argument in favor of their re-interpretation as Have-Possessives. It does not discuss the associated semantic shifts in detail.

The second objective of this study is a diachronic one to examine the semantic and syntactic changes responsible for the intriguing synchronic patterns of polysemy evident in the four types identified from the data in MESEA. On the one hand, it is shown in general that a very common diachronic change in this linguistic area is for 
Dwell and Postural verbs to develop into Locative verbs. On the other hand, specifically in Tibeto-Burman languages, Locative verbs derived from these two lexical fields may further evolve into Existential, then into Possessive verbs, a grammaticalization pathway clearly dispreferred in Kra-Dai, Hmong-Mien, most of Austroasiatic as well as in Sinitic. In the latter language families, identical ExISTENTIAL and Possessive verbs are distinct from the LocATIVE and, we argue, have distinct sources and grammaticalization pathways. Diachronically, locative constructions do not directly evolve into possessive predicates as consecutive stages in a grammaticalization chain, or vice versa, in our MESEA data. We find neither ^LocAtive > Possessive nor *Possessive > Locative. Crucially, the intervening stage of an existential construction provides the bridging context for reanalysis into a possessive predicate: LocATIVE > ExISTENTIAL > POSSESSIVE in Tibeto-Burman.

On the basis of these shared patterns of polysemy across the Mainland East and Southeast Asian area, we propose an implicational universal to the effect:

If a language uses the same verb for locative and possessive constructions, then this verb can also be used in existential constructions.

The diachronic relationship between Copulas and Locative verbs is also explored with respect to two micro-areas for Sinitic and in a small number of Hmongic languages. The two micro-areas, characterized by polysemous COPULAR-LOCATIVE verbs, are located in China in (i) a central-eastern area which straddles Hunan Anhui, Zhejiang and northern Fujian provinces and (ii) in the southern area of Guangdong province and the adjacent Guangxi Autonomous Region.

Examining the shared patterns of polysemy from this Asian areal perspective (Koptjevskaja-Tamm and Liljegren 2017), we make use not only of formal, morphosyntactic criteria but also semantic criteria to pinpoint diachronic change in terms of reanalysis and conceptual transfer, Heine's term (1997b) for 'semantic shift' between cognitive schemata.

The layout for this article is as follows: this introduction leads into Section 2 which spells out our definitions for the constructions, our terminology and methodology, followed by the description and analysis of the four types of patterns in Section 3, classified according to their sharing and splitting of the lexical fields of copular, locative, existential and possessive verbs. The findings on these areal patterns of our study are discussed in terms of phylogeny in Section 4, while the three grammaticalization chains, their accompanying semantic shifts and morphosyntactic reanalysis are presented in Section 5. The relationship between the synchronic structural patterns and the diachronic scenarios is found in the final section, Section 6, followed by a short conclusion in Section 7. 
The verb forms and the details for all the data sources are to be found in Table 5 in the Appendix. The full sample of examples is available in the Zenodo openaccess repository (https://doi.org/10.5281/zenodo.5762053).

\section{Methodology and definitions}

The sample of 116 languages assembled for this study covers the four language families of Mainland East and Southeast Asia in as representative a way as possible, shaped to some extent by the availability of reliable data. It was clearly not our goal to assemble a balanced sample for statistical purposes, in the technical sense of this term. Both fieldwork data from a large number of informants are used, as well as data from reference grammars in which we were able to find the full paradigms for the four semantic domains and their constructions.

All the verb forms are provided in Table 5, found in the Appendix, while the entire set of language examples may be consulted at https://doi.org/10.5281/ zenodo.5762053. A second smaller sample of 18 languages has also been compiled for the purposes of comparison, bringing the total to 134 languages in the expanded sample. Partial data are only available for this supplementary set. For this reason, they are not included in the figures given throughout the present study for the types of polysemy sharing under examination.

The locations and types for all the languages in the expanded sample are found in Map 1 directly below. Note that languages from the main sample are tagged by circles on this map, color denoting their type, while those from the smaller sample are tagged by black triangles.

That the four semantic domains are conceptually discrete is reflected in their coding by distinct construction types in all the languages of our sample. These correspond to the same set of constructions analyzed by Clark (1978) in her seminal work on word order and definiteness properties, hers based on a sample of 30 languages. Conceptually, each construction is associated with a distinct cognitive schema, as proposed by Heine in two studies on possession (1997a, 1997b). For the reader's convenience, beneath each definition we indicate in parentheses to which schema each construction type belongs in Heine's work.

(i) Copular verb: $\mathrm{X}$ is a $\mathrm{Y}$

Li Qingzhao was a grand poetess of the Song dynasty.

The copular construction classifies or judges the subject $\mathrm{X}$ as belonging to the category $\mathrm{Y}$ or codes equivalence between the referents of its two noun arguments, 


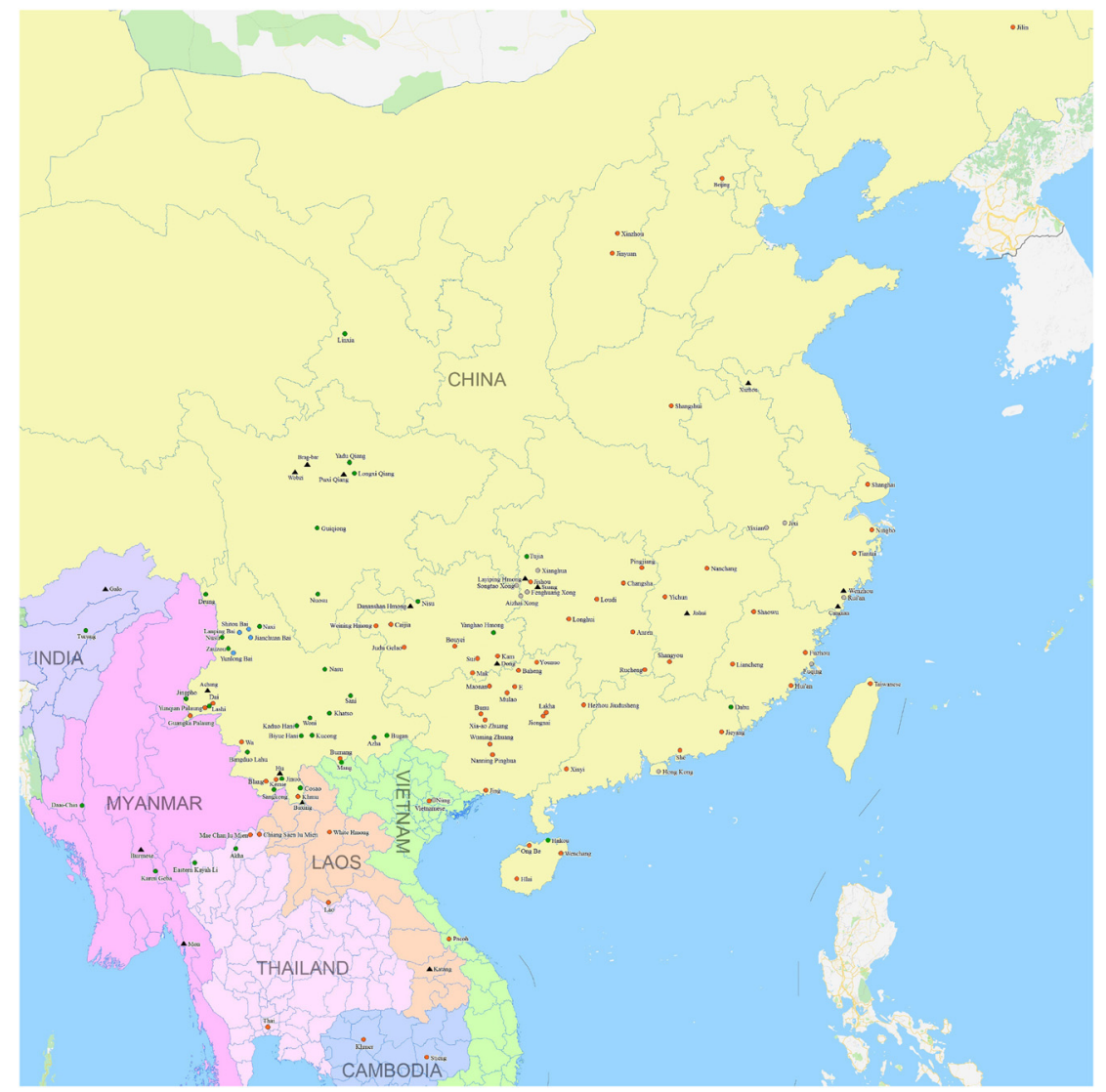

Map 1: Locations of 134 languages in extended sample.

the subject and the copular complement noun; $X$ is $a Y$. The copular complement forms part of its predicate. (Equation Schema)

(ii) Locative verb: $\mathrm{X}$ is at a place $\mathrm{Y}$.

This pagoda is in Mandalay.

The locative construction has two arguments: a locus and a located entity. It is semantically intransitive, expressing the position of the subject noun with respect to a given spatial context, the locus. The subject or located entity is typically definite while the noun denoting the location generally takes the form of a predicate complement, being non-omissible in our data; $X$ is at place $Y$. For this 
category, we prefer the use of the term 'locative verb' for the lexical domain coded by 'be at', 'be in' or 'stay' in order to avoid the potential confusion that the term 'locative copula' might cause with the equational copula in (i) (cf. Clark 1978: 88; Stassen 1997: 59-60; Koch 2012). (Location Schema)

(iii) Existential verb: $\mathrm{X}$ exists / There is a $\mathrm{X}$ Too many problems exist to ever solve it. /There is also a Buddhist monastery (in this remote valley).

The intransitive existential construction has an important discourse function as a presentative device for introducing new information by means of a typically indefinite or generic NP which may be postverbal or in a non-clause-initial position, the latter depending on the basic word order of the language. There is $X / X$ exists. ${ }^{1}$

This syntactic configuration could be seen as the main existential construction for generic existence (cf. Koch 2012: 538-539 and Lyons 1967, 1968, on 'generic' vs. 'bounded' existence).

It is crucial to observe here that the locative noun in the adjunct NP 'in this remote valley' is not a core constituent of the existential construction. It is entirely omissible, as opposed to its constituency in the locative construction, where it is not. A further contrast resides in the fact that the locative noun appearing in the locative construction is typically definite or referential.

(Nuclear Existence Schema)

(iv) Possessive verb: $\mathrm{X}$ has $\mathrm{Y}$

Xiao Mei has many cousins ... and cats.

The possessive construction is the only construction with transitive syntax, with the possessor acting as the subject and the possessed item acting as the direct object. ${ }^{2} X$ has $Y$. In our data, this construction type can express both ownership and inalienable possession. (Action Schema)

Possessive predication in many East and Southeast Asian languages has previously undergone regular analysis as a type of topic-comment construction,

\footnotetext{
1 Extended (as opposed to 'nuclear') existential constructions that combine with locative, dative and benefactive NP adjuncts are all confusingly labeled 'Locational' by Stassen and so we have decided to avoid using this term in our study. 'Locative construction' will refer unequivocally to the use of a true locative verb with an obligatory locative complement NP, i.e., one that is not an adjunct. 'Existential construction' is used in our study in the same way as Clark in her seminal paper (1978).

2 The caveat here is of course that these clause types are not the only means for coding these broad areas of constructional meaning. They represent rather the basic clause types.
} 
for example, in Stassen (2009). The possessor NP is treated as a dangling topic and the possessum NP as the grammatical subject of a predicate that contains an intransitive verb, such as a locative or an existential one. Using a series of syntactic tests, Chappell and Creissels (2019) have presented counter-arguments to this treatment in favor of classification as a straightforward case of the HAvE-Possessive in Asian languages, the standpoint adopted in the present study.

To avoid creating new terminology, from hereon we label these four constructions simply as the 'copular construction', the 'locative construction', the 'existential construction' and the 'possessive construction'.

The term 'polysemy', as used in this study, will refer to possible multiple meanings of the one verbal form as viewed within a purely synchronic analysis and which pair up with different syntactic properties (Koptjevskaja-Tamm 2008: 8-10). In other words, the meanings are in part determined by the syntactic and pragmatic environments in which they occur. 'Polyfunctionality' regards the same phenomenon from a different perspective in referring to the multiple uses of this same set of verbs, defined by occurrence in different grammatical environments.

The term 'polysemy sharing' refers to areal patterns of polysemy which arise due to recurrence in a geographically contiguous group of related and unrelated languages, and for which it is difficult to discern which is the model and which, the replica language (Koptjevskaja-Tamm and Liljegren 2017). In an area so defined, the same, if not overlapping, sets of semantic shifts, accompanied by syntactic reanalysis, are exhibited for given construction types or what Koptjevskaja-Tamm and Liljegren call "lexico-constructional patterns".

The term 'shared forms' will be used in an informal way, to refer to polysemy, focusing here on the identity of a phonetic form for two or more meanings. As per above, these meanings or functions can nonetheless be distinguished by use in the different syntactic constructions defined above. The possible causes of this polysemy - and the associated polyfunctionality - are treated in terms of diachronic change in Section 4. En revanche, 'splitting' refers to the use of distinct forms to separately code different semantic domains, a term also used in Stassen (1997) and Koch (2012).

For the different patterns of polysemy, the semantic space can be split or fused in several different ways. As a consequence, synchronically viewed, polysemy in the mainland Asian linguistic area can be initially characterized by the finite range of different combinations that result. To give one example, in most Austroasiatic languages, including $\mathrm{Wa}$, the locative verb, $\mathrm{V}_{\mathrm{LOC}}$ is distinct from the copula, $\mathrm{V}_{\mathrm{COP}}$, but also from the existential, $\mathrm{V}_{\mathrm{EX}}$, and possessive verb, $\mathrm{V}_{\mathrm{POSS}}$, while the latter two 
share the same form. In this case, the resulting pattern is Type IV with three distinct verbal forms, as exemplified for Wa in (1) to (4) below:

(1) Wa (Austroasiatic)

Existential construction

sibum prạuk ?ịn kọ

garden side this there.be bamboo two clump

'There are two clumps of bamboo beside the garden.'

(Zhou and Yan 1984: 49)

(2) Possessive construction

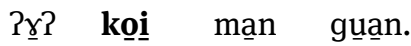

1SG have cloth so.wide

'I have a piece of cloth so wide.'

(Zhou and Yan 1984: 57)

(3) Locative construction

Pin moh lai toie maii?,

this COP book POSS 2SG

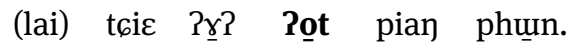

book POSS 1sG be.at on table

'This is your book, mine is on the table.

(Zhou and Yan 1984: 70)

(4) Copular construction

noh moh pui propitcin.

3SG COP person Beijing

'He's Pekinese.'

(Zhou and Yan 1984: 36)

In the next section, we discuss the synchronic aspect for the semantic typology that is formed by the four areal patterns of polysemy and splitting.

\section{The four types - patterns of areal polysemy}

On the basis of 116 languages, including the language families of Sino-Tibetan, Hmong-Mien, Kra-Dai and Austroasiatic in Mainland East and Southeast Asia (MESEA), we propose a typology determined by the patterns of use for the four 
domains coded by $\mathrm{V}_{\mathrm{COP}}, \mathrm{V}_{\mathrm{LOC}}, \mathrm{V}_{\mathrm{EX}}$, and $\mathrm{V}_{\mathrm{POSS}}$. This typology comprises four main patterns of correlation, as shown in Table 1. The areal distribution for these four types is given in Map 2 directly after this table. ${ }^{3}$

Table 1: Four main patterns of correlation for copular, locative, existential and possessive verbs.

\begin{tabular}{llr}
\hline ONE FORM & & $\mathbf{N}^{\mathbf{0}}$ of languages \\
\hline & Type I: Quadruple polysemy & 4 \\
& $\left(\mathrm{~V}_{\text {COP }}=\mathrm{V}_{\mathrm{LOC}}=\mathrm{V}_{\mathrm{EX}}=\mathrm{V}_{\mathrm{POSS}}\right)$ \\
& Several varieties of Bai \\
& \\
\hline
\end{tabular}

Two FORMS

Type II: Binary split with two

polysemous binomes

$\left(\mathrm{V}_{\mathrm{COP}}=\mathrm{V}_{\mathrm{LOC}}\right) ;\left(\mathrm{V}_{\mathrm{EX}}=\mathrm{V}_{\mathrm{POSS}}\right)$

Cantonese \& Yue, many Hui

and Wu dialects, Xianghua (all

Sinitic), Hmongic

Type III: Binary split with a

polysemous trinome and a

distinct copula

$\left(\mathrm{V}_{\mathrm{COP}}\right) ;\left(\mathrm{V}_{\mathrm{LOC}}=\mathrm{V}_{\mathrm{EX}}=\mathrm{V}_{\mathrm{POSS}}\right)$

Predominant in Tibeto-

Burman (Lolo-Burmese Qian-

gic, Karenic, Jingpho, also

Tujia); some Austroasiatic

languages in close contact

with Lolo-Burmese

THREE FORMS

Type IV: Ternary split with a

single polysemous binome

$\left(\mathrm{V}_{\text {COP }}\right)$; $\left(\mathrm{V}_{\mathrm{LOC}}\right)$; $\left(\mathrm{V}_{\mathrm{EX}}=\mathrm{V}_{\text {POSS }}\right)$

Widespread in Sinitic, Caijia ${ }^{4}$,

Kra-Dai, Hmong-Mien, and

Austroasiatic

Total

${ }^{\mathrm{a}}$ Bai and Caijia are both unclassified Sino-Tibetan languages.

3 The areas for Type II found on Map 2 are based partly on Cao (2008) while the six Type II languages in our sample are listed in Appendix. See Cao (2008, vol. 3, Map 39) for a larger sample of Sinitic Type II with COP = LOC polysemy. 


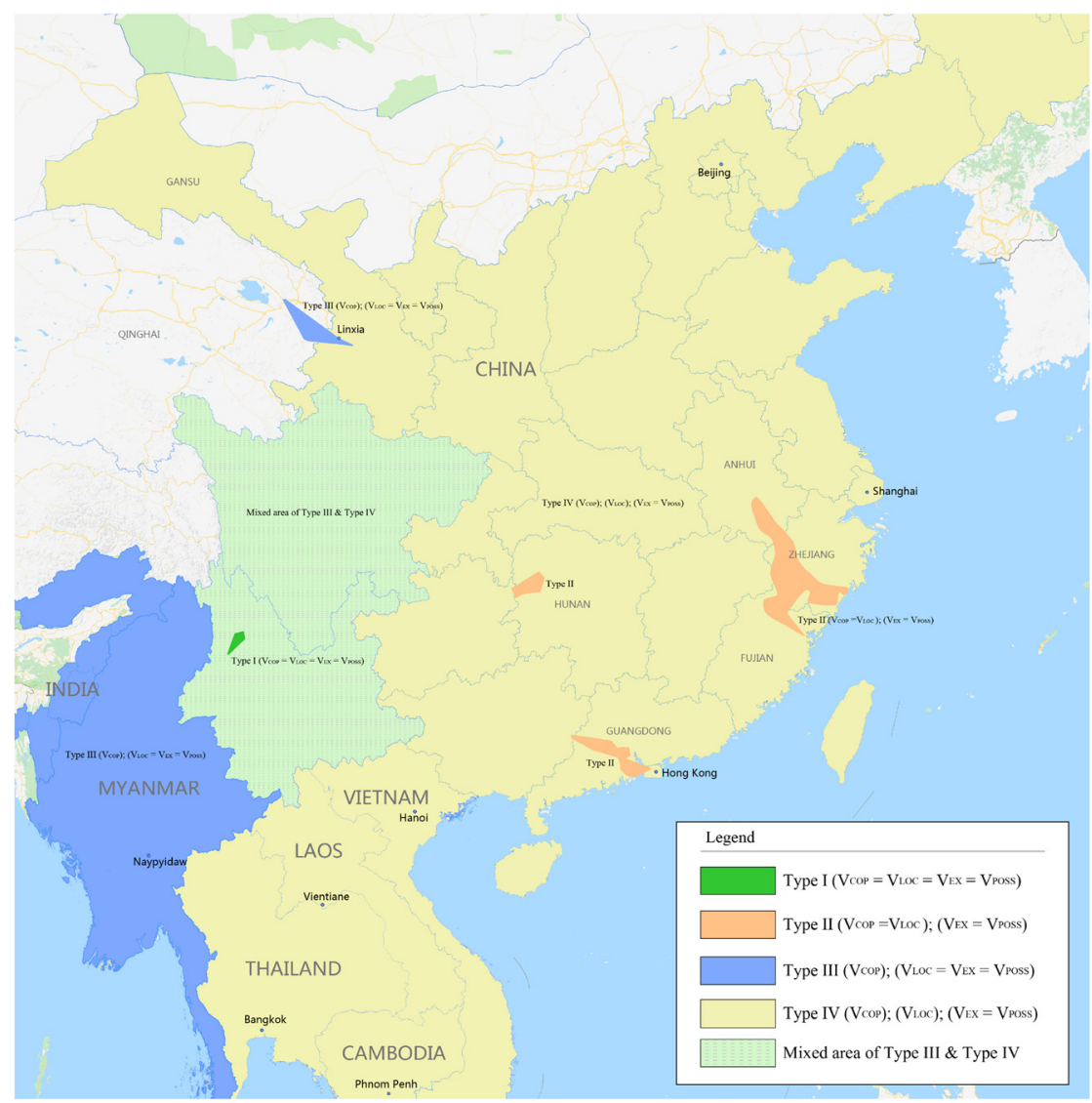

Map 2: Areal distribution for the four language types.

For the Sinitic, Hmong-Mien, Kra-Dai and Austroasiatic language families, which mainly have SVO as one of their basic word orders, the four semantic domains can be distinguished by the use of different syntactic constructions, as follows: ${ }^{4}$

I. Copular construction

$\mathrm{NP}_{\mathrm{S}} \quad \mathrm{Verb}_{[\mathrm{COP}]} \quad$ Copular NP Complement

II. Locative construction

$\mathrm{NP}_{\mathrm{S}} \operatorname{Verb}_{[\mathrm{LOC}]} \quad$ Locative NP Complement

4 The grammatical abbreviations used in the glossing are listed after the conclusion to the paper. 
III. Existential construction

(Locative NP) $\quad \operatorname{Verb}_{[\mathrm{EX}]} \quad\left[\mathrm{NP}_{\mathrm{INDEF}}\right]_{\mathrm{S}}$

IV. Possessive construction

$\left[\mathrm{NP}_{\text {Possessor }}\right]_{S} \quad \operatorname{Verb}_{[\text {POSS] }} \quad \mathrm{NP}_{\text {Possessed }}$

Tibeto-Burman languages are typologically quite distant from the above language groups in having SOV as a major word order and varying degrees of inflectional morphology. For this reason, we present the relevant syntactic constructions in Section 3.3 and describe them in Section 4.5 below.

In the next section, we briefly introduce and exemplify each of the four types for the Mesea linguistic area. Note also that the term 'subject' (S) is used in this analysis as a term for a valency role, which groups together canonical properties of agents in transitive clauses and those for the single argument in intransitive clauses, in the spirit of Malchukov and Comrie (2015).

\subsection{Type I languages - one form with quadruple polysemy (4/116): $\left(\mathrm{V}_{\mathrm{COP}}=\mathrm{V}_{\mathrm{LOC}}=\mathrm{V}_{\mathrm{EX}}=\mathrm{V}_{\mathrm{POSS}}\right)$}

In Type I languages, the four lexical meanings share the one single verb form, $t_{s u}{ }^{33}$. In our sample, this type is only found to date in four varieties of Bai, spoken in Yunnan province of China (unclassified under Sino-Tibetan): ${ }^{5}$ Jianchuan Bai, Lanping Bai, Shitou Bai and Yunlong Bai.

(5) Jianchuan Bai (unclassified Sino-Tibetan)

Copular construction

$\mathrm{NP}_{\mathrm{S}} \quad \mathrm{VP}_{[\mathrm{COP}]} \quad \mathrm{NP}_{\mathrm{CC}}$

$\mathrm{no}^{31}$ tsu $^{33} \quad \mathrm{nu}^{55} \quad \mathrm{ta}^{55}$.

1sG COP 2sG.POSs elder sister

'I'm your elder sister.'

(Xu and Zhao 1984: 40)

(6) Locative construction

$\mathrm{NP}_{\mathrm{S}} \quad \mathrm{VP}_{\text {[LOC] }} \quad$ Locative $\mathrm{NP}$

$\mathrm{nu}^{55} \quad \mathrm{k}^{33} \mathrm{mo}^{33} \quad \mathrm{tsu}^{33} \quad \mathrm{xa}^{31} \mathrm{tị}^{55} \mathrm{nc}^{55}$ ?

1sG.Poss mother-in-law be.at home Q

'Is my mother-in-law at home?'

(Xu and Zhao 1984: 88)

5 There is a longstanding debate as to whether Bai is a highly sinicized Tibeto-Burman language or simply belongs to Sinitic. 
(7) Existential construction

\begin{tabular}{|c|c|c|}
\hline (Locative NP) & $\mathrm{VP}_{[\mathrm{EX}]}$ & {$\left[\mathrm{NP}_{\text {INDEF }}\right]_{\mathrm{S}}$} \\
\hline $\operatorname{tch} \tilde{\varepsilon}^{55} \quad \mathrm{xu}^{31}$ & $t^{\prime s u}$ & $\mathrm{kh} \varepsilon^{44}$ \\
\hline inside & there.be & guest \\
\hline $\begin{array}{l}\text { 'There are gues } \\
\text { (Xu and Zhao } 1\end{array}$ & $\begin{array}{l}\text { in the ro } \\
34: 39)\end{array}$ & n.' \\
\hline
\end{tabular}

(8) Possessive construction

\begin{tabular}{lllll}
{$\left[\mathrm{NP}_{\text {PoSSESSOR }}\right]_{\mathrm{S}}$} & \multicolumn{3}{c}{$\mathrm{VP}_{[\mathrm{POSS}]}$} & $\mathrm{NP}_{\text {PoSSESSED }}$ \\
$\mathrm{a}^{31} \mathrm{no}^{35} \mathrm{mo}^{33}$ & $\mathrm{va}^{42}$ & $\mathbf{t s u}^{33} \mathrm{tci}^{31} \mathrm{ta}^{55}$ & $\mathrm{p}^{42}$. \\
NAME mother & PROP have scissor & $\mathrm{CLF}$ \\
'Ano's mother has a pair of scissors.' &
\end{tabular}

(Xu and Zhao 1984: 23)

The Bai languages thus constitute a singleton in our sample. In other studies on this same set of four verbal domains, Sun (2015) includes Korean (isolate) and Tajik (Indo-Iranian) in her corpus while Clark (1978: 106-107, Table 8) includes several potential additional cases of the same type. Further studies may uncover more languages that similarly use one single form in different syntactic constructions to code the four semantic domains.

\subsection{Type II languages - binary split with two polysemous binomes (10/116): $\left(V_{\text {COP }}=V_{\text {LOC }}\right) ;\left(V_{E X}=V_{\text {POSS }}\right)$}

The Type II languages constitute a small but robust group of 10 languages in our sample. They use two verb forms to express the four meanings, in which $\mathrm{V}_{\mathrm{COP}}$ and $\mathrm{V}_{\mathrm{LOC}}$ share the same form, as do $\mathrm{V}_{\mathrm{EX}}$ and $\mathrm{V}_{\mathrm{POSS}}$. This type is found in six Sinitic languages in our sample, including Jixi Hui and Yixian Hui, Cantonese Yue, Rui'an Wenzhou Wu, Fuqing Min and Xianghua (unclassified Sinitic). To this group can be added Nùng, a Central Tai language spoken in Vietnam and three Hmongic languages spoken in western Hunan province of China, bringing the total to ten (10/116).

To take one example, in Jixi Hur, the copula $s e^{55}$ is also used to denote 'be located, be at' a particular place, while $i \partial^{55}$ is used to express existence and possession. The Jixi examples and constructions for Type II are presented below:

(9) Jixi Hui (Sinitic)

Copular construction

$\mathrm{NP}_{\mathrm{S}} \quad \mathrm{VP}_{[\mathrm{COP}]} \quad \mathrm{NP}_{\mathrm{CC}}$

$\mathbf{a}^{55} \quad \mathbf{s e}^{55} \quad \mathrm{n} 2^{55-53} \mathrm{si}^{21}$.

1sG COP teacher

'I'm a teacher.'

(Field notes, Jian Wang) 
(10) Locative construction

$\mathrm{NP}_{\mathrm{S}} \mathrm{VP}_{[\mathrm{COP}]}$ Locative $\mathrm{NP}$

$\mathrm{a}^{55} \mathbf{s e}^{55} \quad \mathrm{ko}^{21-22} \quad \mathrm{ni}^{\mathrm{O}}$.

$1 \mathrm{sg}$ be.at home inside

I'm at home.'

(Field notes, Jian Wang)

(11) Existential construction

(Locative NP) $\quad \mathrm{VP}_{[\mathrm{EX}]}$

io $^{55} \quad \mathrm{ko}^{324-35}$

$\left[\mathrm{NP}_{\text {INDEF }}\right]_{\mathrm{S}}$

there.be

CLF

ny $^{32}$ miã $^{32}$

$\mathrm{me}^{21-22} \mathrm{xa}^{0} \quad \mathrm{ta}^{55} \mathrm{ny}^{32}$

'There is a fisherman who is fishing.'

(Field notes, Jian Wang)

(12) Possessive construction

$\left[\mathrm{NP}_{\text {PosSeSSoR }}\right]_{S} \quad \mathrm{VP}_{\text {[POSS }]} \mathrm{NP}_{\text {PosSESSED }}$

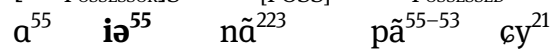

1SG have that CLF book

'I have that book.'

(Field notes, Jian Wang)

In fact, within Sinitic, the Type II pattern proves to be widespread in the Hui branch located in Southern Anhui province in central China, while it is found in a large number of $\mathrm{Wu}$ dialects located in the coastal province of Zhejiang, as well as in the Yue dialects of Guangdong (discussed in Section 3.1 below). For this reason, it is reasonable to claim it as a robust pattern.

For the three Hmongic languages, the main difference is that the locative verb and copula have their source in a verb 'to dwell' (Section 4.1.4.).

(13) Aizhai Xong (Hmong-Mien)

Copular construction

$\mathrm{du}^{35} \quad \mathrm{kj}^{44} \mathrm{tsi}^{44} \quad \mathbf{n i}^{\mathbf{2 2}} \quad \mathrm{ne}^{31} \mathrm{pz}_{\mathrm{u}}{ }^{44} \quad \mathrm{na \eta}^{44}$.

tree orange cop other POSS

'The orange tree is someone else's.'

(Yu 2010: 37)

(14) Locative construction

$\mathrm{x}^{53} \mathrm{bc}^{44} \quad \mathbf{n}_{\mathbf{i}} \mathbf{i}^{53} \quad \mathrm{lə \eta}^{35} \quad \mathrm{tso}^{53}$.

ladle be.at upside oven

'The ladle is on the oven.'

(Yu 2010: 39) 


\subsection{Type III languages - binary split with a polysemous trinome (35/116): $\left(\mathrm{V}_{\mathrm{COP}}\right) ;\left(\mathrm{V}_{\mathrm{LOC}}=\mathrm{V}_{\mathrm{EX}}=\mathrm{V}_{\mathrm{POSS}}\right)$}

The Type III languages also show a binary split by means of two verb forms. In stark contrast to Type II languages, it is the copula that is distinctly coded, while $\mathrm{V}_{\mathrm{LOC}}, \mathrm{V}_{\mathrm{EX}}$ and $\mathrm{V}_{\mathrm{POSS}}$ all share the one form. This type is mainly found in Tibeto-Burman languages (29/35) but is also attested in two Austroasiatic languages, Bugan and Mang, in one Hmongic language, Yanghao, as well as in three Sinitic languages in our sample, Hainan Southern Min, Linxia and Dabu Hakka. Among the Sinitic languages, Linxia forms a larger cross-provincial island of Type III with several neighboring Sinitic languages in Gansu and Qinghai, including Kangle (Hao Li pers. comm.), Tongren and Huangyuan (Cao 2008, vol. 3: Map 35).

The examples below from Woni (a Hani variety, Loloish) show that the predicate contains the same existential verb, $t s a^{33}$ used with inanimate subjects in each of the first three cases, while the copular verb is different in (18).

(15) Woni (Loloish, Tibeto-Burman)

Locative construction

$\mathrm{NP}_{\mathrm{S}} \quad$ Locative NP $\quad \mathrm{VP}_{[\mathrm{LOC}]}$

$\mathrm{ho}^{55} \mathrm{ho}^{31} \mathrm{ho}^{55} \mathrm{phi}^{31} \quad \mathrm{tc}^{33} \mathrm{ji}^{55} \mathrm{ho}^{55} \mathrm{wa}^{13} \quad \mathrm{to}^{33} \quad$ tsa $^{33} \quad \mathrm{ti}^{55}$.

field land TOP house underside LOC be.at PRT

'The field and land are below the house.'

(Yang 2016: 158)

(16) Existential construction

(Locative NP) $\left[\mathrm{NP}_{\text {INDEF }}\right]_{S} \mathrm{VP}_{[\mathrm{EX}]}$

$\mathrm{ho}^{55} \mathrm{to}^{31} \mathrm{to}^{33} \quad \mathrm{i}^{55} \mathrm{tshu}^{31} \quad \mathbf{t s a}^{33}$.

field Loc water there.be

'There's water in the field.'

(Yang 2016: 126)

(17) Possessive construction

$\left[\mathrm{NP}_{\text {Possessor }}\right] \quad\left[\mathrm{NP}_{\text {Possessed }}\right]_{S} \quad \mathrm{VP}_{\text {[POSS] }}$

tsho $^{55} \mathrm{i}^{55} \mathrm{hu}^{31} \mathrm{hu}^{31} \mathrm{tsh}^{31} \mathrm{~kJ}^{31} \mathrm{tsh}^{55} \mathrm{~m}^{55} \mathrm{tsu}^{31} \mathrm{ji}^{55}$ tsa $^{33} \mathrm{tsh}^{31}$.

person little one CLF what idea have can

'What ideas can such a little person have!' (rhetorical)

(Yang 2016: 247) 
(18) Copular construction

$\mathrm{NP}_{\mathrm{S}} \quad \mathrm{NP}_{\mathrm{CC}} \quad \mathrm{VP}_{[\mathrm{COP}]}$

$\mathrm{ji}^{55} \quad \mathrm{l}^{31} \mathrm{ku}^{55}$ nuu $\mathbf{u}^{55} \mathrm{ti}^{55}$.

3SG Lolo COP PRT

'He is a Lolo.'

(Yang 2016: 123)

As foreshadowed, the different syntactic patterns for Tibeto-Burman that are evident in these examples will be described in Section 3.5 below.

\subsection{Type IV languages - ternary split with a single polysemous binome (67/116): $\left(V_{\text {COP }}\right)$; $\left(V_{L O C}\right) ;\left(V_{E X}=V_{\text {POSS }}\right)$}

In the 67 languages belonging to Type IV, there are three different forms: both $\mathrm{V}_{\mathrm{LOC}}$ and $V_{\mathrm{COP}}$ are respectively distinct from each other and also from a third form which shares the domains of $\mathrm{V}_{\mathrm{EX}}$ and $\mathrm{V}_{\mathrm{POSs}}$. This group constitutes the majority in our sample: it is the dominant pattern in Sinitic (29/38), Kra-Dai (15/16), Hmong-Mien (10/14) and Austroasiatic (12/14). In Caijia (the only unclassified language in this type: 1/67), the copula $s 1^{33}$ is contrasted with the locative verb $t u^{21}$ while the existential and possessive verb is $\gamma \tilde{a}^{33}$. The syntactic configurations remain the same as for Types I and II, despite the fact that the pattern of splitting and sharing is distinct.

(19) Caijia (unclassified, quasi-Sinitic)

Copular construction

$\mathrm{NP}_{\mathrm{S}} \quad \mathrm{VP}_{[\mathrm{COP}]} \quad \mathrm{NP}_{\mathrm{CC}}$

$\mathrm{no}^{33} \mathbf{s 1}^{33} \quad \mathrm{~kJ}^{33} \mathrm{sv}^{21} \mathrm{na}^{55}$.

1sG COP student

'I'm a student.'

(Field notes, Shanshan Lü)

(20) Locative construction

$\mathrm{NP}_{\mathrm{S}} \mathrm{VP}_{[\mathrm{COP}]} \quad$ Locative NP

no $^{33} \mathbf{t u}^{\mathbf{2 1}} \quad \mathrm{J}^{55} \quad \mathbf{z i}^{21}$.

1sG be.at house inside

'I'm at home.'

(Field notes, Shanshan Lü) 
(21) Existential construction

(Locative/temporal NP) $\mathrm{VP}_{[\mathrm{EX}]} \quad\left[\mathrm{NP}_{\mathrm{INDEF}}\right]_{\mathrm{S}}$

$\mathrm{mo}^{21} \mathrm{ku}^{55} \quad \mathrm{\gamma a}^{21} \quad \mathrm{u}^{21} \mathrm{ts}^{\mathrm{h}} \mathrm{o}^{21} \mathrm{f}^{51} \quad \mathrm{~s}^{55}$.

that moment there.be people family conT

'There once was a family.'

(The corn and the grass text, Shanshan Lui)

(22) Possessive construction

$\left[\mathrm{NP}_{\text {PosSESSOR }}\right]_{\mathrm{S}} \quad \mathrm{VP}_{\text {[POSS }]} \quad \mathrm{NP}_{\text {PoSSESSED }}$

$\mathrm{je}^{33} \quad \mathbf{y}^{21} \quad \mathrm{la}^{21} \quad \mathrm{~J}^{55} \quad \mathrm{ji}^{33} \quad \mathrm{pie}^{21}$.

3SG have big house one CLF

'He has a big house.'

(Field notes, Shanshan Lü)

Most of the languages in our sample thus fall into either Type III or Type IV with totals of (35/116) and (67/116) respectively.

Were a larger study of this phenomenon to be undertaken, patterns with more complex semantic interrelationships would need to be modeled for further types found in the Tibeto-Burman languages. We refer here specifically to the phenomenon of multiple sets of existential and locative verbs which are semantically conditioned and whose use overlaps in a variety of ways. We were not able to include many examples from this type of language in our sample, generally due to the lack of availability of complete sets of data for the four lexical domains under investigation. Notwithstanding this, examples of languages possessing such multiple sets are discussed in Section 4.5 below.

To summarize this section, the patterns of sharing and splitting found in the four patterns for the lexical fields under study can be represented graphically, as in Table 2.

Table 2: Semantic patterning for the four types of languages.

\begin{tabular}{|c|c|c|c|c|}
\hline \multirow{2}{*}{\multicolumn{5}{|c|}{ Copular }} \\
\hline & & & & \\
\hline Type II & & & & \\
\hline Type III & & & & \\
\hline Type IV & & & & \\
\hline
\end{tabular}

Having illustrated the four main configurations for splitting and sharing of forms, the data are next reconsidered from the angle of areal and sub-areal patterns, according to language family. 


\section{The four areal patterns by language family}

The areal patterns are treated in this section, combining the viewpoints of language family, geographical region and principal types in use for our four patterns.

\subsection{Sinitic}

The 38 Sinitic languages in our sample include representative languages from all 10 branches (see Table 5 in the Appendix): six varieties of Mandarin, two Jin, three Xiang, four Gan, two Hui, four Wu, eight Min, three Hakka, two Yue, two Pinghua, one southern Hunan patois and the unclassified Xianghua, also known as Waxiang. The predominant pattern for Sinitic is indeed Type IV with 29/38 languages in this group, while a minor but nonetheless important pattern is Type II (6/38). There are just three languages which fall into Type III (3/38) - Dabu Hakka, Linxia and Haikou Southern Min. Examples are presented below for Type IV from Shaowu, a Northwestern Min language, spoken in Fujian province, China. The first two examples once more show the sharing of the verb $i u^{55}$ 有 for existential and possessive constructions: ${ }^{6}$

(23) Shaowu Northwestern Min (Sinitic)

Existential construction

$\mathrm{kie}^{21} \operatorname{cion}^{35}$ iju $^{55} \operatorname{tin}^{55}$ vai $^{55} \operatorname{nin}^{22}$.

street on there.be very many person

'There are many people on the street.'

(Ngai 2021: 441)

(24) Possessive construction

$\mathrm{xan}^{35} \mathrm{iju}^{35-55} \mathrm{iju}^{55} \mathrm{ci}^{22} \quad \mathrm{kəi}^{213} \quad \mathrm{vən}^{213} \mathrm{t}^{\mathrm{h}} \mathrm{i}^{22}$.

1SG again have one CLF question

'I have another question.'

(Ngai 2021: 181)

In Type IV languages, the copular verb has a distinct form from the existential and possessive verbs:

6 Standard Mandarin $i \partial u^{214}$ 有 is cognate with this polysemous verb in Shaowu, as it is with many other Sinitic languages in our sample. 
Copular construction

$\mathrm{xan}^{35} \mathrm{tai}^{21} \quad \mathrm{ka}^{35} \quad 6 \mathrm{i}^{55} \quad \mathrm{iiau}^{213} \mathrm{u}^{55} \quad \operatorname{nin}^{22}$.

1PL.EXCL all COP Shaowu person

'We are all Shaowu people.'

(Ngai 2021: 451)

Shaowu also has a third, distinct, form for its locative verb, $t^{h} u^{55}$ 处 'be at', 'be alive'.

\begin{tabular}{|c|c|c|c|c|}
\hline Locative c & onstructio & & & \\
\hline$i u^{55}$ & $\mathrm{xan}^{35}$ & $t^{\mathrm{h}} \mathbf{u}^{55-35}$ & $\mathrm{vi}^{213}$ & $6 \mathrm{ia}^{53} ?$ \\
\hline there.be & $1 \mathrm{sG}$ & be.at & afraid.of & what \\
\hline
\end{tabular}

This form, $t^{h} u^{55}$ 处, is notably different from the more common Sinitic form for the verb 'be at', which is $t s a i^{51}$ 在 in Standard Mandarin or $t s^{h} \mathrm{oi}^{24}$ in Shangyou Hakka. Another example for Type IV is Caijia, a quasi-Sinitic language spoken in Guizhou, as yet unclassified, which is illustrated in Section 3.4 above.

For the smaller group of Type II languages, the characteristic feature is the polysemy of the copula with the locative verb. Apart from Nùng in Vietnam, most of the Type II languages in our sample are located in China, including six Sinitic and three Hmongic languages. The six Sinitic languages are Hong Kong Cantonese YuE, Jixi Hu, Yixian Hu, Rui'an Wu, Xianghua (unclassified Sinitic) and Fuqing Min, while the three Hmongic languages are Fenghuang, Aizhai and Songtao, discussed in Sections 4.2, 5.1.3 and 5.1.4. Map 39 of the Atlas of Chinese Dialects (Cao 2008, vol. 3) pinpoints a total of $43 / 930$ Sinitic languages which use the copula as a locative verb. Interestingly, there are two different copular forms involved in this polysemy, discussed immediately below.

(i) According to Map 39, in a contiguous area of southern Anhui, Zhejiang and northern Fujian provinces, there are 25 languages which use cognates of Mandarin $s l^{51}$ 是 'be' in these two main functions of copular and locative verb. These areas include Hui (5/25), Wu (14/25) and Northern Min groups (3/25). A little further afield, in western Hunan, three varieties of Xianghua also show this pattern in a non-adjacent area to the former group (3/25).

In our sample, Jixi and Yixian Hui, Gaofeng Xianghua, Rui'an Wu and Hong Kong Cantonese overlap with the sample in the Atlas of Chinese dialects (Cao 2008, vol. 3: Map 39). Examples of this type from Jixi Hui have been presented in Section 4.2. Some further examples follow from Xianghua. 
(27) Gaofeng variety of Xianghua, Hunan (unclassified Sinitic)

Copular construction

$\mathrm{ni}_{\mathrm{i}}{ }^{25} \quad \mathbf{t s}^{\text {h }} \mathbf{\gamma}^{25} \quad \mathrm{sa}^{55} \mathrm{fu}^{55} \quad \mathrm{ba}^{0}$ ?

2SG be teacher $Q$

'Are you a teacher?'

(Field notes, Hilary Chappell)

(28) Locative construction

$\mathrm{zr}^{13} \quad \mathrm{ts}^{\mathrm{h}} \mathrm{\gamma}^{25} \quad \mathrm{t}_{6} \mathrm{i}^{41}=\mathrm{ta}$

3SG be.at home $=$ LOC

'She's at home.'

(Field notes, Hilary Chappell)

The existential and possessive verbs share the same form of $v a^{25}$ :

(29) Existential construction

$\mathrm{ni}^{35} \quad \mathrm{sai}^{55}$-ta $\mathbf{v a}^{25} \quad \mathrm{ba}^{41} \quad \mathrm{liau}^{25}$ la.

2SG body-LOc there.be CLF insect PRT

'There's an insect on you.'

(Field notes, Hilary Chappell)

(30) Possessive construction

$\mathrm{zr}^{33} \mathrm{i}^{41} \mathrm{t}_{6} \operatorname{in}^{33} \quad \mathbf{v a}^{25} \quad \mathrm{i}^{13}$-kəu $\mathrm{tsa}^{25} \quad$ liau $^{41}$

3SG already have one-CLF son CRS

'She already has a son.'

(Field notes, Hilary Chappell)

Hence, Xianghua has just the two forms $t s^{h} \gamma^{25}$ 是 'be $\sim$ be at' and $v a^{25}$ 有 'there is have' to cover the four semantic fields.

(ii) The second copular form is found predominantly in the Yue and Hakka dialects of Guangdong and Guangxi: hei ${ }^{22}$ 係 in Hong Kong and Guangzhou Cantonese. The consensus is that $h \mathrm{i}^{22}$ 係 is not etymologically related to $s l^{51}$ 是 'be', but rather to the meaning of 'bind'. According to the same map as above, Map 39, there are 14 Yue dialects, two Southern Hunan patois and two Hakka dialects which all use cognate forms in these two functions of copular and locative verb, bringing the total to 18. Only Cantonese Yue overlaps with this group in our sample.

In the following examples from Hong Kong Cantonese, it is important to note that there is a tone change between the copular and locative verb uses. The copula haih 
has the low-level tone 22, indicated by the final $-h$, whereas the locative verb hái has the high rising 25 tone (see also Matthews and Yip (2011: 144) on this point). ${ }^{7}$

(31) Copular construction

Jūk Yīng-Tòih haih luíhjái làih gā ma=

NAME COP girl PRT PRT PRT

'Juk Ying-Toi was a girl, to be sure.'

(Balcony Rendezvous text, Hilary Chappell)

(32) Locative construction

Kéuih yìhgā hái bāanfóng-do.

3sG now be.at classroom-Loc

'She's in the classroom now.'

(Field notes, Hilary Chappell)

Similar to Xianghua, Cantonese has just one other form for use as either the existential or possessive verb: this is yáuh 有:

(33) Existential construction

daahnhaih yáuh yāt-go tiùhgihn lē,...

but there.be one-CL condition PRTTOP

'But there was one condition on this, ...'

(Balcony Rendezvous text, Hilary Chappell)

(34) Possessive construction

ngóh yíhgīng yáuh-jó sāmseuhngyàhn lā.

1sG already have-PFv heart-in-person PRT

'I've already got a sweetheart.'

(Balcony Rendezvous text, Hilary Chappell)

Generally, Hakka dialects also use a cognate of $h e i^{22}$ 係 for their copula so that further research may turn up more examples of Type II with its binary split and two pairs of binomes. However, our data from Liancheng Hakka and Shangyou Hakka varieties do not show the expected Type II, but rather the Type IV pattern. Notably, both Hakka varieties are outside the Yue-speaking areas of Guangdong province.

7 Lexical and grammatical tone are rampant in the MESEA linguistic area. Semantic splits which create polysemy conditioned by tone change are considered in this analysis to be a kind of nonsegmental 'inflection', rather than a derivational process. Tone change on verbs in many Yue dialects, for instance, may signal aspectual meanings. Hence, we treat tone change as a core feature of this polysemy and not as a case of splitting into two related but distinct forms, cf. Martha Ratliff's classic work on this topic (1992). 
There are, nonetheless, some striking exceptions to these two main patterns of Type II and Type IV within Sinitic, these being Linxia Central Plains Mandarin, Dabu Hakka and Haikou Southern Min. Located at a great distance from one another in China, they have just two forms, one coding only the copular verb, $s l^{55}$, hei $i^{51}$ and $t i^{33}$ respectively, and the other uniting the locative, existential and possessive functions: $j u u^{55}, z i u^{44}$ and $u^{33} / 2 d u^{33}$ respectively (see Map 1 for locations and the website indicated for sentence examples). In other words, these three languages belong to Type III $\left[\left(\mathrm{V}_{\mathrm{COP}}\right) ;\left(\mathrm{V}_{\mathrm{LOC}}=\mathrm{V}_{\mathrm{EX}}=\mathrm{V}_{\mathrm{POSS}}\right)\right]$, a type which is geographically discontinuous since most of the Type III languages in our sample are Tibeto-Burman languages located much further away in the west and southwest.

In sum, there are two main patterns of polysemy evident in our data for Sinitic languages: While they belong predominantly to Type IV with three distinct forms $\left[\left(\mathrm{V}_{\mathrm{LOC}}\right) ;\left(\mathrm{V}_{\mathrm{COP}}\right) ;\left(\mathrm{V}_{\mathrm{EX}}=\mathrm{V}_{\mathrm{POSS}}\right)\right]$, among which the polysemous or shared form is for the existential and possessive meanings, there is a subset of Type II Sinitic languages that possess only two forms with a binary split for locative/copular and existential/possessive verbs: $\left[\left(\mathrm{V}_{\mathrm{COP}}=\mathrm{V}_{\mathrm{LOC}}\right)\right.$; $\left.\left(\mathrm{V}_{\mathrm{EX}}=\mathrm{V}_{\mathrm{POSS}}\right)\right]$. This concerns, above all, a group of languages that belong mainly to the Hui, Wu and Yue branches of Sinitic as well as Xianghua (unclassified Sinitic) and Hmongic. In addition, there are sporadic examples of Sinitic languages belonging to Type III.

As is already evident, unlike the existential and possessive verbs, there is much greater variety found for the locative forms in Sinitic, and to a lesser extent for the copula. We will discuss the sources in Sections 5.1.4 and 5.1.5 (see also Table 5 in the Appendix).

\subsection{Hmong-Mien}

The Hmong-Mien languages comprise the two main branches of Hmongic and Mienic. ${ }^{8}$ Their communities of speakers are scattered across the south and southwest of China in western Hunan, Guizhou, Sichuan, and Yunnan provinces but also in Guangxi Autonomous Region. In recent centuries, they have gradually migrated further south into Laos, Northern Vietnam, and Northern Thailand (Jarkey 2015: 9-11; Ratliff 1992: 15-21).

In general, the Hmongic languages belong to Type IV with three forms, only one of which is polysemous: as for the dominant pattern in Sinitic languages, the

8 The She language is considered an isolate in some phylogenies or included under Core Miao (our 'Hmongic') in others (Sposato 2015: 26). Note that 'Mienic' is referred to as 'Yao' in Sposato (2014, 2015) which is also the older term and the name in use in China for this language family - 'MiaoYao'. We have kept the term 'Hmong-Mien' whose use remains current in the west, since an examination of classification and phylogenetic relationships is not the main topic in this paper. 
possessive and existential meanings are coded by the same form while, for the copular and locative verbs, each has its own distinct form. In our sample, 10/14 Hmong-Mien languages belong to this type. Another three, detailed below, belong to Type II, while just one, Yanghao Hmong has a paradigm that can be classified as a possible variant of Type IV. It possesses a second Type III pattern that may have developed on the basis of Type IV, with two polysemous verbs both expressing possession and existence (cf. Table 5, presented in the Appendix).

One of these Type IV languages is White Hmong (Hmongic, Laos), for which we provide a representative paradigm below. First, the copular verb is yog $\left[j j^{42}\right]:^{9}$

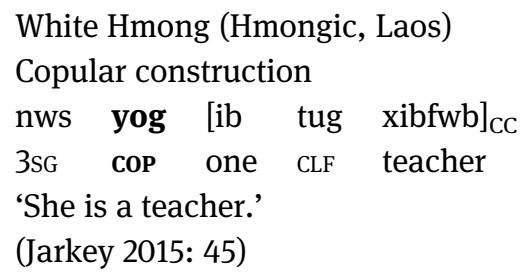

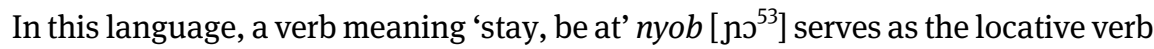
(Jarkey 2015: 202-206).

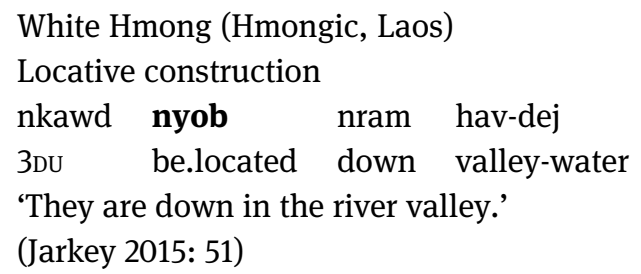

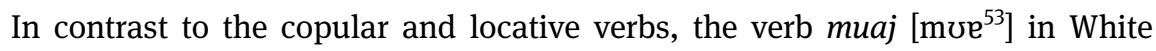
Hmong has both existential and possessive uses, depending on the relevant syntactic constructions (Jarkey 2015: 43-44):

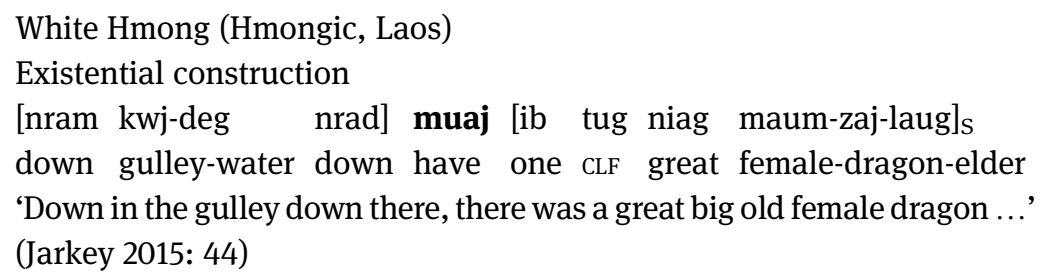

9 For White Hmong and Xong, the Romanized Popular Alphabet has been adopted in the given sources for the orthography. For representing the tonal values, this orthography makes use of a single consonant at the end of each syllable: b, d, g, x etc. (see Jarkey 2015: 14). 
The monovalent existential use is typically found in presentative constructions, frequently with a locative or temporal adposition, as in (37) above. The postverbal NP and sole argument shows a tendency to be indefinitely marked, according to Jarkey (2015: 43).

In contrast to the monovalent use of muaj, transitive possessive clauses make use of a clause-initial NP which can be highly referential, such as the first person pronominal subject in the following example:

$$
\begin{aligned}
& \text { White Hmong (Hmongic, Laos) } \\
& \text { Possessive construction } \\
& \text { peb tsis muaj tes muaj taw } \\
& \text { 1PL NEG have hand have foot } \\
& \text { 'We have neither hands nor feet.' } \\
& \text { (Jarkey 2015: 235) }
\end{aligned}
$$

In the three Type-II Hmongic languages, Fenghuang, Songtao and Aizhai, all belonging to the Xong branch of Xiangxi Miao of western Hunan, China, the copular verbs all appear to be tonally related to the locative verbs. Such is the case in Fenghuang Xong for copular nins [nĩ $\left.{ }^{22}\right]$ and locative ninb [nĩ $\left.{ }^{41}\right]$.

$$
\begin{aligned}
& \text { Fenghuang Xong (Xiangxi Miao, Hmongic, China) }{ }^{10} \\
& \text { Copular construction } \\
& \text { beul-leb nins wel naond geub.bul. } \\
& \text { 3-DU } \quad \text { cop } 1 \text { SG ASSOC friend }
\end{aligned}
$$

'Those two are my friends.'

(Sposato 2015: 302)

(40) Locative construction

aod-ngonl deb-naus yab ninb dox, deit ninb dox.

one-CLF:animate DIM-bird also at that still at that

'The little bird was there again, it was still there.'

(Sposato 2015: 629)

Ratliff (2010: 213) observes that the reconstructed locative and copular forms for proto-Hmongic may have been linked by what has now become an opaque morphological process, manifested synchronically in a tonal difference. ${ }^{11}$ For this reason, the three Hmongic languages in our sample are provisionally classified as Type II, awaiting confirmation of such a possible diachronic semantic relationship;

10 Pace Sposato (2014, 2015) who uses the term 'Miao' for which we have substituted the term in current usage 'Hmongic'. White Hmong spoken in Laos belongs to Nuclear Miao in Sposato's classification. See also fn. 10.

11 We thank Adam Sposato for bringing this to our attention (pers. comm.). 
noting that we have similarly treated the tonal differences for the Cantonese Yue locative and copular verbs, $h e i^{25}$ and $h e i^{22}$ (Section 4.1). ${ }^{12}$ Table 3 presents data from four Hmongic languages, classified as Xiangxi Miao by Sposato $(2014,2015)$. Note that Suang is not included in our sample of 116 languages.

Table 3: Copular and locative verbs in four Type II Hmongic languages (Xiangxi Miao).

\begin{tabular}{llll}
\hline Language & Copula & Locative & Source \\
\hline Fenghuang Xong & $\mathrm{ni}^{22}$ & $\mathrm{ni}^{41}$ & Sposato (2015) \\
Songtao Xong & $\mathrm{ni}^{42}$ & $\mathrm{ni}^{\mathrm{a}}$ & Luo (2005) \\
Aizhai Xong & $\mathrm{ni}^{22}$ & $\mathrm{ni}^{33}$ & Yu (2010) \\
Suang & $\mathrm{n}^{5}$ & $\mathrm{n}^{2}$ & Sposato (pers. comm.) \\
\hline
\end{tabular}

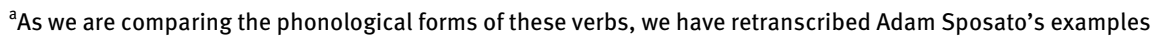
into IPA for the copula nins and the locative verb ninb. Scholars of Hmongic languages generally use tonal spelling, whereby an added final consonant represents the tone category.

Similar to White Hmong, and despite belonging to a different type, Xong shares the invariant feature that $\operatorname{mex}\left[\mathrm{m}^{2}\right]$ is used in both the intransitive existential and transitive possessive frames:

\author{
Fenghuang Xong (Xiangxi Miao, Hmongic, China) \\ Existential construction \\ aod-del ndaut dox mex hliob daob-ginb-daob-npad guaot! \\ one-CLF:rigid.length tree that have many AN-bug-AN-ant pass \\ 'There are tons of bugs on that tree.' \\ (Sposato 2015: 176)
}

12 One of our anonymous reviewers proposed that the Hmongic and Cantonese Yue examples could be treated as intermediate between Type II and Type IV, rather than as Type II. For a consistent account of our data, we believe it preferable to treat the tone changed forms as belonging to the one semantically general verb 'to be' that can serve as either a copula or as a locative copula. Just as in a verb paradigm in an inflectional language, where the forms may change for person, number and tense, the core meaning remains the same. The non-segmental nature can be regarded as an unusual type of non-canonical inflection. The verb forms in our data with two different tones thus correspond to use in different construction types, namely, the locative and the copular constructions. The syntactic features of the latter also clearly contribute to the global syntactic meaning (cf. definitions in Section 1.1). A diachronic connection in the form of Type II developing into Type IV would be difficult to uphold without the support of sufficient historical or crosslinguistic evidence. This is due to the fact that the morphological process in proto-Hmongic to which Ratliff (1992) has alluded is now 'synchronically opaque', as the reviewer nicely put it. Note also that Sposato $(2014,2015)$ has reverted to using the older nomenclature of Miao-Yao for this language family in his new classification, while we use the broad label of 'Hmongic', still in currency for languages belonging to this division. See also fn. 10. 
Possessive construction

boub at mex aod-bioud deul.

1PL SAT have one-CLF:home firewood

'We have a whole house of firewood.'

(Sposato 2015: 263)

What distinguishes Hmong-Mien from most of the Sinitic languages is the fact that the locative verb, 'be at', also means 'live, stay, dwell'. This is the case for both White Hmong nyob (Jarkey 2015: 202) and Xong ninb, while in Yanghao, Jiongnai and Baheng, the locative verbs, respectively $n_{\diamond} a \eta^{33}, n_{b} a \eta^{44}$ and $n \tilde{o}^{35}$, are related to both meanings of 'sit' and 'dwell'.

To conclude, in spite of the dominant Type IV pattern, a small proportion of Hmongic languages spoken in Western Hunan, China, are clearly Type II languages. These include Aizhai, Fenghuang and Songtao Xong.

\subsection{Kra-Dai}

The Kra-Dai or Tai-Kadai languages are found in Thailand, Laos, Myanmar (Burma), Vietnam and southern China, particularly in Guangxi, where the Zhuang languages are situated (Diller 2008; Ostipirat 2000). The family is generally divided into the three main branches of Hlai, Kra (or Geyang) and Kam-Tai, to whose Southwestern branch belong Standard Thai and Lao. In our representative sample, we have included data from languages in these three primary divisions. Kra-Dai languages, like Sinitic and Hmong-Mien, largely belong to the Type IV pattern for the four semantic domains in our study, this being the case for 15/16 languages. Only Nùng belongs to Type II.

Hence, the Kra-Dai languages which we surveyed are coded by three forms: once more, the possessive and existential verbs share the same form but not the same syntactic frames, while the locative and copular verbs are coded by distinct forms and occur in distinct constructions. In this, they resemble the majority of Sinitic languages, not to mention Hmong-Mien and Austroasiatic. What is a tendency for Hmong-Mien proves to be an absolute for the Kra-Dai languages in our sample: the locative verb 'be at' has the same form as the verb 'to dwell' in all the languages in our sample from this phylum, and has a further use as a locative preposition, 'in' or 'at', except in Standard Thai. In contrast to this, there is a variety of forms for the copular verb, evident from a first glance at Table 5 in the Appendix.

The single polysemous verb form in Type IV has a transitive SVO frame for the possessive interpretation, 'have' and an intransitive one for the general existential sense 'there is'. In the case of the existential verb, the subject occurs postverbally: 
VS, reflecting the fact that the syntactic frame has a presentative function. Moreover, the postverbal NP is generally required to be morphologically indefinite (Enfield 2007: 157-161 on Lao; Iwasaki and Ingkaphirom 2005: 16 on Thai; Lu 2008 on Maonan inter alia). This feature is similarly viewed as an important defining feature of intransitive existential constructions in Chappell and Creissels (2019: 508-509) which distinguishes it from predicative possession. A paradigm from Standard Thai is presented below:

(43) Standard Thai

Copular construction

kháw pen phûan.

3 COP friend

'He is a friend.'

(Smyth 2002: 56)

(44) Locative construction

bâan yùu thîi nôon.

house be.at at there

'The house is over there.'

(Smyth 2002: 108)

(45) Existential construction

pòkkatì mii khon mâak.

usually there.be person many

'Usually there are a lot of people.'

(Smyth 2002: 104)

(46) Possession construction

kwian $^{1}$ thai $^{1}$ mii $^{2}$ sóóng ${ }^{5}$ lóó ${ }^{4}$

cart Thai have two wheel

'A Thai cart has two wheels.'

(Morev 1994: 890-891)

A second example comes from Hlai, spoken on Hainan Island, China. The copular verb is $\operatorname{man}^{1}$, the locative verb is $P d u^{3}$ while the possessive and existential verbs share the form, $t s a u^{2}$ :

(47) Hlai, Kra-Dai, Hainan, China

Copular construction

na $\operatorname{man}^{1}$ gu: $\eta^{1} \quad$ hou ${ }^{1}$.

3SG COP younger.brother $1 \mathrm{sG}$

'He's my younger brother.'

(Yuan 1994: 51) 
(48) Locative construction

pha $^{3} \mathrm{za}^{1} \mathbf{P d u}^{\mathbf{3}} \mathrm{plon}^{3}$.

father be.at home

'Father is at home.'

(Yuan 1994: 66)

(49) Existential construction

ka: $\mathrm{u}^{3} \quad \mathrm{tshi}^{1}$ hau $^{2}$, tsau $^{2} \quad \mathrm{tsu}^{3}-$ hom $^{1}$ hwe: $\eta^{1}$ lom $^{3}$ Pbe: $\eta^{1}$ Pom $^{3}$

long.time moment there.be one-CLF pool also wide also

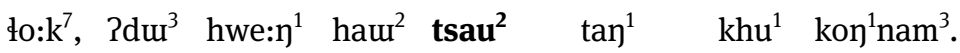

deep at pool there there.be dragon and aquatic.animal 'Once upon a time, there was a pool, wide and deep. In the pool, there was

a dragon and other aquatic animals there.'

(Yuan 1994: 187)

(50) Possessive construction

na $\operatorname{man}^{3} n_{0} 0: n^{2}$ tsau $^{2}$ tsu' ${ }^{3}-t s u: n^{1}$ tu: $k^{7}$.

3SG only have one-cLF child

'He only has one child.'

(Yuan 1994: 99)

In short, except for Type II Nùng, the Kra-Dai languages behave quite uniformly as Type IV languages for the four semantic domains in question, regardless of the division to which they belong or their far-flung locations, from the island province of Hainan westwards to Guangxi and Guizhou on the mainland of China and southwards to Myanmar, Thailand, Laos and northern Vietnam.

\subsection{Austroasiatic}

In peninsular Southeast Asia, Austroasiatic languages are concentrated in Vietnam, Laos and Cambodia while pockets are scattered across northern Thailand, Myanmar, Southern China and the Malaysian peninsula. They extend as far southwest as the Nicobar Islands, situated in the Andaman Sea. An important outlier, the Munda branch, is found in central and northeastern India. The bestknown members of Austroasiatic are undoubtedly the two national languages of Vietnamese and Khmer (Cambodian).

From a typological perspective, Jenny et al. (2014) classify Austroasiatic into three large groups: Nicobarese, Munda and Mainland Southeast Asia while, from a phylogenetic perspective, a classification into 13 branches has been proposed, including the more familiar Vietic and Khmer but also the lesser- 
known groups of Aslian, Bahnaric, Katuic, Palaungic, Pakanic, Mangic and Khmuic (Sidwell 2014).

Our sample of 14 languages includes the national languages of Vietnamese and Khmer, and also Palaungic, Khmuic and Monic languages (for the full details, see Table 5 in the Appendix). As the Nicobarese and Munda languages of India are outside the geographical area under study, we have not included them in our survey. Of the 14 languages in our sample, 12 belong to Type IV (12/14) which we first discuss.

The Type IV Austroasiatic languages pattern in a very similar manner to Sinitic, Hmong-Mien and Kra-Dai languages. Following our definition, the 12 languages concerned use the identical verb form for both possessive and existential uses, while displaying distinct forms for the copular and locative: $\left[\left(\mathrm{V}_{\mathrm{COP}}\right)\right.$; $\left(\mathrm{V}_{\mathrm{LOC}}\right) ;\left(\mathrm{V}_{\mathrm{EX}}=\mathrm{V}_{\mathrm{POSS}}\right)$ ]. Here are some examples from Cambodian Khmer which illustrate the use of three distinct verb forms to cover the four lexical domains.

(51) Khmer (Khmeric, Austroasiatic)

Copular construction

cru:k cia neak tohtiaj.

pig COP person prophesy

'The pig is a prophet.'

(Haiman 2011: 212)

(52) Locative construction

cru:k nev kraom pteach.

pig be.at beneath house

'The pig is under the house.'

(Haiman 2011: 212)

(53) Existential construction

nev leu: tumpoa ti: pi: robawh NYT taeng tae mian

at on page place two of NYT always have

seckdej kae damrev.

NOM correct correct

'On page two of the NYT, there are always corrections.'

(Haiman 2011: 208)

(54) Possessive construction

preah awng mian preah riac botra: tae pram

HON CL have HON king son only 5

awng ponno:h.

CL that.many

'The king had only five sons.'

(Haiman 2011: 322) 
There are two exceptions to the rule in our Austroasiatic sample: Bugan and Mang are Type III languages (2/14). In Bugan, according to the description given in Li (2005), the same form, $k a i^{44}$, is shared by the existential, possessive and locative verbs. This is precisely the widespread pattern in Tibeto-Burman (Section 4.5) which, by way of contrast, we rarely find in Sinitic, Hmong-Mien or Kra-Dai.

(55) Bugan (Pakanic, Austroasiatic)

Existential construction

ha $^{55}$ gum $^{31}$ ndzon ${ }^{31}$ kai $^{44}$ mbei $^{31}$ tson $^{44}$ sü $^{31}$.

front door there.be two CLF tree

'There are two trees in front of the door.'

(Li 2005: 215)

(56) Possessive construction

o $^{31}$ kai $^{44}$ mur $^{55}$ tsen $^{44}$ nau ${ }^{44}$ mbon $^{31}$.

1SG have one CLF shoe leather

'I have a pair of leather shoes.'

(Li 2005: 193)

(57) Locative construction

$\underline{0}^{31} \quad \mathbf{k a i}^{44} \mathrm{nei}^{44}, \quad \mathrm{mu}^{31} \quad \mathbf{k a i}^{44} \quad \mathrm{lo}^{24}, \quad \mathrm{x}^{31} \mathrm{x} \underline{0}^{31} \mathrm{da}^{24} \mathrm{ph}^{31}$,

$1 \mathrm{sG}$ be.at here $2 \mathrm{SG}$ be.at there well look DUR

no $^{31} \quad \operatorname{zan}^{24} \quad \mathrm{i}^{31}$ qhei $^{44} \mathrm{a}^{44}$.

NEG.IMP let 3sG run PFV

'I'm here; you are there; guard him well and don't let him run away.'

(Li 2005: 225)

(58) Copular construction

$\mathrm{i}^{31} \mathbf{e i}^{\mathbf{2}^{4}} \operatorname{pjau}^{24} \quad \operatorname{nin}^{44} \mathrm{mbo}^{44}$.

3SG COP person bad CLF

'He's a bad person.'

(Li 2005: 199)

The verb $\boldsymbol{k a i}^{\mathbf{4 4}}$ also has a basic lexical meaning 'to live' as well:

$\begin{array}{llll}\mathrm{o}^{31} \quad \mathbf{k a i}^{44} \text { tou }^{44} \mathrm{mbjo}^{44} & \text { nou }^{55} & \mathrm{i}^{55} . \\ \text { 1sG live opposite.side } & \text { home } & \text { 3sG } \\ \text { 'I live across from his home.' }\end{array}$

(Li 2005: 74) 
The majority of Austroasiatic languages in our sample revealed verbs meaning 'to live, dwell' as the source verbs for the locative schema, just as for almost all of the Kra-Dai and many Hmong-Mien languages.

Other Austroasiatic languages with a shared form for the existential, possessive and locative constructions are Mon (Jenny 2005), Buxing (Gao 2004) and Hu (Kunge) (Jiang and Shi 2016). ${ }^{13}$

\subsection{Tibeto-Burman and unclassified Sino-Tibetan languages}

There are 29 languages in our sample from the Tibeto-Burman (T-B) family which we have grouped together with a further five unclassified Sino-Tibetan languages, bringing the total to 34. Our sample thus includes 19 languages from the LoloBurmese branch, four from Qiangic, two Kachinic, two Karenic, one Nungish and the isolate, Tujia. The five unclassified Sino-Tibetan languages include Caijia and four varieties of Bai.

These branches of Tibeto-Burman and Sino-Tibetan are mainly located in southwestern China in the provinces of Yunnan, Guizhou, Sichuan, and also in parts of Guangxi Autonomous Region and the neighboring countries to the south, particularly Northeastern India and Myanmar. Tujia is deemed to be the easternmost representative of these groups, being located in Hunan province of China (see Table 5 in the Appendix for the precise language affiliations).

The 29 Tibeto-Burman languages in our sample are geographically adjacent to Sinitic, Kra-Dai and Austroasiatic, verifiable by means of Map 1. In spite of this proximity to the area of Type IV, they reveal another major type - Type III (29/35) with a binary split in which one member is a polysemous trinome: the existential, possessive and locative verbs share the one form, while the copula contrasts in possessing a distinct form. Some examples of Type III have already been presented in previous sections - in Section 3.3 for Woni (Loloish) and in Section 4.4 on Austroasiatic for Bugan where Type III constitutes a minority.

Across all 29 Tibeto-Burman languages, the copular verb is always distinct from the three other verbs in the set, the latter being all identical in form, regardless of how many existential verbs are present (see Naxi and Guiqiong examples directly below for an elaboration on this point). This clearly contrasts with Types I and II, where locative and copular verbs bear the same form. With regard to the unclassified

13 These were not included in the final sample due to incomplete data or, as in the case of Mon, the fact that there is no transitive possessive use of the existential verb, that is, possessive and existential predicates are not syntactically distinct. 
Sino-Tibetan languages, these include four varieties of Bai which belong to Type I in which one form is used to express the four semantic domains (Section 3.1), as well as Caijia which belongs to Type IV (Section 3.4), patterning like Sinitic, Kra-Dai and most of the Hmong-Mien and Austroasiatic languages in our sample. We will therefore focus on the Tibeto-Burman languages in this section.

Clearly, for these mainly SOV Tibeto-Burman languages, a different set of syntactic constructions is required in the analysis of the predicative expression of the four semantic domains, in comparison with the SVO Sinitic, Kra-Dai, HmongMien and Austroasiatic languages. ${ }^{14}$ The constructions are presented below. ${ }^{15}$

(i) Copular construction frame

$$
\mathrm{NP}_{\mathrm{S}} \quad \mathrm{NP}_{\mathrm{CC}} \quad \mathrm{VP}_{[\mathrm{COP}]}
$$

(ii) Locative construction frame

$\mathrm{NP}_{\mathrm{S}} \quad$ Locative NP(-PostP) $\quad \mathrm{VP}_{[\text {Loc] }}$

(iii) Existential construction frame

(Locative NP(-PostP)) $\quad\left[\mathrm{NP}_{\mathrm{INDEF}}\right]_{\mathrm{S}} \quad \mathrm{VP}_{[\mathrm{Ex}]}$

(iv) Possessive construction frame

$$
\left[\mathrm{NP}_{\text {Possessor }}\right]_{\mathrm{S}} \quad\left[\mathrm{NP}_{\text {Possessed }}\right]_{\mathrm{O}} \mathrm{VP}_{[\text {poss }}
$$

Naxi is a Na-Qiangic language (Jacques and Michaud 2011) spoken in Yunnan province of China. It is closely allied to the Loloish languages and may usefully serve as a prototype for Type III languages in our sample. Depending on the syntactic construction of which it partakes, the interpretation of the polyfunctional verb $\eta g y^{33}$, used with inanimates, may be one of existence, possession or location at a place. The counterpart form for animate entities is the tonally distinct $\eta g y^{21}$.

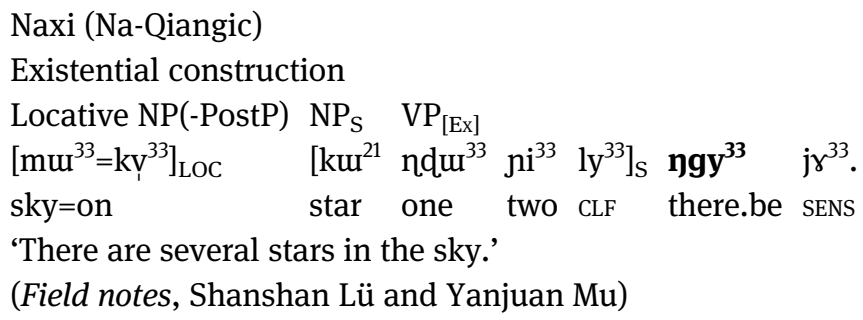

'There are several stars in the sky.'

(Field notes, Shanshan Lü and Yanjuan $\mathrm{Mu}$ )

14 Karen and Bai are the only exceptions in our sample of Tibeto-Burman and unclassified SinoTibetan languages with SVO basic word order.

15 Note that Huang (2013) has independently proposed a similar set of frames for the 100 TibetoBurman languages in his corpus, observing, as we do, that argument positions are crucial for distinguishing the different constructional meanings. We heartily concur with his standpoint. 


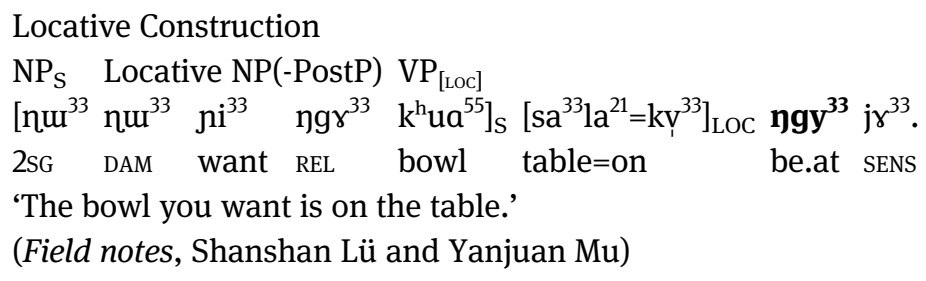

(62) Possessive construction

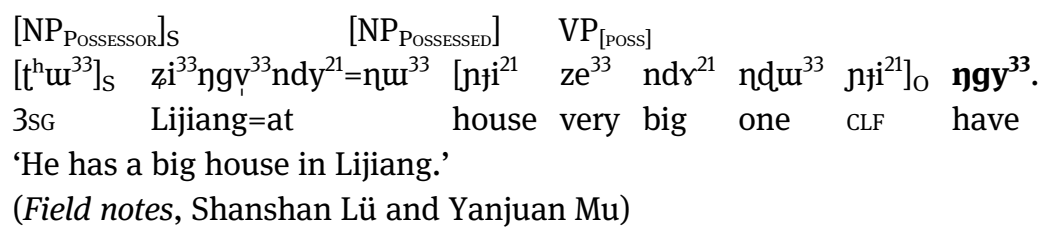

The distinct copula verb in Naxi is $w a^{21}$ as shown in the following example:

$$
\begin{aligned}
& \text { Copular construction } \\
& \mathrm{NP}_{\mathrm{S}} \quad \mathrm{NP}_{\mathrm{CC}} \quad \mathrm{VP}_{\text {[COP] }} \\
& \mathrm{ny}^{21} \quad \mathrm{si}^{21} \mathrm{tsi}^{33} \quad \mathbf{w a}^{21} \text {. } \\
& \text { 1SG teacher COP } \\
& \text { 'I'm a teacher.' } \\
& \text { (Field notes, Shanshan Lü and Yanjuan Mu) }
\end{aligned}
$$

As is evident from the examples above, the different syntactic constructions clearly identify the associated interpretation for $\eta g y^{33}$ as coding existence of inanimate entities in a general way ((at $Z)-X$-there.is), a specific location (X-at place $Z$ be.at), or possession with two NP arguments ( $X-Y$ [inanimate]-have). In addition, there is a large deal of variation in our Tibeto-Burman data as to the use of inflectional marking on the verb phrase for TAME or person and number crossreferencing, without overlooking case-marking on nominal elements. ${ }^{16}$

As for the syntax, the Naxi examples above are representative of our TibetoBurman sample as a whole in showing that for existential predicates, the optional locative NP, as in (60), tends to fall into the clause-initial slot. Depending on the language, it may be marked by a locative postposition, as it is in this example. For toponyms such as 'Tibet', the locative postposition may not be required, depending on the given language. By contrast, the subject occurs in the argument slot following the locative (or any other adjunct phrase) and is morphologically marked as indefinite or non-specific, for example, by a classifier phrase, $\left[\mathrm{kw}^{21} \mathrm{ndu}^{33} \mathrm{ni}^{33} \mathrm{ly}^{33}\right]$

16 We use the term 'case' in its broad sense to cover all kinds of marking from inflections to adpositions, following Blake (2004: 1-12). 
star-one-two-CLF 'several stars', in (60). The use of existential constructions as a presentative device is well-described in the literature on this topic, as already remarked upon in Section 2 (see also Sections 4.2 and 4.3).

In contrast to this, the syntactic structure for the locative construction typically codes the figure in clause-initial position in the subject role with a definite or referential interpretation, as in (61). It is followed by a non-omissible locative complement NP and then by the same verbal form as for the existential predicate, $\eta g y^{33}$, in that order. Unlike existential constructions, the locative construction gives priority to coding information about the place or position where a given referent, the subject NP, is to be found.

In the case of possessive predication, $\eta g y^{33}$ may also be used in a third syntactic construction, distinct from that of existential and locative predication, exemplified by (62). In this transitive construction, there are two core arguments associated with the verb. Notably, this example cannot be interpreted as having a genitive NP as its subject and an existential verb in the predicate, due to the position of the locative adjunct between possessor and possessed nouns. That is, it cannot be analyzed as belonging to the Existence Schema where the subject NP contains a genitive modifier: X's Y exists (at place L).

In Tibeto-Burman languages, sets of multiple existential verbs are a widespread feature, and their use is typically semantically conditioned (Huang 2013). Similar to the examples just discussed, these sets of verbs are also polysemous, since they cover the entire range of existence, possession and location, cooccurrence restrictions being determined to some extent by their lexical source (Section 4.1.1.).

Classificatory semantic features that recur across this branch of languages are animacy, shape including posture gestalts, movability, inalienability, attachment to another object, or existence in an enclosed space, such as in a cave or a pocket (Chirkova 2009; Post 2008; Rao 2017). These features may also be intertwined with the evidentiality system (Acuo 2004: 40-45; Huang 2013: 40).

Guiqiong, a Qiangic language of Sichuan, can be used to illustrate such a paradigm for which we have a full set of data. It has a set of three polysemous verbs, each of which can code existence, location and possession but with respect to subjects belonging to different semantic categories, as described below (Rao 2015, 2017):

(i) nã $\tilde{a}^{35}$ used for existence, location and possession of animate entities

(ii) $\quad \mathrm{j} \tilde{\varepsilon}^{55} \quad$ used for existence and possession of inanimate entities, particularly valued possessions, also for abstract entities

(iii) bu $^{35}$ used for immovable things that are attached to another larger entity (trees, body parts) 
Below, we provide just the existential construction for comparing each of these three different verbs:

(64) Guiqiong existential predicates

(Locative NP(-PostP)) $\left[\mathrm{NP}_{\text {INDEF }}\right]_{\mathrm{S}} \mathrm{VP}_{[\mathrm{EX}]}$

Existence of an animate entity: $\mathbf{n} \tilde{a}^{35}$

$\begin{array}{lllll}\mathrm{ti}^{55} \mathrm{ga} \tilde{a}^{53} & \mathrm{xu}^{33} \mathrm{tca}^{33} & \mathrm{mu}^{35} & \mathrm{ka}^{33} \mathrm{la}^{53} & \mathbf{n} \tilde{a}^{35}, \\ \text { at.this.moment } & \text { street } & \text { person many } & \text { there.be } \\ \mathrm{ts}^{\mathrm{h}} \varepsilon^{55} \mathrm{tso}^{33} & \mathrm{ka}^{33} \mathrm{la}^{53} & \mathrm{j} \tilde{\varepsilon}^{55} \text {. } & & \\ \text { car } & \text { many } & \text { there.be } & & \end{array}$

'At that moment, there were many people in the street and there were also many cars.'

(Rao 2015: 356)

(65) Existence of an inanimate entity: $\mathbf{j} \tilde{\varepsilon}^{55}$
$\tilde{\mathrm{u}}^{33} \mathrm{pu}^{55}=\mathrm{gur}^{53}$
$\mathrm{Ndi}^{33} \mathrm{pi}^{53}$
$\mathrm{t}^{\mathrm{h}} \mathrm{u}^{33}-\mathrm{t} 6^{\mathrm{h}} \mathrm{w} \varepsilon^{55}-\mathrm{lu} \mathrm{u}^{33}$
$\mathrm{j} \tilde{\varepsilon}^{55}$.
mouth $=$ LOC
treasure DIR-exit-NMZ
there.be

'There are treasures spouting from its mouth.'

(Rao 2017: 88)

(66) Existence of an immovable entity: bư ${ }^{35}$

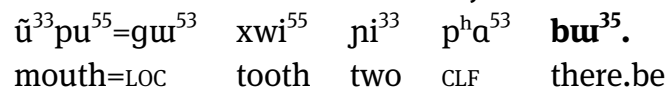

'There are two teeth in its mouth.'

(Min Rao, pers. comm. 2018)

The distinct copula verb in this Type III language is $d z \partial^{35}$, as in (67):

(67) Copular construction

\begin{tabular}{|c|c|c|c|}
\hline$n \partial^{33}-m \tilde{\varepsilon}^{55}$ & $\mathrm{~min}^{33} \mathrm{ts}^{\mathrm{h}} \mathrm{J}^{33}$ & $\mathrm{t} 6 \mathrm{a}^{55} \mathrm{t}^{\mathrm{h}} \partial^{55} \mathrm{ts}^{\mathrm{h}} \partial^{55} \mathrm{li}^{55}$ & dza $\partial^{35}$. \\
\hline 1SG-GEN & name & Gya-theg-mtho-legs & $\mathrm{COP}$ \\
\hline
\end{tabular}

Huang (2013) examines a corpus of over 100 Tibeto-Burman languages and classifies the existential verbs according to many of the semantic features listed above. Although copular verbs have not been included in his survey, Huang finds that 27/100 languages in his corpus possess at least one verb which can code all three existential, locative and possessive meanings. Furthermore, the majority of the

17 For reasons of convenience and limitations of space, we have taken the liberty of rendering $\mathrm{M}$. Rao's French translations into English. 
languages in his survey possess two or more existential verbs, and all display this same polysemous behavior in serving as locative and possessive verbs as well. According to his survey, certain varieties of Hani (Loloish) apparently differentiate up to a maximum of 10 such polysemous verbs. ${ }^{18}$

For the expression of possession, it is important to note that a large number of Tibeto-Burman languages combine an intransitive existential or locative verb with a possessor marked by a locative postposition, for example, Burmese and Mon, or else they mark the subject NP by the dative, genitive or the allative. Consider the following example from Burmese:

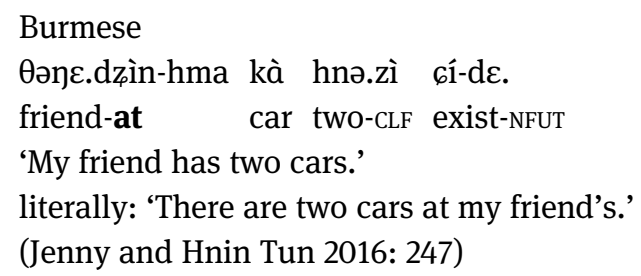

We have not included languages in our sample which invariably use this kind of intransitive construction for coding possession. In terms of morphosyntax, its syntactic configuration is indistinguishable from the existential construction. Put differently, for morphosyntactic reasons, the construction cannot be considered as two-ways polysemous for 'there be' and 'have'. According to the grammatical descriptions consulted, the existential meaning is applicable in both cases and consequently such examples can be glossed as 'there be' or 'exist', but not, strictly speaking, as 'have'.

In sum, the form of the syntactic constructions used to code each of these four semantic domains by means of a polysemous or 'shared' verb provides the key for distinguishing the expression of existence, location or possession in Type III languages. It can also be observed that 'dwell', and sometimes 'sit', 'stand' or 'lie', is a common source for these verbs in 23/29 languages in our Tibeto-Burman sample and also in Caijia.

18 In our original, much larger, sample of 47 languages for Tibeto-Burman, the data sources frequently did not provide sufficient information to enable us to verify whether each existential verb could also serve as a possessive and a locative verb as well. For this reason, we only include Tibeto-Burman languages where we could find data for a minimum of one complete set of verbs for the three domains of locative, existential and possessive, in addition to the typically distinct copula (see also Section 1). Huang (2013) evinces the same problem with the data he collected from 100 reference grammars of Tibeto-Burman languages. It is rarely possible to gather the full paradigm of uses for each verb and, moreover, unclear if this is due to a gap in the data presented in the grammar or due to the actual situation for the given verb paradigm - that only one or two of the three possible functions exist. 


\subsection{Interim summary for the synchronic analysis}

While the majority of the languages in our sample fall into either Type III or IV, the resulting classification crosscuts the four main continental Asian language taxa to reveal distinct sub-areal patterns (see Map 2 above). There is only one group of languages which codes the four lexical domains by a single verb form - the Bai languages, which form a tiny minority, whereas there are no 'splitter' languages in this Asian sample that consistently use distinct forms for each of the four semantic domains, as Table 5 clearly displays (see the Appendix). Strikingly, in all the 116 languages investigated, the possessive and existential verbs share the same form, regardless of genetic affiliation. We are thus able to confirm an earlier observation by Clark (1989: 206-208) that this is an important areal feature, a point similarly made in Chappell and Creissels (2019) who use a subset of our sample. In Section 5, we refine this observation as the outcome of two different and opposing grammaticalization pathways.

The topic of diachronic change in the form of three main grammaticalization pathways is next addressed in Sections 5 and 6, the second half of our analysis.

\section{Diachronic sources and pathways for locative, existential, possessive and copular verbs}

In this section, we discuss the pathways of development which include the possible lexical sources for locative, existential, possessive and copular verbs. We take the standpoint that these four semantic domains should be treated as discrete ontological categories but ones that are nonetheless clearly linked by specific diachronic processes (cf. Heine 1997a, 1997b; Kuteva et al. 2019).

To provide a framework for the following discussion, we propose that there are three main pathways of polygrammaticalization responsible for the patterns of polysemy found in our sample on MESEA: one is radial and two are linear. These are represented in the following figure, with an indication as to which of the four areal patterns they belong.

Needless to say, the pathways for grammaticalization and reanalysis do not take place automatically in any language. The diachronic processes of change described in this present analysis allow us to model an explanation in a nondeterministic way for the synchronic state of affairs that pertains to the different patterns formed by these four high frequency verbs. Our approach is similar to the one adopted in Cristofaro and Zúñiga (2018) on typological hierarchies and illustrates what Croft refers to as the 'dynamicization of typology' (2002: Ch. 8). 
(i)

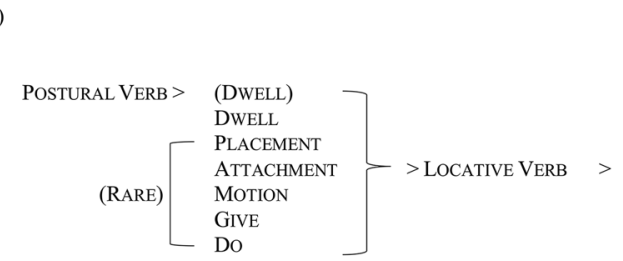

(LOCATIVE ADPOSITION) $>$ (PROGRESSIVE)

(b) $\nearrow$

(Type IV and a few Type III)

(a) $\rightarrow$ EXISTENTIAL $>$ POSSESSIVE (Type III)

(c) $>$ COPULA (RARE)

(ii) (DEMONSTRATIVE) $>$ COPULA $>$ LOCATIVE VERB $>$ (LOCATIVE PREPOSITION) $>$ (PROGRESSIVE ASPECT) (Type II)

(iii) GRASP/SEIZE/TAKE > HAVE POSSESSIVE > EXISTENTIAL (Type II \& Type $I V$ )

Figure 1: Major grammaticalization chains involving COPULAR, LOCATIVE, EXISTENTIAL and PoSSESSIVE verbs.

We begin the discussion with locative and copular verbs, examining their sources and their pathways of grammaticalization within the first two of the grammaticalization chains.

\subsection{Locative and copular verbs}

In our sample, four diachronic changes that involve locative, and in some cases copular verbs, are implicated in the important processes of polygrammaticalization given in Figure 1, in particular for pathway (i). The concept of 'polygrammaticalization' refers to the case of multiple grammaticalization chains which share the same lexical source morpheme (Craig 1991: 455, 486).

Noting that these chains are composed of stages or sections presented in Figure 1 above, the first two to be discussed concern the source of locative verbs in typically either a Postural or a Dwell verb [i], the first link in the chain and their further development along either pathway [i(a)] or [i(b)].

A third potential semantic shift is for COPULAR verbs to develop into LOCATIVE verbs in pathway [ii]. Finally, in a fourth possible diachronic change, under pathway [i(c)], Locative verbs can themselves be the source for Copulas, albeit rarer in our sample. ${ }^{19}$

19 Another well-attested segment of the pathway is the development of locative adpositions into imperfective aspect markers, as in [i(b)] and [ii], a recurring feature of our data. As it is not germane to the present discussion, we refer the reader to Bybee et al. (1994: Ch. 5), Lord (1993), Matisoff (1991) and Vittrant and Watkins (2019) for detailed analyses. 
[i(a)]:

(Postural Verb) $>$ (Dwell) $>$ Locative Verb $>$ Existential Verb (found in Type III only)

[i(b)] and [ii]:

(Postural Verb) $>$ (Dwell) $>$ Locative Verb $>$ Locative Adposition

(found mainly in Type IV and in a few Type II and III)

[ii]:

(Demonstrative) $>$ Copula $>$ Locative Verb

(found in Type II only)

[i(c)]:

Dwell/Stick $>$ Locative Verb $>$ Copula

(rare in our sample, found in Type II only)

Locative verbs 'to be at' prove to be synchronically related to verbs meaning 'live, dwell' or PostuRAL verbs in more than half of our sample, yielding a total of 64 languages (64/116). The Postural verbs are represented by 'sit', 'stand', 'lie' and 'squat'. Such a semantic shift conforms to one of the main parameters of grammaticalization, semantic generalization or bleaching, according to which, the more semantically specific postural or 'dwell' meanings are diachronically prior to the more generalized locative meaning, 'be at'.

This shift to the Locative VerB stage is almost invariant for Kra-Dai (15/16) and Austroasiatic (13/14), common in Hmong-Mien (10/14) and Tibeto-Burman (23/ 29), but synchronically rarer in Sinitic (2/38) (see Sections 5.1.1 and 5.1.2 for details). It can also be identified in one of the unclassified Sino-Tibetan languages, Caijia (1/5). Other rarer sources for locative verbs indicated in Figure 1 are discussed in Section 5.1.5.

These diachronic changes are discussed in turn below, beginning with the core part of the first chain which involves the grammaticalization pathway for (Postural Verb) > (Dwell) > Locative Verb, whence it bifurcates into the further stage of either an Existential Verb or a Locative Adposition. ${ }^{20}$ Note that the

20 Hereafter, for ease of presentation in this section, we do not use the full expansion for DweLL and PostuRAL VERbs in the figure for the grammaticalization chain in order to avoid the cumbersome:

Postural verb > (Dwell) $>$ Locative Verb

Dwell

Typically, most of the postural verbs in our sample are also used as verbs meaning 'dwell', via semantic extension and generalization of meaning. Nonetheless, in reference works for certain languages, the DwELL meaning is not always given for this particular class of postural verbs, which 
complete chain with all its successive stages, for example, all the way to the progressive aspect use in [i(b)], may not necessarily be attested in one and the same language. Nonetheless, it should be possible to show that the attested stages are adjacent to one another. ${ }^{21}$

\subsection{1 (Postural Verb) > (Dwell) > Locative > Existential in Type III languages Pathway [i(a)]}

In this section, we focus on the Type III Tibeto-Burman languages which evince a distinct pathway of grammaticalization for their DwELL verbs, when compared with the other four language families. This is the first pathway, [i(a)], beginning with (Postural) $>$ (Dwell) $>$ Locative > Existential and eventually proceeding to a final Possessive stage. In the largely Type IV languages, Locative Verbs generally develop into Locative Adpositions [i(b)] (see Section 5.1.2 below).

As foreshadowed above, in quite a number of Tibeto-Burman languages, twenty-three (23/29) to be precise, the source for polysemous LocATIVE/ExISTENTIAL/ Possessive verbs can be traced to a DwELl verb and five to an even earlier stage of a Postural Verb, such as 'sit', 'lie' and 'stand' (the source unknown for one language). Naxi is such a case where two of the Locative/Existential/Possessive verbs are in fact derived from Postural verbs: one from 'sit', $n d z 1^{21}$, and one from 'lie', $z_{0} i^{55}$. Denoting location, existence, or possession, $n d z 1^{21}$ is restricted to objects attached to some larger frame of reference, for example, an earring worn on one's ear, while $z_{0} i^{33}$ is restricted to objects existing inside a container-like object, metaphorically extended in (70) to expressing an emotion. Note that a change of tone is involved for the 'be at' meaning ( $z_{0} i^{55}$ 'lie' $\rightarrow z_{i} i^{33}$ 'be at'). The following examples, (69)-(72), show just the polysemy of the postural verb $z_{i}{ }^{55}$ 'lie' in Naxi.

$$
\begin{aligned}
& \text { Naxi, (Na-Qiangic, Tibeto-Burman) } \\
& \mathrm{zi}^{55}=\text { 'lie' } \\
& {\left[\text { zue }^{21}\right]_{S} \quad\left[\mathrm{tsua}^{33}=\mathrm{kv}^{33}\right]_{\text {LOC }} \quad \mathrm{t}^{\mathrm{h}} \mathrm{e}^{21} \quad \mathbf{z i}^{\mathbf{i}^{55}} \quad \mathrm{jr}^{33} \text {. }} \\
& \text { child bed=on DUR lie SENS } \\
& \text { 'The child is lying/sleeping in the bed.' } \\
& \text { (Field notes, Shanshan Lü and Yanjuan Mu) }
\end{aligned}
$$

explains the use of parentheses for (DwELL) in the pathway above. We are nonetheless convinced that this intervening stage can be reconstructed in such cases. In the discussion above, the figure of (64/116) exclusively reflects this segment of pathway (i).

21 In other words, this predicts that we should not find, for example, the grammaticalization pathway COPUla > LOCATIVE PREPOSITION without the LOCATIVE VerB stage intervening. 


$$
\begin{aligned}
& \mathrm{zi}^{33}=\text { 'be in' } \\
& {\left[\mathrm{nu}^{21}\right]_{\mathrm{S}}\left[\mathrm{nr}^{33} \mathrm{ngr}^{33} \mathrm{nv}^{55} \mathrm{me}^{33}=\mathrm{lø}^{21}\right]_{\text {LOC }} \mathrm{t}^{\mathrm{h}} \mathrm{e}^{21} \mathrm{ta}^{55} \quad \mathbf{z i}^{\mathbf{3}^{33}} \text {. }} \\
& \text { 2SG 1SG POSS heart=in DUR always be.in }
\end{aligned}
$$

One can immediately observe that the locative construction in (70) syntactically mirrors the construction with 'lie' in (69). However, the lexical meaning of 'lie' is bleached out in (70), for which $z_{0} i^{33}$ denotes the spatial relation of 'be inside', instead of the specific posture of lying.

Example (71) illustrates the existential construction (in italics) formed by $z_{0} i^{33}$.

$$
\begin{aligned}
& \mathrm{zi}^{33}=\text { 'there be } \ldots \text { inside' }
\end{aligned}
$$

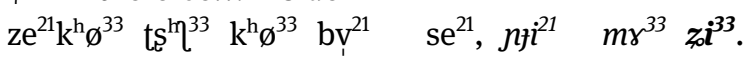

$$
\begin{aligned}
& \text { well this CLF be.dry PFV water NEG there.be.in } \\
& \text { 'The well is dry and there's no water (inside).' } \\
& \text { (Field notes, Shanshan Lü and Yanjuan } \mathrm{Mu} \text { ) }
\end{aligned}
$$

Different from the case of Burmese in (68) above, $z_{0} i^{33}$ is unequivocally a transitive verb when expressing possession (see (72) below). The possessor 'this person' is in its nominal form without any case marking. One should also be aware that the NP $\left[\mathrm{çi}^{33} \mathrm{tS}^{\mathrm{h}} \chi^{33} \mathrm{kv}^{55}\right.$ ] person-this-CLF 'this person' and the noun [cir ${ }^{55}$ ' 'money' cannot be analyzed as forming a larger genitive NP denoting 'this person's money', since the possessor, a lexical NP, is not linked with its possession by the genitive marker $\eta g r^{33} \cdot 22$ (See also (61) for the use of the latter as a relativizer.):

$$
\begin{aligned}
& \mathrm{zi}^{33}=\text { 'have' } \\
& \begin{array}{lllllll}
{\left[\mathrm{çi}^{33}\right.} & \mathrm{ts}^{\mathrm{h}} \eta^{33} & \left.\mathrm{kv}^{55}\right]_{\mathrm{S}} & \mathrm{cir}^{55} & \mathrm{ngy}^{33}, & \mathrm{ti}^{55} \mathrm{we}^{55} & \mathrm{ngy}^{33} \\
\text { person } & \text { this } & \mathrm{CLF} & \text { money } & \text { have } & \text { social.status } & \text { have } \\
\mathrm{se}^{21} \mathrm{me}^{33}, & {\left[\mathrm{pe}^{33} \mathrm{si}^{55}\right]_{\mathrm{O}}} & \mathbf{z i}^{33} & \mathrm{mr}^{55} \mathrm{si}^{33} & &
\end{array} \\
& \text { besides capacity have PRT }
\end{aligned}
$$

'He's not only rich and of high social standing, but he has the capacity as well.'

(Field notes, Shanshan Lü and Yanjuan $\mathrm{Mu}$ )

Crucially for our hypothesis, certain Tibeto-Burman languages, not in our sample, possess monosemous locative verbs that are only used in the function of a locative, or else have locative verbs which do not evolve past the existential stage, that is, they share only the locative and existential meanings. In contrast, we significantly

22 Note that the genitive marker, $\eta g r^{33}$, which is not found in (72) has a different vowel from the verb 'to have', $\eta g y^{33}$, in (72). 
do not find any locative verb which is polysemous with just the possessive verb meaning. One case in point is the Tani group of languages.

As reported by Post (2008: 142), the postural verbs 'sit', 'lie' and 'stand' in several Tani languages (Tibeto-Burman), namely Galo, Mising and Apatani, show different degrees of polysemy. The three postural verbs in Apatani, 'sit', 'lie' and 'stand', in addition to 'sit' in Mising, all extend along the grammaticalization chain under discussion to express existence and then possession, as do $n d z 1^{21}$ 'sit' and $z_{0} i^{55}$ 'lie' in Naxi. By way of contrast, all three postural verbs in Galo, only reach the locative meaning 'be at' on this pathway, whereas 'lie' and 'stand' in Mising remain at the initial postural verb stage.

Compare the following two examples from Galo: In (73), one of the postural verbs dóo 'lie down' has extended in use to a locative verb 'to be at/in (a place)'. It is distinct from the existential and possessive verb káa in (74) which does not have either a postural or locative use. Note that obligatory genitive or locative marking is not required on the possessor NP in Galo possessive constructions. It acts as the topic NP rather than as part of a genitive or adjunct phrase, supporting our point regarding the Naxi possessive in (72).

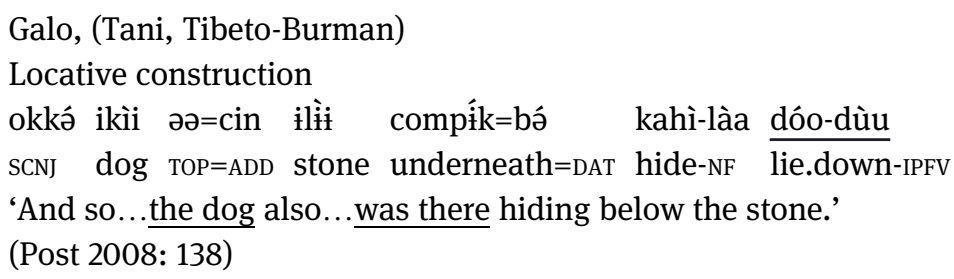

SCNJ=sentence conjunction; $\mathrm{TOP}=$ topic; $\mathrm{ADD}=$ additive; $\mathrm{DAT}=$ dative $\mathrm{IPFV}=\mathrm{imperfective}$

(74) Possessive construction

\begin{tabular}{|c|c|c|}
\hline bulù=əəə & dùu-dée-kò & káa-kú-máa \\
\hline 3.PL=TOP & stay-PSBL-NZR:LOC & have/exist-CMPL-NEG \\
\hline [Possessor] & [Possessed] & \\
\hline
\end{tabular}

'They...had no place where they could stay.' (lit. 'Concerning them, a place to stay did not exist.')

(Post 2008: 141)

$\mathrm{PL}=$ plural; $\mathrm{TOP}=$ topic; $\mathrm{PSBL}=$ possible; $\mathrm{NZR}=$ nominalizer; $\mathrm{LOC}=$ locative; $\mathrm{CMPL}=$ completive; $\mathrm{NEG}=$ negative

Jingpho similarly possesses a verb $\eta a^{31}$ which has locative and existential uses but not a possessive one. The possessive verb $l u^{31}$ 'have' is derived from 'obtain' and only has this use. 
(75) Locative construction

$\begin{array}{lll}\text { nú }^{51} \quad \mathrm{n}^{55} \underline{\mathrm{ta}}^{55} \quad \mathbf{n a}^{\mathbf{3 1}} & \mathrm{ai}^{33} . \\ \text { mother home be.at } & \text { IND.3sG } \\ \text { 'Mother is at home'. } & \end{array}$

(Dai 2012: 102)

(76) Possessive construction

nai $^{33} \mathrm{na}^{33} \mathrm{lă}^{55} \mathrm{nai}^{51} \mathrm{mi}^{33} \mathrm{lu}^{31} \mathrm{n}^{31} \mathrm{nai}^{33}$
1sG ox one one have ${ }^{\text {IND. }} \mathrm{sG}$
'I have an ox.'

(Dai 2012: 103)

It is worth noting that the phenomenon of postural verbs serving as locative verbs is found in other languages outside of MESEA, such as Arrernte (Pama-Nyungan) and Goemai (Afro-Asiatic) (Ameka and Levinson 2007). See also Stassen (1997: 55-61).

In the next section, we consider a second and distinct pathway involving DweLL verbs which is largely found in the Type IV languages and for which there is no extension to an existential stage. This concerns pathway [i(b)] for the stages LOCATIVE VERB > LOCATIVE ADPosition which is mainly found in Type IV languages.

\subsection{2 (Postural Verb) > (Dwell) > Locative verb > Locative Adposition in Type IV and some Type II and III languages Pathway [i(b)]}

The second pathway, [i(b)], in which a Locative VerB develops further into the function of a Locative ADposition, comprises 30 Type IV languages, three Type III languages (Bugan, Mang and Sani) and two Type II languages (Aizhai Xong and Nùng) (35/64).

To illustrate by a first example, in Judu Gelao, a Kra-Dai language spoken in Guizhou province of China, the verb $q a u^{33}$ has developed along the pathway SIT > Dwell > LOCATIVE VERB stages, respectively illustrated by the following three examples: ${ }^{23}$

23 For the languages in our sample with 'sit', 'squat' or 'stand' as the source for the locative verb, the overall tally of 13 languages is as follows (13/64), noting that an intervening 'dwell' stage between the postural verb and the locative verb may not be attested in all cases.

Type III: $\quad$ TiвETo-Burman: Drung, Yuanjiang Kucong, Nasu, Nusu, Zauzu, Naxi, Longxi Qiang; HMONG-Mien: Yanghao

Type IV: $\quad$ Hmong-Mien: Jiongnai, Baheng; Kra-Dai: Judu Gelao; Austroasiatic: Stieng; Sinitic: Changsha Xiang 


$$
\begin{aligned}
& \text { Judu Gelao (Kra-Dai) } \\
& \text { Lexical verb 'sit' } \\
& \mathrm{mi}^{35} \mathrm{a}^{31} \mathrm{den}^{31} \Lambda^{312} \operatorname{lan}^{31} \mathbf{q a u}^{33} \mathrm{zi}^{33} \mathrm{k}^{\mathrm{h}} \mathrm{en}^{31} \text {. } \\
& 3 \mathrm{sg} \text { at side road sit rest } \\
& \text { 'He sat by the roadside to have a rest.' } \\
& \text { (Kang 2009: 50) }
\end{aligned}
$$

(78) Lexical verb 'live'

$$
\begin{aligned}
& \mathrm{di}^{33} \mathrm{to}^{31} \mathrm{ta}^{31} \mathrm{kan}^{31} \mathrm{tsi}^{33} \mathbf{q a u}^{33} \mathrm{a}^{31} \mathrm{tu}^{31} \mathrm{lu}^{35} \mathrm{pai}^{35} \mathrm{ai}^{33} \text { bur }{ }^{35} \text {. } \\
& \text { 1PL three CLF all live at village opposite that }
\end{aligned}
$$

'We three all live in that village that is on the opposite side.'

(Kang 2009: 175)

(79) Locative verb 'be at'

$$
\begin{aligned}
& \mathrm{t}^{\mathrm{h}} \mathrm{i}^{31} \mathrm{nzi}^{35} \text { məư } \mathrm{uau}^{33} \mathrm{ko}^{35} \mathrm{t}^{\mathrm{h}} \mathrm{u}^{33} \\
& \text { shoe 2sG be.at foot bed } \\
& \text { 'Your shoes are under the bed.' } \\
& \text { (Zhongde Kang pers. comm.) }
\end{aligned}
$$

Note that in some of our secondary references, only the PostuRAL verb meaning is listed alongside the locative uses. In spite of this lacuna, we believe that DwELL is likely to be a necessary and a plausible stage in the semantic change for these postural verbs (see also Fn. 21).

In further support of this pathway, many Sinitic languages possess cognates of the Standard Mandarin locative verb $t s a i^{51}$ 在 'be at', a verb whose diachronic source is indeed 'dwell' (Peyraube 1981). ${ }^{24}$ Notably, this use is synchronically obsolete, as opposed to a secondary meaning of 'be present, exist' (Section 4.3.4). As predicted for all of these Type IV languages, the grammaticalization pathway does not proceed past the locative stage to an existential or possessive verb.

Clark $(1989: 192,195)$ has broadly observed that it is very common in Southeast Asian languages to find a development from 'location locus verb', as she calls it, to locative preposition. This is exactly what we find in Type IV languages, such as the Sinitic family, where $t s a i^{51}$ 'be at' and its cognates further develop into a locative preposition but also in Gelao for $q a u^{33}$ :

24 There is a total of 38 Sinitic languages in our main sample (38/116). Eleven of these have cognates of $t s a i^{51}$ 在 'be at' as their locative verb. 
(80) Judu Gelao (Kra-Dai)

Locative preposition 'at', 'in'

$\mathrm{vu}^{31} \mathrm{no}^{35} \mathbf{q a u}^{33}$ tu $^{35} \mathrm{lui}^{31} \mathrm{no}_{\circ} \mathrm{u}^{33} \mathrm{na}_{0} \mathrm{a}^{35} \quad \partial^{31} \mathrm{phau}^{35}$.

bird at sky without.order fly

'The birds are flying in the sky.'

(Kang 2009: 244)

The same development is equally valid for the locative verb, $k a i^{44}$, in Bugan, an Austroasiatic language, discussed in Section 4.4.

(81) Bugan (Austroasiatic)

Locative preposition

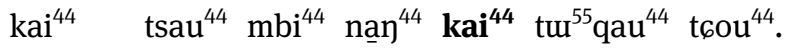

there.be dog CLF sleep at middle road

'There's a dog sleeping in the middle of the road.'

(Li 2005: 206)

While it is true that locative verbs rarely develop into locative postpositions in Tibeto-Burman languages, the possibility is however not to be excluded: there are two such cases in our sample: $t s o^{33}$ 'be at' in Sani (Loloish) and $t \partial^{31}$ 'be at' in Achang (Burmish), the latter belonging to our extended sample.

(82) Achang (Burmish, Tibeto-Burman)

Locative construction

nan $^{33} \quad \mathrm{xa}^{55} \mathrm{tchi}^{33} \quad \mathrm{k}^{33} \mathrm{ta}^{33} \quad \mathbf{t a}^{31}$ ?

2SG now where be.at

'Where're you now?'

(Shi 2009: 113)

(83) Locative postposition

$\mathrm{na}^{255} \mathrm{tsa}^{33} \mathrm{na}^{255} \mathrm{sut}^{31} \mathrm{ta}^{33} \mathrm{lun}^{33} \mathrm{nci}^{255}$.

fledgling nest Loc be.in ConT

'The fledgling is in the nest.'

(Shi 2009: 105)

In a small number of languages in our data, locative verbs meaning 'be at' share an identical phonetic form with copular verbs. There are 10 of these Type II 
languages in total: six Sinitic, three Hmongic and one Tai. ${ }^{25}$ It turns out that there are two grammaticalization chains responsible for this polysemy: pathway (ii) COPULAR > LOCATIVE for five of the languages and a much rarer pathway, [i(c)], of LOCATIVE > Copula for three languages. The data are not available, however, in the remaining two languages for us to be able to reconstruct their pathways. Distinct lexical sources for the two pathways account for the resultant polysemy sharing and classification as Type II. These are next discussed in turn.

\subsubsection{Copular > Locative Pathway (ii)}

When the source of a locative verb is not a Postural or Dwell verb, locatives may be diachronically linked with copulas in our Asian survey. In the second main chain of grammaticalization, pathway (ii), the core diachronic change is from COPULAR > LOCATIVE.

In Sinitic languages, including a majority of the Hui branch but also Xianghua and a large number of $\mathrm{Wu}$ and Yue dialects (Section 3.2), the essential difference between the two constructional meanings of locative and copular is determined once more by the semantic category of the predicate noun. In (84) from the Wu dialect of Rui'an Wenzhou, the copular complement is a kin term, and the construction shows its typical equational function, whereas in the case of locative predication in (85), there is a locative noun complement, gau ${ }^{434}$ 'here'.

(84) Rui'an variety of Wenzhou (Wu, Sinitic)

Copular construction

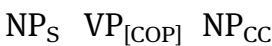

$\mathrm{ni}^{214} \mathrm{zi}^{214} \quad \mathrm{fu}^{35} \quad \mathrm{zi}^{214} \mathrm{gi}^{31} \mathrm{gi}^{53} \mathrm{a}^{0} \mathrm{ku}^{55}$ ?

2SG COP NEG COP 3SG POSS brother

'Are you his brother?'

(Field notes, Milena Lazzaretti)

(85) Locative construction

$\mathrm{NP}_{\mathrm{S}} \mathrm{VP}_{[\mathrm{LOC}]}$ Locative NP

$\mathrm{ni}^{214} \mathbf{z t}^{\mathbf{2 1 4}} \mathrm{nia}^{35}$ a? $\mathrm{n}^{214}\left(\mathbf{n a u}^{\mathbf{2 1 4}}\right) \mathrm{zi}^{214}$ gau ${ }^{434}$.

2SG be.at where INT 1SG (NEG) be.at here

'Where are you? I am (not) here.'

(Field notes, Milena Lazzaretti)

25 For evident reasons, we temporarily leave aside the Type I Bai languages. The 10 languages include:

Sinitic (6): Hong Kong Cantonese Yue, Jixi Hu, Yixian Hui, Rui’an Wu, Xianghua, Fuqing Min HMongic (3): Aizhai Xong, Fenghuang Xong, Songtao Xong

TAI (1): $\quad$ Nùng 
The relevant documentation for the grammaticalization pathway in Sinitic languages establishes the copular use as preceding the locative one for earlier periods of written Chinese. Shi 是 $\left[\mathrm{s}^{51}\right]$ is claimed to have developed into a copular verb from a demonstrative pronoun in the period of Late Archaic Chinese (sevenththird centuries вс) (Wang 1958: 353) and apparently its first attested uses as a locative verb 'to be at' appear much later, as seen in the literature of poetry from the Tang dynasty, which corresponds to the period of Late Medieval Chinese (sevenththirteenth centuries) (Hirata 1999; Ma and Cai 2006b). Synchronically, it does not have the locative verb use in the Mandarin group of languages (Cao 2008, vol. 3: Map 39). Further examples from Jixi Hui and from Xianghua (unclassified Sinitic) can be found in Sections 3.2 and 4.1 respectively.

Noting that we only have historical data for the demonstrative stage for these earlier periods of written Chinese named above, the development appears to be as follows for this subset within Sinitic:

(Demonstrative Pronoun) $>$ Copular verb $>$ Locative verb $>$ Locative preposition $>$ (Progressive aspect Marker) Pathway (ii)

Note that the DEMONSTRATIVE > COPULA development is not uncommon outside of MeSEA. Kuteva et al. (2019: 136-137) furnish examples from Ancient Egyptian (AfroAsiatic) and Sranan, an English-based creole Surinam creole.

In the next section we take a brief look at a Hmongic and a Tai language, whose copula is derived from the verb 'dwell', as well as one Sinitic language whose copula derives from 'stick (to)'.

\subsubsection{Dwell/Stick > Locative > Copula Pathway [i(c)]}

According to our sample data, the pathway from locative verb to copula is rare. The largest group in our sample, Type IV, which crosscuts Sinitic, Kra-Dai, Austroasiatic and Hmong-Mien, has been defined in terms of the fact that locative verbs generally do not evolve into any copular verb stage. And as we have seen for Type III Tibeto-Burman, the copular verb is always distinct from the locative/existential/ possessive verb. There are however three languages which constitute exceptions, one Tai, one Hmongic and one Sinitic, each of which attest to precisely such a diachronic relation. Dwell verbs are the source of this pathway in Nùng (Tai) and Aizhai Xong (Hmongic; see also Section 4.2), while the verb sтіск is the source in Fuqing, a Sinitic Min language. These three languages all belong to Type II.

In Nùng, a Central Tai language, a lexical Dwell verb, $d u$, can clearly be used as a locative and copula in different grammatical environments. 
Nùng (Central Tai, Kra-Dai, Vietnam)

DwELL verb

slỉ cưhn dụ chòn hơn nưhng

four person live together house one

'Four persons live together in one house.'

(Saul and Wilson 1980: 55)

(87) Locative construction

mưhng dụ hơn mưhng tẹo pehn hư lam-đáng

2sG at house 2sG again like what pregnant

'If you were at home, how could you become pregnant?'

(Saul and Wilson 1980: 118)

$$
\begin{aligned}
& \text { Copular construction } \\
& \text { mưhn dụ cưhn sláy } \\
& \text { 3sg cop person priest } \\
& \text { 'He’s a sorcerer.' } \\
& \text { (Saul and Wilson 1980: 72) }
\end{aligned}
$$

It appears more plausible in terms of regular semantic change for a two-argument DWELL verb to undergo semantic shift to a locative and thence to a copula rather than postulating that a DWELL verb directly evolves into a copula and then reverts to a two-place locative verb. This semantic shift once more involves a generalization from the more specific 'dwell' or 'live' to 'be at a place' - just as we saw above for pathways [i(a)] and [i(b)] - and then evolves from this stage to the copula in an equative construction. The difference lies in the semantic category of the postverbal predicate noun which shapes the interpretation of the grammatical construction and its two arguments. In both derived constructions - locative and copular - the predicate is stative and contains either a locative NP or a complement noun. This allows the syntactic reanalysis process to be accomplished with ease, particularly if there is no locative case marking on the locus noun, as in Nùng.

The Sinitic case of Locatrve > Copula shows an even rarer source - it is the verb $k a$ ? $^{5}$ 㪉 'stick (to)' in Fuqing Min, according to a study by Lin and Sheng (2018). They argue that $k a P^{5}$ first develops into a locative verb, out of which the copula is reanalyzed. Lin and Sheng (2018: 693) also point out that the verb 'stick' can be readily observed as a copula in several other neighboring Min varieties.

Fuqing Min (Sinitic)

Lexical STICK verb

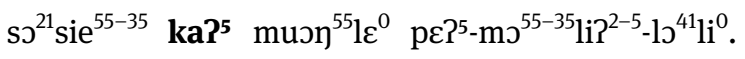

key stick door.LOC pull-NEG.obtain-fall.come

'The key is stuck in the door and can't be pulled out.'

(Lin and Sheng 2018: 688) 
(90) Locative construction

$\operatorname{seu}^{32} u_{\supset \eta^{55}}$ mo $^{55}$ ka? $^{\mathbf{5}}$ ts $^{\mathrm{h}} \mathrm{J}^{21}$.

NAME NEG be.at house

'Xiao Wang is not at home.'

(Lin and Sheng 2018: 688)

(91) Copular construction

$\mathrm{aP}^{2-5} \operatorname{tau}^{32} \mathrm{i}^{5^{1-55}} \mathrm{pa}^{41} \quad \mathbf{k a P}^{5} \mathrm{lau}^{55} \mathrm{pi}^{41}$.

NAME 3SG father COP NAME

'A-Dou's father was Liu Bei.

(Lin and Sheng 2018: 689)

The Locative- Copular polysemy is discussed in more detail for the Sinitic Hu languages in Hirata (1998), for Fuzhou GAN (Xu 2009), for Southern Wu (Ma and Cai 2006a) and also for a Southern Hunan patois (Xie 2014). A larger sample and the geographical distribution are provided in Cao et al. (2008, vol. 3: Map 39) for Sinitic languages in general, albeit without discussion.

A brief overview of some rarer sources for locative verbs is presented in the next section.

\subsubsection{Rarer sources for locative verbs}

It is striking that many of the rarer sources for locative verbs are mainly found in Sinitic languages. These belong to the following five semantic domains.

(i) VERBS OF PLACEMENT:

GE 搁 'put' in many Mandarin varieties (Jin and Wu 2017) including Jilin and Shangshui in our sample

$k^{h} o^{4^{2}}$ 园 'store, place' in Cangnan Wu (Jiang and Chi 2018)

(ii) VERBS OF ATTACHMENT:

$k a P^{5}$ 㪉 'stick (to)' in Fuqing Min (see (89)-(91) above)

tuoPs $^{5}$ 着 'adhere' in Fuzhou Min (Liang 1990)

$t e^{35}$ 着 'adhere' in Liancheng Hakka (Xiang 1997)

(iii) VERBS OF MOTION

$t_{6}{ }^{h} e^{21}$ 去 'go' in Jishui Gan (Li and Wu 2018),

$\mathrm{lie}^{22}$ 来 'come' in Ningbo Wu (Ruan 2009)

$\mathrm{tou}^{33}$ 到 'arrive' in Xinyi Yue (Luo 1987)

$\mathrm{tau}^{33}$ 到 'arrive' in Jishou Southwestern Mandarin (Q. Li 2002)

$l^{4^{2}}$ 落 'fall' in Pingjiang Gan (Lü and Peng 2020)

$k \partial n^{55}$ 跟 'follow' in Pekinese (Chen 1985) 
(iv) GIVE

$k e^{55}$ 给 'give' in Xuzhou Central Plains Mandarin (Su and Lü 1996)

$k \gamma^{6} \quad$ 'give' in She (Hmong-Mien) (Mao and Meng 1986)

(v) Do

$k a u^{53}$ 搞 'do' in Tujia (Tibeto-Burman) (Meiyan Lu, pers. comm.)

Examples of 'fall' in Pingjiang Gan (Sinitic), 'give' in She (Hmong-Mien) and 'do' in Tujia (Tibeto-Burman) are presented below, all of which are used to form locative constructions. Note that the verb $k a u^{53}$ 'do' in Tujia is, in fact, a loanword from the variety of Southwestern Mandarin spoken in western Hunan province, namely, GAO 搞 ‘do’ (Meiyan Lu pers. comm., 9th March, 2017).

(92) Pingjiang Gan (Sinitic)

FALL as a lexical verb

$t^{\text {hai }}{ }^{55}$ ion $^{13} l^{42}$ ta $^{42} \operatorname{san}^{33}$.

sun fall PFV mountain

'The sun set.'

(Lü and Peng 2020: 189)

(93) Locative construction

$n^{21} \quad \mathrm{li}^{42} \quad \mathrm{ia}^{13} \quad \mathbf{l o}^{42} \quad \mathrm{p}^{4 i^{42}} \quad \mathrm{lo}^{42} \quad \mathrm{u}^{42} \mathrm{li}^{42} \quad \mathrm{a}^{33}$ ?

2sG POSs.KIN father be.at NEG be.at home Q

'Is your father at home?'

(Lü and Peng 2020: 189-190)

(94) She (Hmong-Mien)

GIVE as a lexical verb

$\operatorname{van}^{4} \mathbf{k r}^{6}$ nun $^{4} i^{6}$ phun ${ }^{6}$ to $^{3}$.

1SG give 3sG one CLF book

'I gave him a book.'

(Mao and Meng 1986: 75)

(95) Locative construction

$\operatorname{van}^{4} \mathbf{k r}^{6} \quad$ nja $^{4}$ mun $^{2} \mathrm{kr}^{6} \quad \mathrm{va}^{4}$.

1sG be.at here 2sG be.at there

'I'm here; you're there.'

(Mao and Meng 1986: 55)

(96) Tujia (isolate, Tibeto-Burman)

Do as a lexical verb

$\mathrm{ni}^{35}$ tchie $^{53} \quad \mathbf{k a u}^{53} \quad \mathrm{la}^{21}$ ?

2sG what do CONT

'What are you doing?'

(Meiyan Lu, pers. comm.) 


$$
\begin{aligned}
& \text { Locative construction } \\
& \mathrm{tsh}^{55} \mathrm{phi}^{55} \mathrm{si}^{21} \text { thie }^{35} \mathrm{ka}^{21} \mathbf{k a u}^{53} \mathrm{la}^{21} \text {. } \\
& \text { book table upside be.at CONT } \\
& \text { 'The book is on the table.' } \\
& \text { (Meiyan Lu, pers. comm.) }
\end{aligned}
$$

Eleven languages in the main sample illustrate these various rarer sources which readers may consult in Table 5 in the Appendix.

Except for the Type I Bai languages, copular verbs in our sample do not show a polysemous relation with existential verbs, as they do historically in certain Semitic languages, to take one example (Kuteva et al. 2019: 163). Apart from the Type II languages, where the copula shares a form with the locative verb, the copula is always distinguished formally from the other three verb categories in Type III and Type IV (that is, from locative, existential and possessive verbs). The copula thus appears to play an inert role in grammaticalization processes for these four domains for Mainland East and Southeast Asian languages.

This section, Section 5.1, has analyzed the sources and attested developments for locative and copular verbs in terms of the two longer pathways of grammaticalization proposed in Figure 1, including their relationship with POSTURAL and DwELL verbs or even more distantly with demonstratives for many Sinitic languages. We have shown that Type III and Type IV languages display quite different outcomes when their source verbs belong to the Postural and Dwell semantic fields: in Type III Tibeto-Burman languages, these develop into locative, then existential verbs, while in Type IV languages, from the locative verb stage, there may be a further evolution into locative adpositions, but never into existential verbs in our sample.

We also considered the diachronic relationships between locative and copular verbs and found that in Type II languages (mainly represented by a subset of Sinitic and Hmong), the source of locative verbs is the copula: CopUla > Locative. The opposing pathway of LOCATIVE > Copula has been described as rare in our Asian sample.

In the following sections, we consider the diachronic relationship between possessive and existential verbs.

\subsection{Sources of possessive and existential verbs}

HAVE verbs in MESEA appear to regularly double up as existential verbs and this proves to be an absolute in our data, as severally observed in the preceding sections. Hence it is not surprising that such polysemy has been regarded as an important areal feature in Clark (1989: 206) who, similarly to the present analysis, describes the distinct grammatical environments of use. Below are two examples 
from Bumang, a Type IV Austroasiatic language, in which hop ${ }^{21}$ is exemplified first in a monovalent existential clause and then in a transitive possessive clause:

Bumang (Austroasiatic):

Existential construction

$\mathrm{i}^{51} \quad$ hop $^{21} \quad \mathrm{p}^{55} \quad \mathrm{ti}^{24} \mathrm{kJi}^{55} \quad l \varepsilon^{24} \quad \mathrm{u}^{55}$.

here there.be fruit banana many very

'There are many bananas here.'

(Dao 2007: 70)

(99) Possessive construction

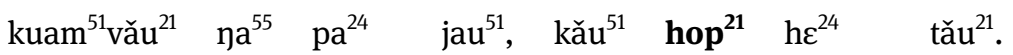

although 3SG height tall but have strengh NEG

'Although he's tall, he doesn't have strength.'

(Dao 2007: 151)

For pinpointing the diachronic relationship between possessive and existential verbs, reanalysis perplexingly appears to go in either direction. Both pathways are attested crosslinguistically. However, as Heine observes (1997a: 96, 1997b: 95-97), this need not be a violation of the unidirectionality principle in any grammaticalization framework. His explanation of the cognitive schemata underlying the relevant syntactic constructions provides important mechanisms both for the morphosyntactic changes in valency and for the conceptual transfers involved, even though we will propose an alternative to his proposed pathway of EXTENDED EXISTENCE $>$ Possession $>$ NuClear ExisTEnCE.

Hence, on close examination of the Asian data, a different scenario is equally possible. While we fully agree that there is no violation of the unidirectionality principle, our standpoint is that the possessive verbs in MESEA arise from two distinct and opposing grammaticalization chains which are responsible for the shared existential and possessive verb forms in Types II, and IV on the one hand (basically Sinitic, Hmong-Mien, Kra-Dai and Austroasiatic) and Type III on the other (largely Tibeto-Burman). ${ }^{26}$ The first is represented by the chain:

Grasp/Seize > Possessive (Have) > Existential (Type II and Type IV) (pathway [iii])

and the second by:

$($ Postural $)>($ Dwell $)>$ Locative $>$ Existential $>$ Possessive (Have) (Type III) (pathway $[i(a)]$ )

26 The minor pattern, Type I, will not be discussed in this section, given that the one polysemous form codes all four semantic domains in Type I Bai languages. 
More specifically, our hypothesis is that for Types II and IV, certain evidence suggests a semantic shift from source verbs in the related semantic domains of TAKE, GRASP, SEIZE or OBTAIN to possessive HAVE, which extends to the existential use along the pathway: GRASP > HAVE > EXISTENTIAL. ${ }^{27}$ In a seemingly paradoxical manner, EXISTENTIAL verbs may also undergo change to possessive verbs. This is the case for Type III languages, where the opposing direction is found of Locative $>$ ExISTENTIAL $>$ Possessive. ${ }^{28}$

Let us look at both pathways, beginning with that of GrasP > Possessive (HAVE) $>$ EXISTENTIAL.

\subsubsection{Lexical sources for HAVE verbs}

With respect to the lexical sources for HAvE verbs, the sources are well-attested in several branches of the Indo-European languages, these being semanticallyspecific lexical verbs such as the highly transitive 'catch', 'grab', 'seize', 'take hold of' (Buck 1988: 740), if not the less dynamic action verbs, 'get', 'hold' and 'keep' (see also Heine 1997a: 91-92, 1997b: 47-54 on his related Action schema). Even 'hold' itself is a semantic 'weakening' of the meaning 'take hold of', according to Buck (1988: 743). Examples from these two related semantic fields, also cited in Buck, include Spanish tener 'have' < 'hold', Proto-Germanic *hafjan 'seize' > English have and German haben (cf. Creissels 1979, 2013).

Similarly, data on a number of languages from the Asian region is suggestive of a close semantic connection between 'seize' or 'hold in the hand' and 'have'. This is particularly the case for Hmong languages, noting the tonal alternation, as does Jarkey (2015: 50), for White Hmong muaj 'have' and muab 'grasp with hand', 'take hold of . ${ }^{29}$

27 This pathway is separate from the semantic field of ACQUIRE which includes verbs meaning GET and OBtain, discussed in Enfield (2003), a lexical field which may evolve to new Possibility, SucCESSFUl ATTAINMENT and CAN meanings, but along a different pathway from the one described here. This undoubtedly reflects a larger case of polygrammaticalization.

It is also possible that there is a further link to be added to the end of the chain above, whereby the existential verb develops into a locative, as in Juba Arabic (South Sudan). We do not however have such data in our Asian sample but note that it would not violate our hypotheses. The longer chain would then be: Grasp/Seize > Possessive > Existential > Locative. We thank Denis Creissels for bringing this to our attention (pers. comm. July 2019).

28 As for the canonical pattern in Type III Tibeto-Burman languages, the reanalysis from (Postural) > Dwell > LOCATIVe Verb 'be.at' > Existential Verb 'there be' has been described and exemplified in Section 5.1.1 above, and so will not be further discussed here.

29 This observation is also made in Chappell and Creissels (2019: 506) and in fact we owe the inspiration to search for more 'catch' and 'seize' verbs as sources for HAvE to Denis Creissels. We also thank one of the anonymous reviewers for pointing out that muab is a highly polysemous verb in White Hmong and may also be used in the give-construction with the meaning of 'give, hand over'. There are also several other synonymous Hmong verbs which mean 'grasp' but apparently do not undergo this 
Stage I

acquisition (e.g. by grabbing)

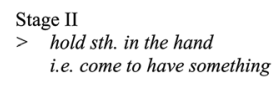

Figure 2: Stages of semantic extension and generalization for possessive verbs.

For another language family, namely Sinitic, Takashima (1996: 304-305) observes that in the earliest sources for Chinese languages, namely the Oracle Bone Inscriptions of the Pre-Archaic Chinese period (fourteenth-eleventeenth c. BC), the meaning of 'result state of acquisition', specifically 'have in abundance in the right hand' is one of two principal meanings identifiable as the precursor of Standard Mandarin yǒu [iəu $\left.{ }^{214}\right]$ 有 'have' and its cognates in Sinitic languages. ${ }^{30}$ Takashima's examples also reveal that this verb had the general meaning of 'have' in this period. We propose that the latter is a subsequent extension of meaning of the former by regular patterns of pragmatic inference and semantic shift, that is, GRASP/SEIZE > POSSESSION > EXISTENCE (as per Figure 2 below). In the later period of Early Archaic Chinese (eleventeenth-seventh c.), examples of this same verb bear witness to the fact that it retained the dynamic meanings of 'occupy' and 'possess' as well as the general meaning of 'have' but also of 'exist'. See also Chappell and Creissels (2019: 497) who provide a more detailed argument in favor of this diachronic change.

In his study of AcQuiRe verbs in Southeast Asia, Enfield (2003: 185-186) points out that in several languages in his corpus, AcQuiRE may also have the meaning of 'have', 'come to have' and 'there is', providing examples from Dong (Kam-Sui; Kra-Dai), Pacoh and Katang (both Mon-Khmer; Austroasiatic). Table 4 below lists some of the languages in MESEA for which we have been able to ascertain GRASP/ SEIZE/TAKE $\sim$ HAVE polysemy. These verbs may naturally have additional meanings which are not listed here.

One such example of this polysemy is presented from a Kra-Dai language, Ong Be (Lingao) spoken in Hainan, China:

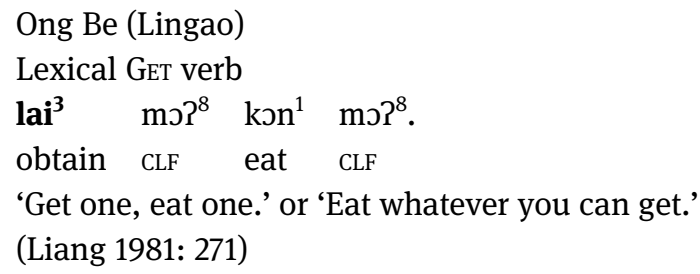

extension to 'have', the same reviewer informs us. Note finally that the tonal values for 'grasp' and 'have' are indicated in White Hmong by the final consonant, here, -j and - $b$, as already observed in $\mathrm{fn} .11$. 30 The other meaning is 'to exist in abundance in the right hand', which Chappell and Creissels argue is not the basic meaning (2019: Section 6.4). 
Table 4: GRASP and TAKE as a source for HAVE in some Asian languages.

\begin{tabular}{|c|c|c|c|}
\hline Language & GRASP & Have & SOURCE \\
\hline Songtao Xong & $\mathrm{me}^{35}$ 'grasp with hand' & $\mathrm{me}^{31}$ 'have' & Luo (2005: 312) \\
\hline Aizhai Xong & $\mathrm{me}^{53}$ 'grasp' & $\mathrm{me}^{31}$ 'have' & Yu (2010: 511) \\
\hline Fenghuang Xong & meb 'take' & mex 'have' & Sposato (2015) \\
\hline Layiping Hmong & me 35 'take, grasp' & $\mathrm{me}^{31}$ 'have' & Wang (1985: 182, 189) \\
\hline Dananshan Hmong & mua $^{43}$ 'take, grasp' & mua $^{31}$ 'have' & Wang (1985: 182,189$)$ \\
\hline White Hmong & muab 'grasp with hand' & muaj 'have' & Jarkey (2015: 50) \\
\hline Jingpho & lu ${ }^{31}$ 'obtain' & lu ${ }^{31}$ 'have' & Liu (1984) \\
\hline Longxi Qiang & tsé 'catch, hold' & tsé 'have' & Zheng (2016) \\
\hline Puxi Qiang & na 'take' & na 'have' & Huang (2004: 240) ${ }^{\mathrm{a}}$ \\
\hline Ong Be & lai 'obtain’ & lai $^{3}$ 'have' & Liang (1981) \\
\hline Dong & $\mathrm{li}^{323}$ 'acquire' & $\mathrm{li}^{323}$ 'have' & $\begin{array}{l}\text { Long and Zheng (1998: } \\
164,175,239)\end{array}$ \\
\hline Khmer & ba:n 'get' & ba:n 'have' & Haiman (2011: 357) \\
\hline Pacoh & boon 'acquire' & boon 'have' & Enfield (2003: 185-186) \\
\hline Katang & been 'acquire’ & been 'have' & Enfield (2003: 186) \\
\hline Pre-Archaic Chinese & you 'have in abundance in & you 'have' & Takashima (1996: \\
\hline Fourteenth-eleventeenth $\mathrm{BC}$ & the right hand' & & $304-305)$ \\
\hline $\begin{array}{l}\text { Archaic Chinese } \\
\text { eleventeenth-third } B C\end{array}$ & you 'occupy, possess' & You 'have' & Schuessler (1988: 770) \\
\hline
\end{tabular}

${ }^{a}$ As severally noted, Tibeto-Burman languages such as Longxi and Puxi Qiang have more than one possessive/ existential verb, such that those listed above should not be understood as the only ones in this domain. The same applies for verbs meaning 'catch' and 'seize'. Note also for Table 4, that some of the languages are not in our sample but have been included just in the table, because both meanings of 'grasp' and 'have' are attested in the given reference.

(103) Possessive construction: generalized meaning of HAVE

$\begin{array}{lllllll}\mathrm{be}^{2} & \mathrm{n}^{4} & \mathrm{hu}^{2} & \mathbf{l a i}^{3} & \mathrm{ki}^{3} & \mathrm{na}^{3} & \mathrm{l}^{3} \mathrm{k}^{8} . \\ \text { man } & \text { that } & \text { CLF } & \text { have } & \text { several } & \text { CLF } & \text { child }\end{array}$

'That man has several children.'

(Liang 1981: 270)

Another important example of GET > HAVE is found in a large number of Xiang, Gan and other languages located in Hunan province. In these Sinitic languages, the negated form of transitive HAVE is a suppletive form derived from a combination of a negative marker with the verb GET, DE 得 (Cao 2008, vol. 3: Map 30). The meaning of 'have' for DE 得 is attested from the period of Medieval Chinese (seventh-thirteenth c.), according to Sun (1996: 108-162). Hence, NEG-GET > 'not have' appears to be an older form that has been able to survive as an archaism in the negated construction in these non-Mandarin branches of Sinitic.

The semantic shift GRASP > HAVE thus appears to involve a series of stages which begin with a dynamic predicate of physical acquisition involving the action of 
catching, seizing or grabbing (Stage I) which has the result state of 'holding something in the hand', in other words, 'coming to have something' (Stage II). When the state of holding in the hand persists, the meaning of the verb may also bleach to the less semantically specific notions of 'carrying, keeping or bearing objects', another common stage in the evolution of Have verbs, Stage III. From Stage III, a further semantic shift occurs to the generalized notion of possession, 'have', in Stage IV.

Stated neatly by Givón: 'If one has taken possession, one has possession' (1984: 134).

In general, little information is available as to the origin of all the possessive verbs in Types II and IV. Nonetheless, the language data presented in Table 4 above are highly suggestive of GRASP/SEIZE/TAKE as a much wider source for HAVE in mainland Asian language families than previously thought, and for which the Sinitic data is highly suggestive. The crosslinguistic evidence is quite solid for this semantic shift, being well-attested in other language families, for example, in Basque (isolate) and Nyulnyul (non-Pama-Nyungan, Australia) (KeEP > H-Possessive entry; Kuteva et al. 2019: 246-247) and in Akan languages (Kwa, Niger-Congo) (TAKE > H-Possessive entry; Kuteva et al. 2019: 422) as well as in French-based creoles (Get/Receive/ OBTAIN > H-Possessive entry; Kuteva et al. 2019: 189-190). ${ }^{31}$ Furthermore, we have also cited precisely the same source domain for Romance and Germanic languages above, which, though reasonably well-established, is not 'synchronically recoverable' in all cases (Heine 1997b: 229).

One of the main parameters of grammaticalization involves semantic generalization ('desemanticization' in Heine [2002]) which means that *EXIST > PoSSESS > GRASP cannot conceivably be regarded as a plausible chain for semantic change. As we have argued, the semantic shift from GRASP > HAVE involves a semantic shift from the specific action of manipulation to a more abstract notion of possession. Nor is the counterargument upheld by our data that the polysemy might result from the nonintervened semantic shift ${ }^{\star}$ GRASP $>$ ExIST, as is the case in other corpora or data compilations we have consulted (cf. in Kuteva et al. 2019; neither of the entries in the World Lexicon of Grammaticalization for synonymous KEEP or TAKE verbs show such a development). Our hypothesized pathway (iii) thus accounts more reasonably, we believe, for the data on GraSP verbs presented in Table 4: GRASP > HAVE (PosSESS) > ExIST. It is modelled in Figure 3 below which illustrates the possible stages of semantic extension for Postural and Dwell verbs on the one hand and GRASP or OBTAIN verbs on the other.

In the following section, we consider the next step in the grammaticalization chain for pathway (iii) in which the semantically bleached possessive verb, the

$31 \mathrm{H}$-Possessive = marker of possessive 'Have'-constructions in their terminology. Note that the World lexicon does not contain an entry for 'hold' or 'seize'. 


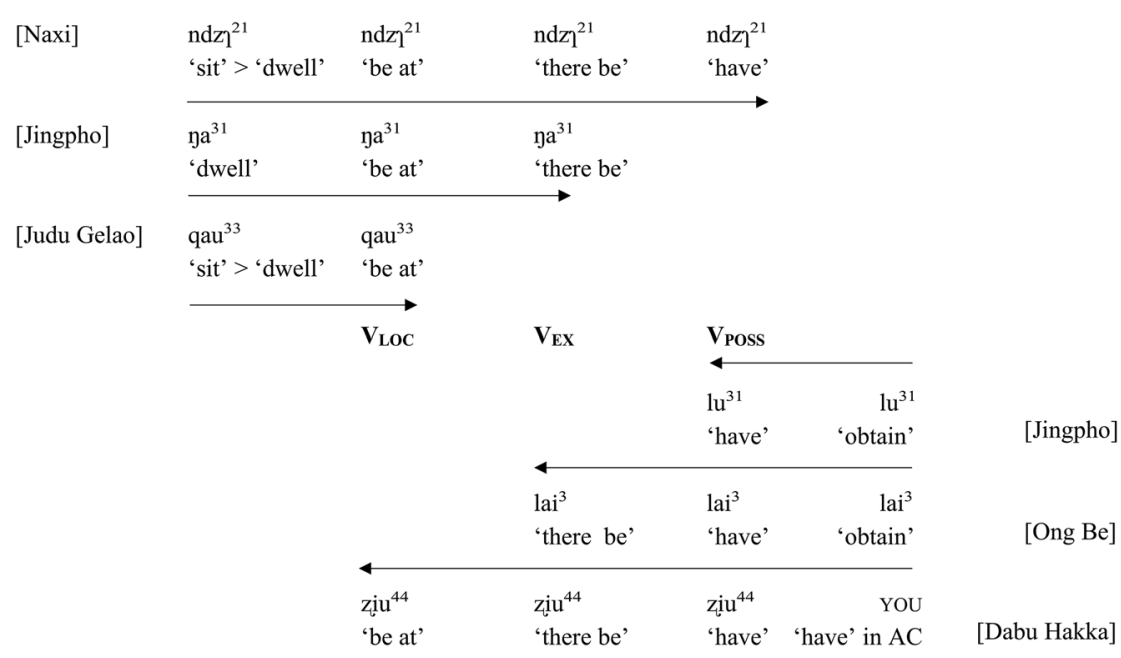

Figure 3: Semantic extension for Postural, Dwell and Grasp or Obtain verbs.

result of semantic change from a highly transitive GRASP and SEIZE verb, may undergo a further semantic extension to express 'existence'.

\subsubsection{Impersonalization: Possessive verb 'Have' > Existential verb 'There be'}

Transitive HAVE verbs may undergo impersonalization to become existential verbs, and thereby become used in a distinct grammatical environment. This pathway is attested in a range of languages from Europe, such as in Romance, but is also reported for the Atlantic languages of Africa, and for many creoles as well (Creissels 2013, 2019; Heine 1997a, 1997b). The process involves loss of the referential content of a subject possessor NP with the use of a non-specific third person expletive pronoun, also known as a 'dummy subject' or 'ambient $i t$ '.

In certain Romance languages such as French, this development also involved the addition of the expletive spatial clitic $y$ 'there' to an equally expletive use of the 3sg pronoun, il, with the verb avoir 'have', while in related Occitan, only the expletive 3sg subject is needed (Creissels 2019): $:^{32}$

32 An anonymous reviewer remarked that expletive spatial clitics are not reserved for exclusive use with possessive verbs but can also be found, for example, with the verb essere 'to be' in Standard Italian: c'e 'there is', ci sono 'there are'. This is an example of a different case of reanalysis and grammaticalization, this time, from a copular to an existential construction. See also Bentley et al. (2015). 
(104) French (Romance, Indo-European)

Possessive construction

Il a un chien.

3SG have a dog

'He has a dog.'

Creissels (2019)

(105) French and Occitan (Romance, Indo-European)

Impersonal existential construction

Il y a un chien dans le jardin. (French)

I a un can dins l'òrt. (Occitan)

3sG there have a dog in the garden

'There is a dog in the garden.'

Creissels (2019)

In our sample, we have found evidence of a similar intermediate stage in Khmer and White Hmong, and also in Thai. Haiman describes an 'ambient it' use of via, '3p', in Khmer, translatable as 'there'. Via can be used with intransitive event verbs such as kaeut 'arise' and notably with mian 'have/there is', the latter in its existential interpretation. For the possessive use of transitive mian, see Example (54) in Section 4.4 above.

(106) Khmer (Austroasiatic)

Impersonal existential construction with ambient via 'it'

Via kmian cao na: mau:k luac krabej

3 not.exist thief any come steal water.buffalo

'There are no thieves coming to steal our buffaloes.'

(Haiman 2011: 193)

As Haiman observes, even though subject pronouns are omissible in Khmer, in the following example, via is used with mian and has an existential interpretation, despite the apparently transitive syntax. In other words, this could represent an intermediate stage between the possessive and a fully evolved existential use. According to the explanation given in Haiman 2011: 209), Example (107) given below cannot mean ‘`Does it have anything?'

(107) Impersonal existential construction with ambient via 'it'

Via mian rwang ej?
3 have matter any
'Is there anything wrong?'


This type of example meshes well with the crosslinguistic evidence from Romance, though the 'have' meaning is more frequent in Khmer. ${ }^{33}$ Another such use of ambient via 'it' is found in Haiman (2011: 402).

Similarly in Hmong, an expletive subject can be used with the existential and possessive verb muaj which Ratliff (1994: 259) describes as a 'dummy subject' in existential and meteorological sentences. Jarkey treats this construction as a "generic existential" use with a non-referential third person pronoun $n w s$ in the clause-initial subject position (Jarkey 2015: 43-44) which is distinct from the presentative use of muaj with one argument.

$$
\begin{aligned}
& \text { White Hmong (Hmong-Mien) } \\
& \text { Impersonal existential construction } \\
& \text { nws muaj tib neej zoo, } \\
& \text { 3sG have human.being be(come).good } \\
& \text { nws muaj tib neej tsis zoo thiab } \\
& \text { 3sG have human.being NEG be(come).good also } \\
& \text { 'There are good people and there are bad people too.' } \\
& \text { (Jarkey 2015: 44) }
\end{aligned}
$$

In both Khmer and White Hmong, the single argument of the existential construction typically occurs postverbally in its presentative use, that is, in a structure distinct from the one with two arguments in examples (106), (107) and (108) above. In other words, preverbally, the existential construction has an 'empty slot' in place of the expletive third person argument, either via or nws, in these examples. Comparison can be made with the relevant existential constructions in Section 4.2 for White Hmong (Example [37]) and Section 4.4 for Khmer (Example [53]).

We conjecture that this may be the common process which allows Have possessive verbs to develop into existential verbs in Type II and Type IV languages, as attested for French, Occitan, Greek, Albanian, Bulgarian, colloquial German and Alemannic among many other languages (cf. Creissels 2013; Heine 1997b: 95-96). Moreover, both Stassen (2009: 722) and Heine (1997b: 95) observe that the process of impersonalization is not restricted to Europe, furnishing examples respectively for Tok Pisin, an English-based creole of New Guinea and Wolof (West Atlantic,

33 One of the anonymous reviewers points out that the Khmer phenomenon is most likely a recent development and that it is undoubtedly infrequent, rather than an intermediate stage, as we propose, retained with generic subjects. The crosslinguistic historical evidence from Romance and Germanic languages would not seem to support this, however. 
Niger-Kordofanian), as well as for noun class markers in Bantu languages used for this purpose. ${ }^{34}$

In the next section, we examine the opposing grammaticalization chain from existential to possessive verb, common in Tibeto-Burman languages.

\subsubsection{Have-Drift: Existential verbs 'There be' > Possessive verbs 'Have' Pathway [i(a)]}

A large number of studies has shown that it is crosslinguistically quite widespread for intransitive existential verbs to be reanalyzed under a process of transitivization as HAVE verbs. This can occur, when, for example, a locative adpositional phrase referring to a human possessor in the existential construction becomes recoded as the subject of a possessive one. The process, called 'Have-drift' by Stassen (2009: 209) has emerged in Brag-bar, a rGyalrongic Tibeto-Burman language included in our extended sample. ${ }^{35}$ The first example, (109), illustrates the locative construction with the verb nde, with which ndō in (110) and (111) shares the same citation (or infinitive) form, i.e., kə-ndō 'be at, exist, have' (Zhang 2018: 306). In this sentence, the 3PL suffix is marked on the verb 'be at' (glossed by 'exist ${ }_{I}$ '), which means that the subject of 'be at' is 'they' or 'some people'. Therefore, even though the overt subject is absent, it cannot be interpreted as an existential construction.

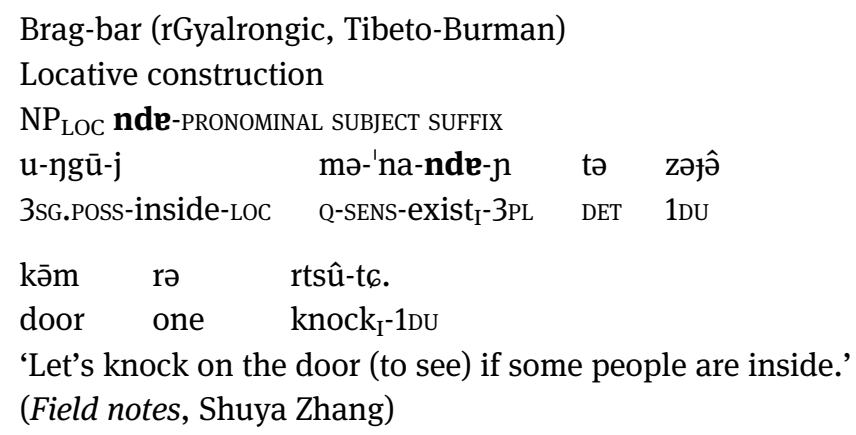

34 Nonetheless, this must remain a conjecture, awaiting further evidence to be uncovered from diachronic research on the languages of Asia, wherever this is possible. For example, Sinitic, Hmong-Mien and Kra-Dai show a high degree of ellipsis of subjects and objects, without the saving grace of concord on the verb to indicate role arguments, as one of the reviewers observed. We thus only have differences in word order to suggest such a process of impersonalization in many of these cases.

35 The use of term 'drift' by Stassen harks back to Sapir's notion of gradual process of language change, caused by internal structural pressures to analogize (1921: Ch. 7). 
The second example is, on the other hand, plainly an existential construction with a locative NP referring to a granary or storage place for grain:

(110) Existential construction

\begin{tabular}{|c|c|c|c|c|c|c|}
\hline $\mathrm{NP}_{\mathrm{S}}$ & ndō & & & & & \\
\hline tə-rgēelk & kət $6 \overline{\mathrm{e}}$ & kə-ndo-ndō & tə & рәүû & zə & ndō. \\
\hline grain & where $_{\text {LOC }}$ & NMLZ-RED-exist & DET & mouse & also & exist $_{I}$, FAC \\
\hline
\end{tabular}

In the ambiguous bridging context, where the locative suffix, -j, marks animate NPs, the construction generalizes to express ownership, as in (111), even though it remains syntactically an existential construction. The term 'bridging context', coined by Evans and Wilkins (2000: 550-551), refers to a stage in which a semantic extension to a different constructional meaning is inferable from the particular context. This is the target meaning of 'have' in (111). Nonetheless, the source meaning of intransitive 'exist' is still possible at this stage and cannot be overlooked. Note also that the locative suffix on the possessor is obligatory in the Brag-bar existential construction: at X's ${ }_{\text {animate }}$ place (LOc), exists a Y > X owns/has Y

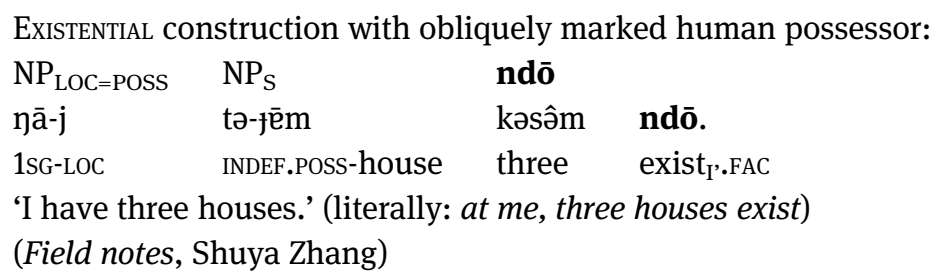

Through metonymy and loss of the oblique morphosyntactic marking, specifically the locative suffix - $j$ in Brag-bar, this structure has been reanalyzed as a transitive possessive one:

$\mathrm{X}_{\text {animate }}$ has a Y

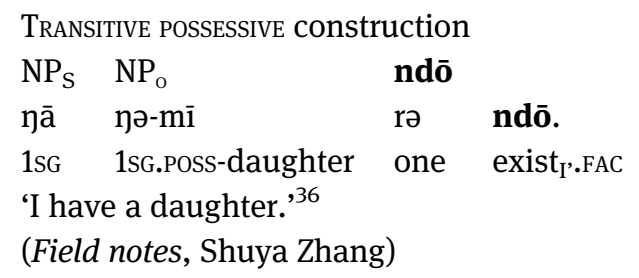

36 Apparently, in this unmarked construction where the possessor is not marked by any locative marker, inalienability is coded. 
This kind of development is given detailed treatment in Heine (1997b: 98-100) in his discussion of the schemata conceptually underpinning possessive constructions. He proposes that intransitive verbs, such as the existential, can be transitivized into HAVE verbs after the possessor is topicalized into clause-initial position and eventually grammaticalized as the new clausal subject. Stassen (2009: 208-243, 247-248) follows suit and discusses a large number of languages with such sets of examples. Much earlier, Clark similarly noted the possibility of thematization of possessors into subject, if not initial position, in possessive constructions (1978: 113). As a consequence of this process, certain morphosyntactic trappings tend to be lost. Our Brag-bar example above shows this process 'in action' for locatively case-marked NPs reinterpreted as possessor subjects, once the locative adposition is omitted.

We also have further examples of possessive constructions with allative or dative marking on the possessor NP, in which existential verbs are potentially on the way to being reanalyzed as possessive verbs. For example, in another rGyalrongic language, Wobzi, the allative and dative marker $=j i$ is used to code possessors in what can be reinterpreted as a Have-Possessive construction, as in Example (113) with the existential verb $f \hat{e}$.

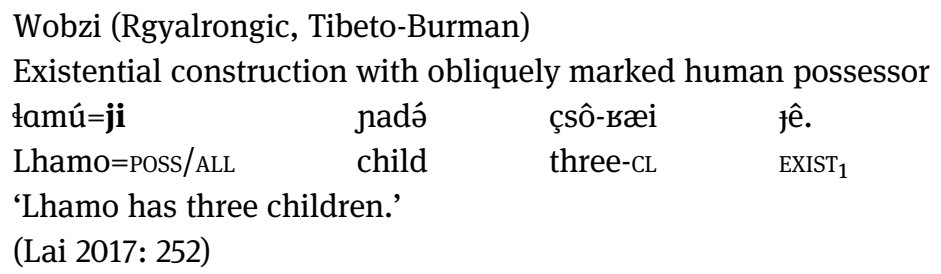

Importantly, (113) may not be interpreted as 'Lhamo’s three children exist' since an evidential prefix would be required on the verb 'exist' (Lai pers. comm.). Example (114) which follows shows the typical use of $=j i$ in a dative construction.

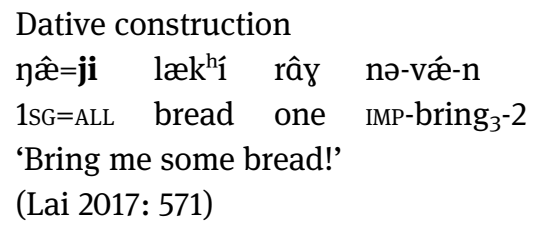

As Heine (1997b: Ch. 5) and Stassen both observe (2009: 230), the difficulty for reanalysis as a Have-Possessive lies in the transfer of subject properties to what was originally an adjunct possessor NP, present in the original existential construction (using our terminology - Authors). Brag-bar and Wobzi, as well as the Galo examples given above, add to the arsenal of languages which reveal exactly 


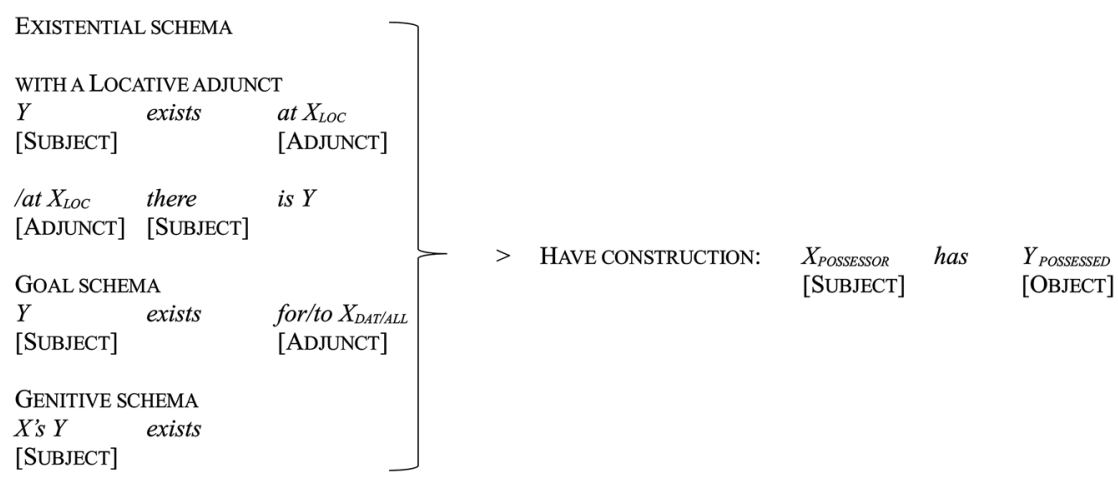

Figure 4: Existential predicates with obliquely marked possessors. Creissels $(2013,2019)$, Heine $(1997 a, 1997 b)$ and Stassen $(2009,2013)$ all refer to this as the either the Location Schema or Locational Possession which we believe confuses the state of affairs for MESEA languages, given that the locative constructions are formally distinct from the existential. Thus, we have taken the liberty of renaming this construction the 'Existential Schema' for the sake of clarity.

how this transfer can take place, Brag-bar showing a fully developed transitive construction and Wobzi, an intermediate step in this potential direction of grammaticalization.

To summarize, in Figure 4, freely adapted from Heine (1997b), existential predicates combined with Possessor NPs marked as locative, dative or genitive case roles may be reanalyzed semantically and syntactically as subject nouns in possessive predicates. ${ }^{37}$

However, in the largest proportion of cases cited in Stassen (2009: 316-321), for example, the possessive constructions are not yet fully 'mature' and still show the morphosyntactic features of the existential constructions from which they arise. For example, in the section discussing 12 of the 13 Tibeto-Burman languages in his sample, Stassen finds that there are six in which the possessor is adnominal, being marked by the genitive (Classical Newari, Thakali, Lepcha, Limbu, Kham, Meithei), four where the locative case marker is used (Garo, Burmese, Lushai and Qiang) and two marked by the dative case (Classical Tibetan and Ladhaki). In all the examples given, the construction is clearly existential in the sense we have defined it in Section 1.1, containing either a verb 'to be' or 'to exist' and one argument.

Therefore, it is evident from the data cited in Stassen that the Possessor NPs are all coded as an oblique argument, that is, one that has not yet been promoted to the role of syntactic subject, unlike our Brag-bar example. The process of transitivization

37 For 'case role', the marking could be inflectional, or be signaled by an adposition, depending on the language. 
is thus clearly not yet complete, in particular, with respect to the morphosyntactic coding. Consequently, these locative, dative and genitive constructions with a possessive interpretation cannot be considered as true possessive constructions in the way that we have defined them. ${ }^{38}$

For Tibeto-Burman languages, 'HAVE-drift' invoking transitivization is a relatively unresearched topic. We expect many more of these languages will be found which show clear morphological indices for the diachronic syntactic and semantic change in question.

\section{The relation between diachronic processes and synchronic typology for the four types of areal patterns}

The final section of this analysis aims to discuss the connection between the semantic typology we have set up and its synchronic structural patterns with the diachronic scenarios outlined in Section 5 in the form of three grammaticalization chains.

\subsection{Semantic typology and the four synchronic patterns}

We first recapitulate the main characteristics of the four types and their areal distribution in order of frequency in our sample:

(i) Type IV with a ternary split $\left(\mathrm{V}_{\mathrm{LOC}}\right)$; $\left(\mathrm{V}_{\mathrm{COP}}\right)$; $\left(\mathrm{V}_{\mathrm{EX}}=\mathrm{V}_{\mathrm{POSS}}\right)$ is the most common type, being widespread across four of the five main language families, namely, in Sinitic, Kra-Dai, Hmong-Mien and Austroasiatic and also includes the unclassified Caijia (67/116).

(ii) TyPE III with a binary split $\left(\mathrm{V}_{\mathrm{LOC}}=\mathrm{V}_{\mathrm{EX}}=\mathrm{V}_{\mathrm{POSS}}\right)$; $\left(\mathrm{V}_{\mathrm{COP}}\right)$ proves to be largely a feature of Tibeto-Burman languages such as those in the Lolo-Burmese group, also Tujia and Jingpho. Included in this group are nonetheless a small number of Austroasiatic languages, located in close proximity to these Tibeto-Burman languages (35/116).

(iii) TyPE II, like TyPE III, has a binary split $\left(\mathrm{V}_{\mathrm{LOC}}=\mathrm{V}_{\mathrm{COP}}\right)$; $\left(\mathrm{V}_{\mathrm{EX}}=\mathrm{V}_{\mathrm{POSS}}\right)$ but divides up the domains for its two distinct verbal forms differently. It is principally

38 It is possible that these constructions are found in a bridging context where the source and the target interpretations may overlap. The information is not sufficient to confirm this further point, of course. 
found in Sinitic, being prevalent in Hui, Wu and Yue branches but also in the unclassified Xianghua and a few Hakka varieties. In addition, several Hmongic languages in western Hunan show this pattern, as well as Nùng (Central Tai) (10/116).

(iv) Finally, in Type I, all four verbs share one form $\left(\mathrm{V}_{\mathrm{LOC}}=\mathrm{V}_{\mathrm{COP}}=\mathrm{V}_{\mathrm{EX}}=\mathrm{V}_{\text {POSS }}\right)$. This has so far only been found in certain varieties of Bai (an unclassified SinoTibetan language) within MEsea but is attested in other studies for Korean (Sun 2015) and apparently in certain Indo-European and Finno-Ugric languages in Clark (1978: 106-107, Table 8) (4/116).

For the semantic typology, we have sought to show that a diachronic account can elucidate and dynamically motivate the relation between the four semantic domains of possession, existence, location and the copula, the constructions they form and the cognitive schemata with which they are associated. To this end, we have argued on the basis of empirical data that three main grammaticalization chains are identifiable, one radial and two linear (Figure 1).

The shared patterns of polysemy with identical forms for existential and possessive verbs can be clearly seen to be an areal feature for all the Mainland East and Southeast Asian languages in our sample. On closer inspection, however, we find that different language types show divergent behavior and that it cannot be accounted for by phylogenetic considerations. In Type III Tibeto-Burman and Austroasiatic languages, the polysemy extends to possessive, existential and locative verbs sharing a single form, whereas in Types II and IV Sinitic, HmongMien, Kra-Dai and Austroasiatic languages; only the possessive and existential verbs share the same form.

This distinction leads to a typological split for the areal patterns (see also Map 2). To explain this split, we have argued that polysemy sharing for existential and possessive verbs needs to be attributed diachronically to two major grammaticalization chains, (1a) and (iii), discussed in Section 5.2 and in resumé form below.

\subsection{Diachronic processes}

We next summarize the findings on the two main grammaticalization chains which underlie the formation of the synchronic areal patterns in MESEA and the implicational universal we have proposed on the basis of this analysis: LocATIVE $>$ EXISTENTIAL > Possessive and GrasP > PosSESSIVE > ExISTENTIAL.

The direction of diachronic change which involves HAVE-drift, a process of transitivization, from Locative $>$ EXISTENTIAL $>$ Possessive has produced the pattern 
found in Type III, whereas in Type IV Sinitic, Kra-Dai, Hmong-Mien and Austroasiatic, we have conjectured that the diachronic change proceeds along a distinct pathway from GrasP > POSSESSIVE > ExISTENTIAL due to the semantic generalization of 'grasp' to 'have', followed by a process of impersonalization for this same 'have' verb. The Type II pattern is also formed by the latter pathway in conjunction with the minor grammaticalization chain from Copula > Locative. By contrast, in Types III and IV, the locative and copular verbs remain distinct.

Types II and IV can be argued to provide further independent support for our implicational universal from the opposite angle: the locative verbs in these two types progress neither to an existential verb stage, nor to a possessive one. As we have shown, Type IV locative verbs are always distinct from the other three verb classes, whereas Type II shares its form with the copula. This scenario once again neatly shows a kind of 'semantic barrier' between location and possession. Hence, there is no evidence in our sample to support either ${ }^{\star}$ LocATIVE $>$ Possessive or *Possessive > Locative: any direct semantic shift from a locative to a possessive verb is blocked, no matter which pattern is in question. If semantic and syntactic change were considered to be arbitrary and without a cognitive basis, then these significant patterns of polysemy sharing that serve to form a linguistic area could not be modelled in diachronic terms. This would consequently exclude an account as to why possessive verbs do not evolve into locative verbs, and vice versa.

As for Type I, we do not have a firm hypothesis, at present, as to how the Bai languages came to have an identical form for all four lexical domains, but assume, given their Sino-Tibetan credentials, that the sharing of at least the locative, existential and possessive verbs belongs to the same pattern and diachronic processes as for the Type III Tibeto-Burman languages. It is conceivable that the copula produced the locative, as in the Type II pattern, whence it developed further along the Type III Tibeto-Burman pathway. This appears to be the case in the Bai language of Xishan Shalang (Kunming, Yunnan) according to Wang (2012: 102) and would produce the following grammaticalization pathway: Copula > Locative Verb > Existential > Possessive, in which the source is a copula, rather than a Postural or Dwell verb (see Section 5.1). However, we do not have sufficient evidence at this stage to support such a conjecture.

In sum, the main findings of our analysis harmonize with the typological profile for a large part of the Tibeto-Burman group versus the rest of the MESEA languages in our sample and adds more evidence of this split. Their distinct profiles typically include respectively SOV word order for Tibeto-Burman as opposed to SVO for Sinitic, Kra-Da Hmong-Mien and Austroasiatic, a high frequency of ergative versus accusative alignment, intricate verbal complexes coding person agreement, TAM and evidentiality in Tibeto-Burman. This 
contrasts with the use of mainly aspectual and modal morphology modifying the verb in combination with rich sets of verb complementation devices in the other four language families, including resultative, manner and directional complements coding displacement and associated motion. Further comparisons can be made with the paucity of classifier systems in Tibeto-Burman languages, as opposed to the large inventories found in the Sinitic, Hmong-Mien, Kra-Dai and Austroasiatic language phyla. Nor is Tibeto-Burman well-known for its use of highly developed tone systems, unlike its neighbors, Hmong-Mien, Sinitic and Kra-Dai. Such features further support this striking typological split, the broad lines of which have been drawn by Dryer $(2003,2008)$ in terms of word order typology for the East and Southeast Asian area.

The geographical division can be easily perceived in Map 2 for the mixed area in western China where Types III and IV intermingle. The north-to-south border for this region roughly corresponds to the Tibetan-Qiang-Yi 'ethnic corridor', a riverine route that is a historical reflection of migrations of the ancestors of the Tibeto-Burman peoples along this pathway from Gansu and Qinghai in the north via Sichuan and Tibet to Yunnan, Myanmar (Burma) and northern India (Huang 2013; Shi 2018; Sun 1983). This corridor continues to serve as a contact zone between Tibetan, Qiang and Yi (or Lolo) on the western side, with the Han Chinese historically on the other. On the other eastern side of the corridor, from approximately 6,000 BP onwards, the peopling of peninsular Southeast Asia is clearly attributable to successive waves of migration by the ancestors of the Austroasiatics, the Hmong and the Tais (Kra-Dai) from central and southern China over many tens of centuries, as those of the Han Chinese pushed ever southwards. Detailed studies may be consulted in the volume edited by Sagart et al. (2005). In particular, see Starosta (2005).

\section{Conclusions}

A semantic typology comprising four synchronic patterns for existential, locative, possessive and copular verbs and their polysemy has been established through our analysis on the basis of data from 116 languages in the MesEA linguistic area. Examination of their areal distribution has allowed us to claim that these patterns represent a true case of polysemy sharing which crosscuts the accepted phylogenetic configurations in this region. We argued that the constructions formed by these four verbs are conceptually discrete but are nonetheless diachronically related in specific sequences via the mechanisms of semantic shift, syntactic 
reanalysis and morphosyntactic change, and that all these can be modeled in terms of conceptual transfer between schemata.

First, all the languages in our sample bear identical forms for their existential and possessive verbs, making it a prototypical areal feature.

Second, based on our findings and diachronic interpretation for the 116 languages in our sample, an implicational universal for the four synchronic areal patterns has been proposed to the effect that possessive verbs can only share the same form as locative verbs, when both are identical to the existential verb in that language. If a language uses the same verb for locative and possessive constructions, then this verb can also be used in existential constructions.

Third, when locative verbs do not share the same form as possessive verbs through mediated diachronic change, they may freely have their source in DwELL or Postural verbs (Type IV, some of Type II). In contrast to this, Locative verbs are identical to and derived from Copular verbs in most of Type II languages. These two main sources for LocATIVE verbs highlight the fact once again that semantic shifts, while they belong to recurrent processes that involve change in meaning, are not deterministic in nature.

As a corollary to our empirically based study, it has become clear that human possessors cannot simply be metaphorically construed as 'animate locations', pace Lyons (1967, 1968), and Clark (1978) as well as Norman (1988) on Mandarin Chinese. There are no syntactic or semantic grounds for claiming that possessive constructions are a subtype of the locative construction, let alone partake of a derivational relationship with them. We have argued that there is, in fact, no direct diachronic relation at all between locative and possessive construction types.

Further in-depth inquiry and investigation of these four classic semantic domains will undoubtedly be able to further test and refine the grammaticalization chains described in our analysis for other language families and regions. Our anticipation is great.

\section{Grammatical abbreviations}

$\begin{array}{ll}1 & \text { first person } \\ 2 & \text { second person } \\ 3 & \text { third person } \\ \text { ALL } & \text { allative } \\ \text { AN } & \text { "animal” nominal prefix }\end{array}$




$\begin{array}{ll}\text { ASSOC } & \text { associative marker } \\ \text { CC } & \text { copular complement noun } \\ \text { CL } & \text { classifier } \\ \text { CLF } & \text { classifier } \\ \text { COP } & \text { copula } \\ \text { CONT } & \text { continuous } \\ \text { CRS } & \text { currently relevant state marker } \\ \text { DAM } & \text { differential agent marker } \\ \text { DEF } & \text { definite article } \\ \text { DET } & \text { determiner } \\ \text { DIM } & \text { diminutive } \\ \text { DIR } & \text { directional } \\ \text { DM } & \text { discourse marker } \\ \text { DU } & \text { dual } \\ \text { DUR } & \text { durative } \\ \text { EX } & \text { existential } \\ \text { EXCL } & \text { exclusive } \\ \text { FAC } & \text { factual } \\ \text { GEN } & \text { genitive } \\ \text { HAB } & \text { habitual } \\ \text { HON } & \text { honorific particle } \\ \text { KIN } & \text { kinship } \\ \text { IMP } & \text { imperative } \\ \text { IND } & \text { indicative } \\ \text { INDEF } & \text { indefinite } \\ \text { IRR } & \text { irrealis } \\ \text { LOC } & \text { locative } \\ \text { LOC.C } & \text { locative complement noun } \\ \text { M } & \text { masculine } \\ \text { NEG } & \text { negative } \\ \text { NFUT } & \text { non-future } \\ \text { NMLZ } & \text { nominalizer or noun marker } \\ \text { NOM } & \text { nominalizer } \\ \text { NP } & \text { noun phrase } \\ \text { O } & \text { object } \\ \text { PFV } & \text { perfective } \\ \text { PL } & \text { plural } \\ \text { POSS } & \text { possessive } \\ \text { PostP } & \text { postposition } \\ \text { PRES } & \text { present } \\ \text { PROG } & \text { progressive } \\ \text { PROP } & \text { proprietive } \\ \text { PRT } & \text { discourse particle } \\ \text { Q } & \text { question marker } \\ \text { RED } & \text { reduplication } \\ & \end{array}$




$\begin{array}{ll}\text { S } & \text { subject } \\ \text { SAT } & \text { the quantifier/intensifier (s)at } \\ \text { SENS } & \text { sensory } \\ \text { SG } & \text { singular } \\ \text { TAME } & \text { tense, aspect, modality and evidentiality markers } \\ \text { TOP } & \text { topic marker } \\ \text { VP } & \text { verb phrase } \\ \text { VCL } & \text { verbal classifier } \\ \text { V }_{\text {COP }} & \text { copular verb } \\ V_{\text {EX }} & \text { existential verb } \\ V_{\text {LOC }} & \text { locative verb } \\ V_{\text {POSS }} & \text { possessive verb }\end{array}$

Acknowledgements: We are indebted to the following colleagues for generously providing us with their language data and explanations: Meixiang Chang (Jishui Gan), Weirong Chen (Hui'an Southern Min), Yujie Chen (Shangshui Central Plains Mandarin), Huy-Linh Dao (Vietnamese), Danh Thành Do-Hurinville (Vietnamese), Hilário De Sousa (Nanning Pinghua), Lisha HE (Rucheng), San San Hnin Tun and Mathias Jenny (Burmese), Yunfan Lai (Wobzi Khroskyabs), Milena Lazzaretti (Rui'an Wenzhou Wu), Huichi Lee (Wenchang Southern Min), Hao Li (Linxia Central Plains Mandarin), Xuping Li (Yichun Gan), Boyang Liu (Jilin Northeastern Mandarin), Meiyan Lu (Tujia), Yanjuan Mu (Naxi), Alexandra Sing Ngai (Shaowu Min and Hong Kong Cantonese), Daxingwang Peng (Pingjiang Gan), Min Rao (Guiqiong), Adam Sposato (Xong), Jian Wang (Jixi Hui) and Shuya Zhang (Brag-bar). For their comments on much earlier versions of this paper, we would also like to thank several colleagues, including participants at ALT12, the 12th Biennial Conference of the Association for Linguistic Typology, held at the Australian National University in Canberra in December 2017, in particular, Denis Creissels, Mathias Jenny, Kristine Hildebrandt, Gwendolyn Hyslop, Mark Post and Ljuba Veselinova. Finally, we are very grateful to Boyang Liu for her talent and meticulous care in creating the two linguistic maps for the locations of the languages in our corpus and their areal patterns. Authorship is shared equally: Lü initially focused on the synchronic, typological section and formulated the implicational universal, while Chappell focused on the diachronic section. Subsequently, both worked on the whole text together.

Research funding: We thank the Centre de recherches linguistiques sur l'Asie orientale (CRLAO) and the Centre national de la recherche scientifique (CNRS) for fieldwork funding which contributed to this project and also the ERC Advanced Grant Project 'The hybrid syntactic typology of Sinitic languages' (230388). 


\section{Appendix}

Table 5: Locative, existential, possessive and copular verbs in the 116 languages in the main sample.

\begin{tabular}{|c|c|c|c|c|c|c|c|c|}
\hline & & & $\mathrm{V}_{\text {Locative }}$ & $\mathrm{ADP}_{\text {Locative }}$ & $V_{\text {EXIStental }}$ & $\mathrm{V}_{\text {POSSESSIVE }}$ & $\mathrm{V}_{\text {COPULA }}$ & \\
\hline \multirow{44}{*}{ 营 } & 1. & Standard Mandarin & tsai $^{51}$ & tsai $^{51}$ & iou $^{214}$ & iou $^{214}$ & $s \tau^{51}$ & Lisha He pers.comm. \\
\hline & 2. & Jilin & $\mathrm{kr}^{214}<$ 'put' & $\mathrm{kr}^{214} / \mathrm{tsai}^{51}$ & $\mathrm{jou}^{214}$ & $\mathrm{jou}^{214}$ & $s \overbrace{}^{51}$ & Boyang Liu pers.comm. \\
\hline & 3. & Beijing & gēn $<$ 'follow' & gēn & yŏu & yǒu & shì & Chen (1985) \\
\hline & 4. & Shangshui & $\mathrm{ka}^{35}<$ 'put' & $\mathrm{kg}^{55}$ & iou $^{55}$ & iou $^{55}$ & $\mathrm{sl}^{51}$ & Yujie Chen Field notes \\
\hline & 5. & Jishou & $\operatorname{tau}^{35}<$ 'arrive' & $\operatorname{tau}^{35}$ & $\mathrm{i}^{4 \mathrm{u}^{42}}$ & $i^{2} u^{42}$ & $\mathrm{sl}^{35}$ & Q. $\operatorname{Li}(2002)$ \\
\hline & 6. & Jinyuan & tsai $^{35}$ & $\mathrm{tsai}^{35}$ & $i r u^{42}$ & $\mathrm{iru}^{42}$ & $\mathrm{Sl}^{35}$ & Wang (2007) \\
\hline & 7. & Xinzhou & $\operatorname{tsa}^{53}$ & $\mathrm{tsæx}^{53}$ & $i \mathrm{u}^{313}$ & $i^{3 u^{313}}$ & $\mathrm{sl}^{53}$ & Hou and Wen (1993) \\
\hline & \multirow[t]{3}{*}{8.} & \multirow[t]{3}{*}{ Changsha New Xiang } & $\mathrm{ku}^{13} \mathrm{tr}^{24} / \mathrm{ku}^{13} \mathrm{ta}^{21}$ [animate] & \multirow[t]{2}{*}{$\mathrm{ku}^{13} \mathrm{ta}^{21}$} & \multirow[t]{3}{*}{$\mathrm{iəu}^{41}$} & \multirow[t]{3}{*}{$\mathrm{isu}^{41}$} & \multirow[t]{3}{*}{$\mathrm{si}^{42}$} & $\mathrm{Wu}(2005)$ \\
\hline & & & $\left(\mathrm{ku}^{13}<\right.$ 'squat') & & & & & Daxingwang Peng pers. comm. \\
\hline & & & tsai $^{21}$ & $\mathrm{tsai}^{21}$ & & & & \\
\hline & \multirow[t]{2}{*}{9.} & \multirow[t]{2}{*}{ Longhui Xiang } & \multirow[t]{2}{*}{$\mathrm{ze}^{31}$} & \multirow[t]{2}{*}{$\mathrm{ze}^{31}$} & \multirow[t]{2}{*}{$\mathrm{t}^{31}$} & \multirow[t]{2}{*}{$\mathrm{u}^{31}$} & \multirow[t]{2}{*}{$z_{1}^{21}$} & Ding (1996) \\
\hline & & & & & & & & Ding and Luo (2006) \\
\hline & 10. & Loudi Xiang & $t s^{6} e^{1} \sim t^{4} e^{1}$ & $\mathrm{ts}^{\mathrm{c}} \mathrm{e}^{1} \sim \mathrm{t}^{\mathrm{c}} \mathrm{e}^{1}$ & $i \omega^{2}$ & $i \omega^{2}$ & ts $^{4} 1^{1}$ & Peng $(1998,2000,2006)$ \\
\hline & 11. & Rucheng & $t^{\mathrm{h}} \mathrm{ai}^{43}$ & $t^{\mathrm{h}} \mathrm{a} \mathrm{i}^{43}$ & $\mathrm{jou}^{33}$ & $\mathrm{jou}^{33}$ & $h \varepsilon^{43}$ & Lisha He pers.comm \\
\hline & 12. & Yichun Gan & $\mathrm{ts}^{\mathrm{h}} \boldsymbol{c}^{213}$ & $\mathrm{ts}^{\mathrm{h}} \mathfrak{c}^{213}$ & $\mathrm{iu}^{42}$ & $\mathrm{iu}^{42}$ & $\mathrm{ci}^{213}$ & Li (2018) \\
\hline & 13. & Nanchang Gan & ts'a $^{21}$ & ts'ai $^{21}$ & $\mathrm{iu}^{213}$ & $\mathrm{iu}^{213}$ & $\mathrm{sl}^{21}$ & $\begin{array}{l}\text { Sagart ms. (1999) and } \\
\text { Field notes }\end{array}$ \\
\hline & 14. & Anren Gan & $t^{\prime} e^{31}$ & os & $i w^{31}$ & $i w^{31}$ & $\mathrm{~s}^{31}$ & Chen (1995) \\
\hline & 15. & Pingjiang Gan & $10^{42}<$ 'fall' & $10^{42}$ & iəm $^{21}$ & $\mathrm{i}^{21}$ & $s \iota^{21}$ & Daxingwang Peng pers. comm. \\
\hline & 16. & Shanghai $\mathrm{Wu}$ & $\mathrm{la} ?^{12} \mathrm{a} a ?^{12} \sim \mathrm{a} ?^{12}$ & $\mathrm{la} ?^{12} \mathrm{la} ?^{12} \sim \mathrm{la} ?^{12}$ & $\operatorname{fir}^{13}$ & fir $^{13}$ & $z_{1}^{13}$ & Zhu (2006) \\
\hline & & & & & & & & $\mathrm{Xu}$ and Tao (1997) \\
\hline & 17. & Ningbo Wu & $\mathrm{lic}^{22}<$ 'come' & $\operatorname{lic}^{22}$ & $\mathrm{fiy}^{24-22}$ & $f y^{24-22}$ & $z 1^{22}$ & Ruan (2009) \\
\hline & 18. & Tiantai Wu & $\mathrm{lei}^{214}$ & $\operatorname{lei}^{214}$ & firru $^{214}$ & firru ${ }^{214}$ & $z_{1}^{214-21}$ & Dai (2006) \\
\hline & & & $\mathrm{ze}^{214}$ & $\mathrm{ze}^{214}$ & & & & \\
\hline & 19. & Taiwanese & $\mathrm{ti}$ & tĩ & $\overline{\mathrm{u}}$ & $\overline{\mathrm{u}}$ & sī & $\operatorname{Lin}(2015)$ \\
\hline & 20. & Hui'an & $\operatorname{tur}^{4} / \mathrm{ti}^{4}$ & os & $u^{4}$ & $u^{4}$ & $\mathrm{si}^{4}$ & Chen (2020) \\
\hline & 21. & Jieyang & $\mathrm{to}^{35}$ & $\mathrm{to}^{35}$ & $u^{35}$ & $\mathrm{u}^{35}$ & $\mathrm{si}^{35}$ & $\mathrm{Xu}(2007)$ \\
\hline & 22. & Wenchang & $\mathrm{du}^{42}<$ 'dwell' & $\mathrm{du}^{42}$ & $u^{42}$ & $\mathrm{u}^{42}$ & $\mathrm{ti}^{42}$ & Huichi Lee Field notes \\
\hline & & & & & & & & Chen (1996) \\
\hline & 23. & Shaowu & $t^{\mathrm{h}} \mathrm{u}^{55}$ & $\mathrm{t}^{\mathrm{b}} \mathrm{u}^{55}$ & $\mathrm{ivu}^{55}$ & iøu $^{55}$ & $\mathrm{ci}^{55}$ & Ngai (2021) \\
\hline & 24. & Fuzhou & tus? $?^{5}<$ 'adhere' & tuo $?^{5}$ & $\mathrm{ou}^{242}$ & $\mathrm{ou}^{242}$ & $\begin{array}{l}\mathrm{si}^{21} \\
\mathrm{se}^{242}\end{array}$ & $\begin{array}{l}\text { Zheng (1985) } \\
\text { Liang (1990) }\end{array}$ \\
\hline & 25. & Shangyou Hakka & $\mathrm{ts}^{\mathrm{h}} \mathrm{oi}^{24}$ & $\operatorname{ts}^{\mathrm{b}} \mathrm{oi}^{-24}$ & $\mathrm{iu}^{24}$ & $\mathrm{iu}^{24}$ & $\mathrm{hi}^{53}$ & Huang (2005) \\
\hline & 26. & Liancheng Hakka & $\mathrm{te}^{35}<$ 'adhere' & $\mathrm{te}^{35}$ & $\mathrm{iau}^{33}$ & $\mathrm{iau}^{33}$ & $\mathrm{hai}^{55}$ & Xiang (1997) \\
\hline & 27. & Nanning Pinghua & $\mathrm{tge}^{33}<$ 'dwell' $^{\prime}$ & $t \mathrm{jei}^{33}$ & $\mathrm{jou}^{13}$ & $\mathrm{jeu}^{13}$ & $\mathrm{Hi}^{22}$ & Hilário de Sousa Field notes \\
\hline & 28. & Hezhou Jiudu & $\mathrm{tsai}^{22}$ & tsai $^{22}$ & $\mathrm{xau}^{22}$ & $\mathrm{xau}^{22}$ & $\mathrm{y}^{33}$ & Zhang (2005) \\
\hline & 29. & Xinyi Yue & tou $^{33}<$ 'arrive' & $\operatorname{tou}^{33}$ & $\mathrm{jeu}^{23}$ & $\mathrm{jeu}^{23}$ & $h i^{11}$ & Luo (1987) \\
\hline & 30. & HongKong Cantonese & hei $^{35}<$ copula & $\mathrm{hei}^{35}$ & $\mathrm{jau}^{23}$ & $\mathrm{jau}^{23}$ & $h i^{22}$ & Matthews and Yip (1994) \\
\hline & 31. & Jixi Hui & $\mathrm{se}^{55}<$ copula & $\mathrm{se}^{55}$ & $i a^{55}$ & $12^{55}$ & $\mathrm{se}^{55}$ & Jian Wang Field notes \\
\hline & 32. & Yixian Hui & $\mathrm{sq}^{53}<$ copula & $\mathrm{r}^{53}$ & iauu $^{53}$ & $\mathrm{iau}^{53}$ & $\mathrm{sq}^{53}$ & Hirata (1998) \\
\hline & 33. & Rui'an Wu & $\mathrm{z}^{214}<$ copula & $\mathrm{zi}^{214}$ & $\mathrm{jiau}^{214}$ & $\mathrm{jiau}^{214}$ & $\mathrm{zi}^{214}$ & Milena Lazzaretti Field notes \\
\hline & 34. & Xianghua & $\operatorname{ts}^{\mathrm{h}} \gamma^{25}<$ copula & $\operatorname{ts}^{6} \gamma^{25} / 0 s$ & $\mathrm{va}^{25}$ & $\mathrm{va}^{25}$ & $\operatorname{ts}^{\mathrm{h}} \gamma^{25}$ & Hilary Chappell Field notes \\
\hline & 35. & Fuqing Min & $\mathrm{ka}^{5}{ }^{5}<$ 'stick' & $\mathrm{ka}^{5}$ & $u^{41}$ & $u^{41}$ & $\mathrm{ka}^{5}$ & Lin and Sheng (2018) \\
\hline & 36. & Dabu Hakka & zị $^{44}<$ 'have, there be' & os & $\mathrm{ziju}^{44}$ & $\mathrm{ziju}^{44}$ & hei $^{51}$ & $\mathrm{He}(1993)$ \\
\hline & 37. & Haikou Min & $\mathrm{u}^{33}<$ 'have, there be $/ 2 \mathrm{du}^{33}$ & $\mathrm{u}^{33} / 2 \mathrm{du}^{33}$ & $\mathrm{u}^{33} / 2 \mathrm{du}^{33}$ & $\mathrm{u}^{33} / 2 \mathrm{du}^{33}$ & $\mathrm{ti}^{33}$ & Chen (1996) \\
\hline & 38. & Linxia & $\mathrm{ju}^{55}$ & os & $\mathrm{ju}^{55}$ & $j u^{55}$ & $s \tau^{55}$ & Hao Li pers.comm. \\
\hline 毒 & 39. & Nisu & $\mathrm{dzz}^{55}$ & os & $\mathrm{dz} \mathrm{p}^{21}$ & $\mathrm{dz} \mathrm{z}^{21}$ & $\mathrm{yuu}^{21}$ & Zhai (2011) \\
\hline 焉 & 40. & Nasu & $\mathrm{dz} \mathrm{\rho}^{33}$ & os & $\mathrm{dz} \mathrm{p}^{21}$ & $\mathrm{dz} \mathrm{p}^{21}$ & $\mathrm{ne}^{33}$ & $\mathrm{Pu}(2016)$ \\
\hline 产 & & & $\mathrm{ni}^{33}{ }^{33}<$ 'sit' $^{\prime}$ & os & $\mathrm{ni}^{33}$ & UNA & & \\
\hline 总 & 41. & Nuosu & jjo $<$ 'dwell' & os & jjo & jjo & nge & Gerner (2013) \\
\hline & 42. & Kucong & $\mathrm{mu}^{33}<$ 'sit, dwell' & os & $\mathrm{mu}^{33}$ & $\mathrm{mu}^{33}$ & $2 \Lambda^{33}$ & Chang (2011) \\
\hline & 43. & Jinuo & $\mathrm{t} \int \mathrm{\Lambda}^{31 / 44}[$ animate $]<$ 'dwell' & os & $t \int \Lambda^{31 / 44}$ & $\operatorname{tg} \Lambda^{31 / 44}$ & $\mathrm{ng}^{31}$ & Jiang (2010) \\
\hline & & & $\mathrm{t} \mathrm{a}^{31}[$ inanimate] & & $\mathrm{tfa}^{31}$ & $t \mathrm{ta}^{31}$ & & \\
\hline & 44. & Bangduo Lahu & $\operatorname{tch}^{5^{3}}<$ 'dwell' & os & $\operatorname{tchh}^{53}$ & UNA & $\varnothing / \mathrm{xe}^{53}$ & $\operatorname{Li}(2012)$ \\
\hline & & & $\mathrm{tso}^{31}$ & os & $\mathrm{ts}^{31}$ & $\mathrm{tso}^{31}$ & & \\
\hline & 45. & Naxi & ygy $\mathrm{y}^{33}$ [inaimate] & os & $\mathrm{ggy}^{33}$ & $\mathrm{ngy}^{33}$ & $w^{21}$ & Shanshan Lü and Yanjuan Mu \\
\hline & & & $\mathrm{ngy}^{21}$ [animate] & os & ggy $^{21}$ & $\mathrm{ggy}^{21}$ & & Field notes \\
\hline & & & ndz $1^{21}<$ 'sit, dwell' & os & $\left.\mathrm{ndz}\right|^{21}$ & $\mathrm{ndz}_{1}^{21}$ & & \\
\hline & & & $z \mathrm{zi}^{33}<z \mathrm{i}^{55}$ 'lie' & os & $\mathrm{zi}^{33}$ & $\mathrm{zi}^{33}$ & & \\
\hline & 46. & Sani & $\operatorname{tsso~}^{33}$ & $\operatorname{tsco}^{33}$ & $\mathrm{tsso}^{33}$ & $\operatorname{tsso~}^{33}$ & $\mathrm{ye}^{33}$ & Ma (1951) \\
\hline & 47. & Sangkong & $\operatorname{tcay}^{55}[$ animate $]<$ 'dwell' & os & tçar ${ }^{55}$ & tcan ${ }^{55}$ & $\mathrm{ygr}^{55}$ & Y. Li (2002) \\
\hline & & Woni & tso $^{55}[$ animate $]<$ 'dwell' & os & $\mathrm{tso}^{55}$ & $\mathrm{tso}^{55}$ & $\mathrm{\eta u}^{55}$ & Yang (2016) \\
\hline & & & $\mathrm{tsa}^{33}$ [inanimate] & & $\mathrm{tsa}^{33}$ & $\mathrm{tsa}^{33}$ & & \\
\hline
\end{tabular}


Table 5: (continued)

\begin{tabular}{|c|c|c|c|c|c|c|c|c|}
\hline & & & $\mathrm{V}_{\text {Locative }}$ & $\mathrm{ADP}_{\text {Locative }}$ & $\mathrm{V}_{\text {EXISTENTIAL }}$ & $V_{\text {Possessive }}$ & $\mathrm{V}_{\text {COPGLAR }}$ & \\
\hline \multirow{2}{*}{\multicolumn{2}{|c|}{49.}} & Kaduo Hani & $\mathrm{tsa}^{33}[$ inanimate $]$ & os & $\mathrm{tsa}^{33}$ & $\mathrm{tsa}^{33}$ & $\mathrm{yr}^{55}$ & Zhao and Zhu (2011) \\
\hline & & & tso $^{55}[$ animate $]<$ 'dwell' & & $\mathrm{tso}^{55}$ & $\mathrm{tso}^{5.5}$ & & \\
\hline \multirow{2}{*}{\multicolumn{2}{|c|}{50.}} & Biyue Hani & $\mathrm{tsu}^{33}[$ animate $]<\mathrm{tsu}^{55}$ 'dwell' & os & $\mathrm{tsu}^{33}$ & $\mathrm{tsu}^{33}$ & $\mathrm{ye}^{33}$ & Jing (2015) \\
\hline & & & $\operatorname{tsa}^{33}[$ inanimate $]$ & & $\mathrm{tsa}^{33}$ & $\mathrm{tsa}^{3^{3}}$ & & \\
\hline \multirow{2}{*}{\multicolumn{2}{|c|}{51.}} & Akha & $\mathrm{dz} \mathrm{o}^{55}$ [animate] $<$ 'dwell' & os & $\mathrm{dz} \mathrm{o}^{55}$ & $\mathrm{~d} z 0^{55}$ & $\varnothing$ & Dai (ed.) (2009) \\
\hline & & & $\mathrm{gja}^{\mathrm{33}}[$ inanimate $]$ & & $\mathrm{gja}^{33}$ & $\mathrm{gja}^{33}$ & $\mathrm{yr}^{55}$ & \\
\hline \multirow{2}{*}{\multicolumn{2}{|c|}{52.}} & Cosao & $\mathrm{tcca}^{33}[$ inanimate $]$ & os & $\mathrm{tca}^{33}$ & $\operatorname{tcc}^{33}$ & $\mathrm{yu}^{s s}$ & Bai, Xu et al. (2015) \\
\hline & & & $\mathrm{tc}^{55}[$ animate $]<$ 'dwell' & & $\operatorname{tco}^{55}$ & $\operatorname{tco}^{55}$ & & \\
\hline & 53. & Azha & $\mathrm{tssu}^{35}<$ 'dwell' & os & $\operatorname{tşu}^{21}$ & $\operatorname{tşu}^{21}$ & $\mathrm{no}^{51}$ & $\mathrm{Li}(2011)$ \\
\hline & 54. & Nusu & 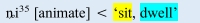 & os & $\mathrm{nij}^{35}$ & $\mathrm{nij}^{35}$ & $u \tilde{\sigma}^{33}$ & Sun and Liu (1983) \\
\hline & 55. & Zauzou & $\mathrm{nid}^{33}$ [animate $]<$ 'sit, dwell' & os & $\mathrm{ni}^{33}$ & $\mathrm{ni}^{33}$ & $\mathrm{y} e^{53}$ & Sun et al. (2002) \\
\hline \multirow{2}{*}{\multicolumn{2}{|c|}{56.}} & Khatso & tso $^{24}$ & os & $\mathrm{tso}^{24}$ & $\mathrm{tso}^{24}$ & $\mathrm{ye} e^{33}$ & $\mathrm{Mu}(2002)$ \\
\hline & & & & & & & & Dai et al. (1991) \\
\hline \multirow{3}{*}{\multicolumn{2}{|c|}{57.}} & Lashi & nje: $i^{53}$ [animate] & os & nje: $\mathrm{i}^{53}$ & nje: $\mathrm{i}^{53}$ & pue: $t^{55}$ & Dai and $\mathrm{Li}(2007)$ \\
\hline & & & po: $^{53}$ & & $\mathrm{p} s^{.33}$ & po: $:^{53}$ & $\mathrm{yot}^{55}$ & \\
\hline & & & lu:y ${ }^{55}<$ 'dwell' & & UNA & UNA & & \\
\hline \multirow{2}{*}{\multicolumn{2}{|c|}{58.}} & Yadu Qiang & zi [animate] < 'dwell' & os & zị & zi & กјиа & LaPolla and Huang (2003) \\
\hline & & & şo [inanimate] & & șo & so & & \\
\hline \multirow{2}{*}{\multicolumn{2}{|c|}{59.}} & Longxi Qiang & jì [animate] < 'stand, dwell' & & $\mathrm{jì}$ & jì & gù & Zheng (2016) \\
\hline & & & & & & tsé $<$ 'catch' & & \\
\hline \multirow{3}{*}{\multicolumn{2}{|c|}{60.}} & Guiqiong & na $^{-35}[$ animate $]<$ 'dwell' & os & $\mathrm{na}^{\tilde{3}^{35}}$ & $\mathrm{na}^{35}$ & $\mathrm{dz} \mathrm{P}^{35}$ & Rao (2015) \\
\hline & & & $\mathrm{j} \tilde{e}^{5 s}[$ inanimate $]$ & & $\mathrm{j} \varepsilon^{-5 s}$ & $\mathrm{j} \varepsilon^{-5 s}$ & & \\
\hline & & & $\mathrm{bud}^{35}$ [inalienable] & & $\mathrm{bur}^{35}$ & $\mathrm{bur}^{35}$ & & \\
\hline \multirow{4}{*}{\multicolumn{2}{|c|}{61.}} & Tujia & $6 \mathrm{e}^{35}$ & & $\mathrm{ce}^{35}$ & $\mathrm{ce}^{35}$ & $\sin ^{35}$ & Meiyan Lu pers.comm. \\
\hline & & & thai $^{35}$ & & thai $^{35}$ & thai $^{35}$ & & Tian et al. (1986) \\
\hline & & & & & & & & Brassett et al. (2006) \\
\hline & & & $\mathrm{kau}^{55}<$ 'do' $^{\prime}$ & & & & & Chen (2006) \\
\hline & 62. & Drung & $\mathrm{ă}^{53}$ & os & $\mathrm{ă}^{53}$ & $\mathrm{al}^{53}$ & $e^{53}$ & Sun (1982) \\
\hline & 63. & Jingpho & $30 \eta^{33}$ & os & $30 y^{33}$ & $3 \mathrm{OI}^{33}$ & $3 \mathrm{e}^{55}$ & Dai (2012) \\
\hline & & & $\mathrm{ya}^{31}<$ 'dwell' & & $\mathrm{na}^{31}$ & UNA & & Liu (1984: 108) \\
\hline & & & & & & $\mathrm{lu}^{31}<$ 'obtain' & & \\
\hline & 64. & Turung & paa $^{2}<$ 'dwell' & os & $\mathrm{naa}^{2}$ & $\operatorname{yaa}^{2}$ & $\varnothing$ & Morey (2010) \\
\hline & 65. & Karen Geba & $\Re \mathrm{\imath}<$ 'dwell' & os & $? 3$ & $? 3$ & $\mathrm{mī}$ & Shee (2008) \\
\hline & 66. & Eastern Kayah LI & ?o $<$ 'dwell' & os & ?o & ?o & ma & Solnit (1997) \\
\hline & 67. & Daai Chin & ve < 'dwell' & os & ve & ve & & So-Hartmann (2009) \\
\hline \multirow{5}{*}{ 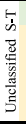 } & 68. & Caijia & $\mathrm{tww}^{21}<$ 'dwell' & $\mathrm{tw}^{21}$ & $\mathrm{ya}^{\tilde{a}^{33}}$ & $\mathrm{Ya}^{\tilde{a}^{33}}$ & $\mathrm{st}^{33}$ & Shanshan Lü Field notes \\
\hline & 69. & Jianchuan Bai & $\mathrm{tsu}^{33}$ & $\operatorname{tsur}^{33}$ & $\mathrm{tsum}^{33}$ & $\mathrm{tsur}^{33}$ & $\mathrm{tsur}^{33}$ & Xu and Zhao (1984) \\
\hline & 70. & Lanping Bai & $\mathrm{z}^{33}$ & $z_{1}^{33}$ & $z_{1}^{33}$ & $z_{1}^{33}$ & $z_{1}^{33}$ & $\operatorname{Li}(2014: 75)$ \\
\hline & 71. & Shitou Bai & $\mathrm{ndz} 1^{33}$ & $\mathrm{ndz} 1^{33}$ & $n d z 1^{33}$ & $\mathrm{ndz} 1^{33}$ & $\mathrm{ndz}]^{33}$ & $\operatorname{Li}(2014: 75)$ \\
\hline & 72. & Yunlong Bai & $\mathrm{dzu}^{33}$ & $\mathrm{dzu}^{33}$ & $\mathrm{dzu}^{33}$ & $\mathrm{dzu}^{33}$ & $\mathrm{dzu}^{33}$ & Li (2014: 75) \\
\hline \multirow{20}{*}{ 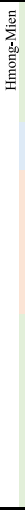 } & 73. & Younuo & nat ${ }^{33}<$ 'dwell' & nay $^{33}$ & $m v^{13}$ & $\mathrm{mo}^{13}$ & $\varphi \mathrm{i}^{22}$ & Mao and $\mathrm{Li}(2007)$ \\
\hline & 74. & White Hmong & nyob $\left[\mathrm{n}^{53}\right]<$ 'dwell' & nyob $\left[\mathrm{no}^{53}\right]$ & muaj $\left[m \oplus e^{53}\right]$ & muaj $\left[\mathrm{m}^{5 e^{53}}\right]$ & yog & Jarkey (2015) \\
\hline & & & & & & & {$\left[i^{42}\right]$} & \\
\hline & 75 & Weining Hmong & $100^{55}<$ 'dwell' & $\mathrm{n} \mathrm{n}^{55}$ & $\mathrm{mfia}^{35}$ & $\begin{array}{l}<\text { muab 'grasp' } \\
\end{array}$ & & Clark (1989) \\
\hline & 75. & Weining Hmong & nan $^{33}<$ 'sit, dwell' & no 0 & $\mathrm{mha}^{3}$ & $\mathrm{mfia}^{35}$ & $\mathrm{ku}^{11}$ & Wang and Wang (1982) \\
\hline & 76. & Yanghao Hmong & nay $^{33}<$ 'sit, dwell' $^{\prime}$ & UNA & nay $^{33}$ & $\operatorname{man}^{33}$ & $\mathrm{ti}^{13}$ & Wang (1985) \\
\hline & 77. & Aizhai Xong & $\mathrm{ni}^{53}<$ 'dwell' & nini $i^{53}$ & $m e^{31}$ & $\begin{array}{l}\mathrm{me} \\
\mathrm{me}^{31}\end{array}$ & $\mathrm{ni}^{22}$ & $\mathrm{Yu}(2010)$ \\
\hline & & & & & & $<\mathrm{me}^{53}$ 'grasp & & \\
\hline & 78. & Fenghuang Xong & $\tilde{n}^{1}$ (ninb) & nĩ ${ }^{1}(\mathrm{ninb})$ & $m \varepsilon^{2}(m e x)$ & $\mathrm{m}^{2}(\mathrm{mex})$ & nî́ $^{6}($ nins $)$ & Sposato (2015) \\
\hline & & & & & & $<$ meb 'take' & & \\
\hline & 79. & Songtao Xong & $\mathrm{ni}^{35}$ & $\mathrm{ni}^{35}$ & $\mathrm{me}^{31}$ & $\mathrm{me}^{31}$ & $\mathrm{ni} \mathrm{i}^{42}$ & Luo (2015) \\
\hline & & & & & & me $^{35}<$ 'grasp" & & \\
\hline & 80. & Jiongnai & nay $^{44}<$ 'sit, dwell' & nar $^{44}$ & $m s^{33}$ & $\mathrm{~m}^{33}$ & $\mathrm{Se}^{22}$ & Mao and $\mathrm{Li}(2002)$ \\
\hline & 81. & Baheng & $\mathrm{n} \tilde{o}^{35}<$ 'sit, dwell' & $\mathrm{n} \tilde{\mathrm{o}}^{35}$ & $\mathrm{mfit}^{33}$ & $\mathrm{mfir}^{33}$ & $\mathrm{ci}^{53}$ & Mao and Li (1997) \\
\hline & 82. & Chiang Saen Iu Mien & jem ${ }^{33}<$ 'dwell' & & ma: $i^{53}$ & ma: $i^{53}$ & $\operatorname{sei}^{33}$ & Saeliao (2012) \\
\hline & 83. & Mae Chan Iu Mien & jem-1< 'dwell' & & ma:il & ma:iv & pent & Arisawa (2016) \\
\hline & 84. & Lakha & $\mathrm{at}^{7}$ & $a t^{7}$ & $\mathrm{mi}^{2}$ & $\mathrm{mi}^{2}$ & $\operatorname{tok}^{7} / \mathrm{tuk}^{8}$ & Mao et al. (1982) \\
\hline & 85. & Bunu & $\mathrm{ji}^{1}<$ 'dwell' & $\mathrm{ji}^{1}$ & $\operatorname{moy}^{2}$ & $\operatorname{moy}^{2}$ & $\mathrm{ci}^{6}$ & Mao et al. (1982) \\
\hline & & & & & & & $\operatorname{tau}^{6}$ & \\
\hline & 86. & She & $\mathrm{kr}^{6}<$ 'give' & $\mathrm{kr}^{6}$ & $\mathrm{ma}^{2}$ & $\mathrm{ma}^{2}$ & tshi $^{4}$ & Mao and Meng (1986) \\
\hline "̈ & 87. & Judu Gelao & $\mathrm{qau}^{33}<$ 'sit, dwell' & $\mathrm{qau}^{33}$ & $a y^{31}$ & $a y^{31}$ & $\mathrm{au}^{31}$ & Kang (2009) \\
\hline 霝 & & & $a^{31}$ & $a^{31}$ & & & & \\
\hline & 88. & Xia'ao Zhuang & $\mathrm{jum}^{33}<$ 'dwell" & $j u^{33}$ & $\mathrm{mi}^{231-31}$ & $\mathrm{mi}^{231-31}$ & $\begin{array}{l}\mathrm{s}^{31} \\
\sin ^{33}\end{array}$ & Wei (2012) \\
\hline
\end{tabular}


Table 5: (continued)

\begin{tabular}{|c|c|c|c|c|c|c|c|}
\hline & & $\mathrm{V}_{\text {LocatVIE }}$ & $\mathrm{ADP}_{\text {LOCATIVE }}$ & $\mathrm{V}_{\text {EXISTENTAL }}$ & $\mathrm{V}_{\text {POSSESSIVE }}$ & $\mathrm{V}_{\text {COPULAR }}$ & \\
\hline & 89. Lao & juu $1<$ 'dwell' & juu1 & mii2 & $\mathrm{mii2}$ & pên3 & Enfield (2007) \\
\hline & 90. Nùng & $\mathrm{du}<$ < 'dwell' & dụ & $\mathrm{mi}$ & $\mathrm{mi}$ & dụ & Saul and Wilson (1980) \\
\hline & 91. Hlai & $2 \mathrm{du}^{3}$ & $2 \mathrm{dur}^{3}$ & $\mathrm{tsau}^{2}$ & $\mathrm{tsau}^{2}$ & $\operatorname{man}^{1}$ & Yuan (1994) \\
\hline \multirow{2}{*}{\multicolumn{2}{|c|}{ 92. Ong Be }} & \multirow[t]{2}{*}{$\mathrm{jou}^{3}<$ 'dwell' $^{\prime}$} & \multirow[t]{2}{*}{$\mathrm{j} \mathrm{u}^{3} / \mathrm{os}$} & \multirow[t]{2}{*}{$l a i^{3}$} & \multirow[t]{2}{*}{ lai $\mathrm{i}^{3}<$ 'obtain' } & \multirow[t]{2}{*}{$\mathrm{ti}^{\prime}$} & Liang (1981) \\
\hline & & & & & & & Liu (2000) \\
\hline & 93. Thai & yùu $<$ 'dwell' & thîi & $\mathrm{mii}$ & $\mathrm{mii}$ & pen & Smyth (2002) \\
\hline & 94. Dai & $\mathrm{ju} \mathrm{s}^{\mathrm{s}}<$ 'dwell' & $\mathrm{ju}^{5}$ & $\mathrm{mi}^{2}$ & $\mathrm{mi}^{2}$ & $\operatorname{pin}^{1}$ & Yu and Luo (1980) \\
\hline \multirow{4}{*}{\multicolumn{2}{|c|}{ 95. Sui }} & \multirow[t]{4}{*}{ na: $\mathrm{u}^{24}<$ 'dwell' } & \multirow[t]{4}{*}{ na: $u^{24}$} & \multirow[t]{4}{*}{ ?nay ${ }^{11}$} & \multirow[t]{4}{*}{2 nay ${ }^{11}$} & $\varnothing$ & \multirow[t]{4}{*}{ Wei (2011) } \\
\hline & & & & & & ${ }^{\text {ndum }}{ }^{33}$ & \\
\hline & & & & & & $\mathrm{tju}^{31}$ & \\
\hline & & & & & & $\mathrm{sl}^{11}$ & \\
\hline \multirow{2}{*}{\multicolumn{2}{|c|}{ 96. Maonan }} & \multirow[t]{2}{*}{ na: $\mathrm{u}^{6}<$ 'dwell' } & \multirow[t]{2}{*}{ na: ${ }^{6}$} & \multirow[t]{2}{*}{$m e^{2}$} & \multirow[t]{2}{*}{$m \varepsilon^{2}$} & $\mathrm{ci}^{4}$ & \multirow[t]{2}{*}{$\mathrm{Lu}(2008)$} \\
\hline & & & & & & $\operatorname{tsin}^{5}$ & \\
\hline & 97. Mak & na: $\mathrm{u}^{6}<$ 'dwell' & nа: ${ }^{6}$ & nạj $^{1}$ & nay $^{1}$ & $\operatorname{cin}^{1 / s} 1^{1}$ & Yang (2000) \\
\hline \multirow{2}{*}{\multicolumn{2}{|c|}{ 98. Bouyei }} & \multirow[t]{2}{*}{$2 \mathrm{ju}^{5}<$ 'dwell" $^{\prime}$} & \multirow[t]{2}{*}{$2 \mathrm{ju}^{5}$} & \multirow[t]{2}{*}{$1 i^{4}$} & \multirow[t]{2}{*}{$1 i^{4}$} & \multirow[t]{2}{*}{$\mathrm{si}^{1}$} & Yu (1980) \\
\hline & & & & & & & Mo (2017) \\
\hline & 99. Kam & na: $u^{6}<$ 'dwell' & na: ${ }^{6}$ & $\mathrm{me}^{2}$ & $\mathrm{me}^{2}$ & ta: $y^{3}$ & Liang (1980) \\
\hline & & & & & & $\sin ^{5}$ & \\
\hline & 100. Mulao & na: $\mathrm{u}^{6}<$ 'dwell' & na: ${ }^{6}$ & $m \varepsilon^{2}$ & $\mathrm{~m} \varepsilon^{2}$ & $\mathrm{si}^{6}$ & Yin (2012) \\
\hline & 101. E & $\mathrm{u}^{5}<$ 'dwell' & $u^{5}$ & $\mathrm{mi}^{2}$ & $\mathrm{mi}^{2}$ & $\mathrm{ci}^{6}$ & Wei and Wei (2011) \\
\hline & 102. Wuming Zhuang & ?jau ${ }^{5}<$ 'dwell' & $\operatorname{lay}^{1}$ & $\mathrm{mi}^{2}$ & $\mathrm{mi}^{2}$ & $\mathrm{twak}^{8}$ & Zhang et al. (1999) \\
\hline & 103. Vietnamese & $\dot{o}<<$ 'dwell' & ơ & có & có & là & Phan (2010) \\
\hline 哥 & 104. Jing & $\mathrm{a}^{3}<$ 'dwell' & $2^{3}$ & $k s^{5}$ & $\mathrm{k} \mathrm{o}^{5}$ & $1 a^{2}$ & Ouyang et al. (1984) \\
\hline & 105. Khmer & nev $<$ 'dwell' & nev & $\operatorname{mian}$ & $\operatorname{mian}$ & cia & Haiman (2011) \\
\hline & 106. Khmu & jiat & jiat & Pah & ?ah & mrh & Chen (2002) \\
\hline & 107. Kemic & $\mathrm{ot}^{31}<$ 'dwell' $^{\prime}$ & $\mathrm{ot}^{31}$ & $\mathrm{pa}^{253}$ & $\mathrm{pă}^{253}$ & $\mathrm{kr}^{753}$ & Chen (2005) \\
\hline & 108. Wa & Pọt < 'dwell' & UNA & koi & koị & $\mathrm{moh}$ & Zhou and Yan (1984) \\
\hline & & & & & & & Wang (1994) \\
\hline & 109. Bumang & $\mathrm{n}, \mathrm{w}^{24}<$ 'dwell' & $\mathrm{n} \mathrm{D}^{24}$ & hop $^{21}$ & hop $^{21}$ & pen $^{55}$ & Dao (2007) \\
\hline & 110. Yunqian Palaung & go:i < 'dwell’' & go:i & mrh & $\mathrm{mrh}$ & muh & Chen et al. (1986) \\
\hline & 111. Guangka Palaung & ${\mathrm{g} j \mathrm{j}^{412}}^{4}<$ 'dwell' & UNA & $m e h^{51}$ & $\mathrm{meh}^{51}$ & $\mathrm{moh}^{51}$ & $\mathrm{Ni}(2007)$ \\
\hline & 112. Stieng & ja: $<$ 'dwell' & na: & ?ən & ?ən & $\varnothing$ & Bon (2014) \\
\hline & & gok $<$ 'sit' & & & & & \\
\hline & 113. Pacoh & ?at $<$ 'dwell' & os & vi: & vi: & la: & Alves (2006) \\
\hline & & & & boon & boon < 'obtain" & & Enfield (2003: 185-186) \\
\hline & 114. Blang & mok $^{1}<$ 'sit, dwell' & os & $\mathrm{kui}^{2}$ & $\mathrm{kui}^{2}$ & $\operatorname{pin}^{1}$ & Li et al. (1986) \\
\hline & 115. Bugan & $\mathrm{kai}^{44}<$ 'dwell' & $\mathrm{kai}^{44}$ & $\mathrm{kai}^{44}$ & $\mathrm{kai}^{44}$ & $\mathrm{ei}^{24}$ & $\operatorname{Li}(2005)$ \\
\hline & & & & & & nou $u^{44}$ & \\
\hline & & & & & & $\mathrm{ci}^{44}$ & \\
\hline & 116. Mang & $2 \mathrm{e}^{51} / 2 \mathrm{e}^{51}<$ 'dwell" & $2 \mathrm{e}^{51 / 2 \varepsilon^{51}}$ & $2 \mathrm{e}^{51 / 2 \mathrm{e}^{51}}$ & $2 \mathrm{e}^{51 / 2 \mathrm{e}^{51}}$ & $\operatorname{tc9} 9^{55}$ & Gao (2002) \\
\hline & & & & & & $\theta 2^{31}$ & \\
\hline
\end{tabular}

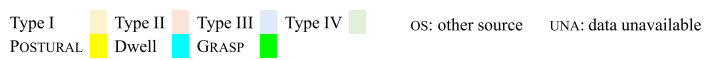

os, other source; UNA, data unavailable.

\section{References}

Acuo, Yixiweisa. 2004. Dao-hua yanjiu 倒话研究 [Research on the Dao language]. Beijing: Minzu Publishers.

Alves, Mark J. 2006. A grammar of Pacoh: A Mon-Khmer language of the Central Highlands of Vietnam. Canberra: Pacific Linguistics.

Ameka, Felix K. \& Stephen C. Levinson. 2007. Introduction-The typology and semantics of locative predicates: posturals, positionals and other beasts. Linguistics 45(5/6). 847-872.

Arisawa, Daniel Tatsuro. 2016. An lu Mien grammar: A tool for language documentation and revitalisation. Melbourne: La Trobe University dissertation. 
Bai, Bibo 白碧波, Xianming Xu 许鲜明, Yan Yang 杨艳, Wenxue Yang 杨文学, Hongli Ji 季红丽, Xuehui Wang 王学慧, Jiashun Qi 漆家顺, Yihui Zhong 仲一卉, Bingxue Cao 曹冰雪, Dan Shao 郡丹, Kunyi Gao 高昆谊 \& Ou Bai 白鸥. 2015. Cuosuo-yu yanjiu 搓梭语研究 [Studies on the Cosao language]. Beijing: Minzu Publishers.

Bentley, Delia, Francesco Maria Ciconte \& Silvio Cruschina. 2015. Existentials and locatives in Romance dialects of Italy. Oxford: Oxford University Press.

Benveniste, Emile. 1960. 'Etre' et 'avoir' dans leurs fonctions linguistiques. Bulletin de la Société Linguistique 55. 113-134.

Blake, Barry. 2004. Case, 2nd edn. Cambridge: Cambridge University Press.

Bon, Noellie. 2014. Une grammaire de la langue Stieng, langue en danger du Cambodge et du Vietnam. Lyon: Université de Lyon 2 dissertation.

Brassett, Cecilia, Philip Brassett \& Meiyan Lu. 2006. The Tujia language. Munich: Lincom Europa.

Buck, Carl Darling. 1988 [1949]. A dictionary of selected synonyms in the principal Indo-European languages: A contribution to the history of ideas. Chicago: University of Chicago Press.

Bybee, Joan, Revere Perkins \& William Pagliuca. 1994. The evolution of grammar: Tense, aspect and modality in the languages of the world. Chicago: University of Chicago Press.

Cao, Zhiyun 曹志耘 (ed.). 2008. Hanyu fangyan dituji 汉语方言地图集 [Linguistic atlas of Chinese dialects], 1st edn. vol. 3. Beijing: The Commercial Press.

Chang, Junzhi 常俊之. 2011. Yuanjiang Kucong-hua cankao yufa 元江苦聪话参考语法 [A reference grammar of Yunjiang Kucong]. Beijing: China Social Sciences Press.

Chappell, Hilary \& Denis Creissels. 2019. Topicality and the typology of predicative possession. Linguistic Typology 23(3). 468-532.

Chen, Gang 陈刚. 1985. Beijing fangyan cidian 北京方言词典 [A dictionnary of Pekinese]. Beijing: The Commercial Press.

Chen, Guoqing 陈国庆. 2002. Kemu-yu yanjiu 克木语研究 [Research on the Khmu language]. Beijing: Minzu Publishers.

Chen, Guoqing 陈国庆. 2005. Kemie-yu yanjiu 克菻语 [Research on the Kemie language]. Beijing: Minzu Publishers.

Chen, Hongmai 陈鸿迈. 1996. Haikou fangyan zidian 海口方言字典 [A dictionary of the Haikou dialect]. Nanjing: Jiangsu Jiaoyu Press.

Chen, Kang 陈康. 2006. Tujia-yu yanjiu 土家语研究 [Research on the Tujia language]. Beijing: Minzu University Press.

Chen, Manhua 陈满华. 1995. Anren fangyan 安仁方言 [The Anren dialect]. Beijing: Beijing Language and Culture University Press.

Chen, Weirong. 2020. A grammar of the Hui'an language of Southern Min. Berlin \& Boston: De Gruyter Mouton.

Chen, Xiangmu 陈相木, Jiangliu Wang 王敬骝 \& Yongliang Lai 赖永良. 1986. De’angyu jianzhi 德昂 语简志 [A sketch of Palaung]. Beijing: Minzu Publishers.

Chirkova, Katia. 2009. Shixing, a Sino-Tibetan language of South-West China: A grammatical sketch with two appended texts. Linguistics of the Tibeto-Burman Area 32(1). 1-89.

Clark, Eve. 1978. Locationals: Existential, locative, and possessive constructions. In Joseph H. Greenberg (ed.), Universals of human language, vol. IV: Syntax, 85-126. Stanford, CA: Stanford University Press.

Clark, Marybeth. 1989. Hmong and areal Southeast Asia. In David Bradley (ed.), South-East Asian syntax (Pacific Linguistics Series A 77: Papers in South-East Asian Linguistics 11), 177-230. Canberra: Australian National University, Research School of Pacific Studies. 
Craig, Colette Grinevald. 1991. Ways to go in Rama: A case study in polygrammaticalization. In Elisabeth Traugott \& Bernd Heine (eds.), Approaches to grammaticalization, vol. 2, 455-192. Amsterdam \& Philadelphia: John Benjamins.

Creissels, Denis. 1979. Les constructions dites possessives, étude de linguistique générale et de typologie linguistique. Paris: Université de Paris IV dissertation.

Creissels, Denis. 2013. Control and the evolution of possessive and existential constructions. In Elly van Gelderen, Jóhanna Bardðdal \& Michela Cennamo (eds.), Argument structure in flux: The Naples-Capri papers, 461-476. Amsterdam \& Philadelphia: John Benjamins.

Creissels, Denis. 2019. Inverse-locational predication in typological perspective. Italian Journal of Linguistics 31(2). 37-106.

Croft, William. 2002. Typology and universals. Cambridge: Cambridge University Press.

Cristofaro, Sonia \& Fernando Zúñiga (eds.). 2018. Typological hierarchies in synchrony and diachrony. Amsterdam \& Philadelphia: John Benjamins.

Dai, Qingxia 戴庆厦 (ed.). 2009. Taiguo Aka-yu yanjiu 泰国阿卡语研究 [Research on the Akha language in Thailand]. Beijing: China Social Sciences Press.

Dai, Qingxia 戴庆厦. 2012. Jingpo-yu cankao yufa 景颇语参考语法 [A reference grammar of Jingpho]. Beijing: China Social Sciences Press.

Dai, Qingxia 戴庆厦 \& Jie Li 李洁. 2007. Leqi-yu yanjiu 勒期语研究 [Research on the Lashi language]. Beijing: Minzu University Press.

Dai, Qingxia 戴庆厦, Aiju Liu 刘菊黄 \& Ailan Fu 傅爱兰. 1991. Gazhuo-yu 嘎卓语 [The Khatso language]. In Qingxia Dai (ed.), Zangmian-yu 15 zhong 藏缅语十五种 [Fifteen Tibeto-Burman languages], 249-280. Beijing: Beijing Yanshan Press.

Dai, Zhaoming 戴昭铭. 2006. Tiantai fangyan yanjiu 天台方言研究 (Research on the Tiantai dialect). Beijing: Zhonghua Book Company.

Dao, Jie 刀洁. 2007. Bumang-yu yanjiu 布芒语研究 [Research on the Bumang language]. Beijing: Minzu Publishers.

Diller, Anthony V. N. 2008. Introduction. In V. N. Diller Anthony, Jerold A. Edmondson \& Yongxian Luo (eds.), The Tai-Kadai languages, 3-8. London \& New York: Routledge.

Ding, Jiayong 丁加勇. 1996. Longhui fangyan de dongtai zhuci 隆回方言的动态助词 [The aspectual markers in the Longhui dialect]. In Yunji Wu (ed.), Hunan fangyan de dongtai zhuci 湖南方言的动态助词 [The aspectual markers in the Hunan dialects], 342-369. Changsha: Hunan Normal University Press.

Ding, Jiayong 丁加勇 \& Gouhua Luo 罗够华. 2006. Longhui Xiang-yu de yuqici 隆回湘语的语气词 [Modal particles in the Longhui Xiang language]. In Yunji Wu (ed.), Hunan fangyan de fuqici 湖南方言的语气词 [Modal particles in the Hunan dialects], 1-25. Changsha: Hunan Normal University Press.

Dryer, Matthew S. 2003. Word order in Sino-Tibetan languages from a typological and geographical perspective. In Thurgood Graham \& Randy LaPolla (eds.), Sino-Tibetan languages, 43-55. Richmond: Curzon Press.

Dryer, Matthew S. 2008. Word order in Tibeto-Burman languages. Linguistics of the Tibeto-Burman Area 31(1). 1-84.

Enfield, Nicholas J. 2003. Linguistic epidemiology: Semantics and grammar of language contact in Mainland Southeast Asia. London: Routledge Curzon.

Enfield, Nicholas J. 2007. A grammar of Lao. Berlin \& New York: Mouton de Gruyter.

Evans, Nicholas \& David Wilkins. 2000. In the mind's ear: The semantic extensions of perception verbs in Australian languages. Language 76(3). 546-592.

Freeze, Ray. 1992. Existentials and other locatives. Language 68. 553-595. 
Gao, Yongqi 高永奇. 2002. Mang-yu yanjiu 䒭语研究 [Research on the Mang language]. Beijing: Minzu Publishers.

Gao, Yongqi 高永奇. 2004. Buxing-yu yanjiu 布兴语研究 [Research on the Buxing language]. Beijing: Minzu Publishers.

Gerner, Mathias. 2013. A grammar of Nuosu. Berlin \& Boston: De Gruyter Mouton.

Givón, Talmy. 1984. Syntax: A functional-typological introduction, vol. 1. Amsterdam \& Philadelphia: John Benjamins.

Haiman, John. 2011. Cambodian Khmer. Amsterdam \& Philadelphia: John Benjamins.

He, Gengyong 何耿镛. 1993. Kejia fangyan yufa yanjiu 客家方言语法研究 [Research on Hakka grammar]. Xiamen: Xiamen University Press.

Heine, Bernd. 1997a. Cognitive foundations of grammar. Oxford: Oxford University Press.

Heine, Bernd. 1997b. Possession: Cognitive sources, forces, and grammaticalization. Cambridge: Cambridge University Press.

Heine, Bernd. 2002. On the role of context in grammaticalization. In Ilse Wischer \& Gabriele Diewald (eds.), New reflections on grammaticalization, 83-101. Amsterdam \& Philadelphia: John Benjamins.

Hirata, Shoji 平田昌司. 1998. Huizhou fangyan yanjiu 徽州方言研究 [Research on the Hui dialects]. Tokyo: Kobun Press.

Hirata, Shoji 平田昌司. 1999. Huizhou fangyan “shi + chusuoci”shi de laiyuan 惠州方言“是+处 所词”式的来源 [The origins of [copula + locative] in the Huizhou dialects]. In Yunji Wu (ed.), Hanyu fangyan gongshi yu lishi yufa yantao lunwenji 汉语方言共时与历时语法研讨论文集 [Synchronic and diachronic perspectives on the grammar of Sinitic languages], 121-134. Guangzhou: Jinan University.

Hou, Jingyi 侯精 \& Duanzheng Wen 温端政. 1993. Shanxi fangyan diaochao yanjiu baogao 山西方 言调查研究报告 [A report on the survey and research on the dialects in Shanxi]. Taiyuan: Shanxi Gaoxiao Lianhe Press.

Huang, Chenglong. 2004. A reference grammar of the Puxi variety of Qiang. Hong Kong: City University of Hong-Kong dissertation.

Huang, Zhiquan 黄智权 (ed.). 2005. Jiangxisheng fangyanzhi 江西省方言志[The dialect gazetteers of Jiangxi Province]. Beijing: Fangzhi Publishers.

Huang, Chenglong 黄成龙. 2013. Zangmianyu cunzai-lei dongci de gainian jiegou 藏缅语存在类动 词的概念结构 [Conceptual structures of locative/existential verbs in Tibeto-Burman]. Minzu Yuwen 民族语文 [Minority Languages of China] 2. 31-48.

Iwasaki, Shoichi \& Preeya Ingkaphirom. 2005. A reference grammar of Thai. Cambridge: Cambridge University Press.

Jacques, Guillaume \& Alexis Michaud. 2011. Approaching the historical phonology of three highly eroded Sino-Tibetan languages: Naxi, Na and Laze. Diachronica 28. 468-498.

Jarkey, Nerida. 2015. Serial verb constructions in White Hmong. Leiden: Brill.

Jenny, Mathias. 2005. The verb system of Mon. Zürich: Faculty of Arts, Universität Zürich. Open Repository and Archive, University of Zürich ZORA.

Jenny, Mathias, Tobias Weber \& Rachel Weymuth. 2014. The Austroasiatic languages: A typological overview. In Jenny Mathias \& Sidwell Paul (eds.), The handbook of Austroasiatic languages, vol. 1, 13-143. Leiden: Brill.

Jenny, Mathias \& San San Hnin Tun. 2016. Burmese: A comprehensive grammar. Abingdon \& Oxford: Routledge.

Jiang, Shuzhen 姜淑珍 \& Changhai Chi 池昌海. 2018. Wuyu 'kang' de duogongneng moshi he yufahua 吴语 “园” 的多功能模式和语法化 [On the multifunctionality and the 
grammaticalization of 'kang' in the Wu dialects]. Zhongguo Yuwen 中国语文 [Languages in China] 2. 150-158.

Jiang, Guangyou 蒋光友. 2010. Jinuo-yu cankaoyufa 基诺语参考语法 [A reference grammar of Jinuo]. Beijing: China Social Sciences Press.

Jiang, Guangyou 蒋光友 \& Jian Shi 时建. 2016. Kunge-yu cankao yufa 昆格语参考语法 [A reference grammar of Kunge]. Beijing: China Social Sciences Press.

Jin, Xiaodong 金小栋 \& Fuxiang Wu 吴福祥. 2017. Guanhua fangyan fangzhiyi dongci 'ge' de yuyi yanbian 官话方言放置义动词 “搁” 的语义演变 [The semantic evolution of verbs of putting in the Mandarin dialects]. Yuyan Kexue 语言科学 [Linguistic Sciences] 4. 372-383.

Jing, Dian 经典. 2015. Mojiang Biyue Hani-yu cankao yufa 墨江碧约哈尼语参考语法 [A reference grammar of the Hani language of Mojiang Biyue]. Beijing: China Social Sciences Press.

Kang, Zhongde 康忠德. 2009. Judu Gelao-yu cankao yufa 居都伦佬语参考语法 [A reference grammar of the Gelao language of Judu]. Beijing: Minzu University of China dissertation.

Koch, Peter. 2012. Location, existence, and possession: A constructional-typological exploration. Linguistics 50(3). 533-603.

Koptjevskaja-Tamm, Maria. 2008. Approaching lexical typology. In Martine Vanhove (ed.), From polysemy to semantic change: Towards a typology of lexical semantic associations, 3-52. Amsterdam \& Philadelphia: John Benjamins.

Koptjevskaja-Tamm, Maria \& Henril Liljegren. 2017. Semantic patterns from an areal perpective. In Raymond Hickey (ed.), The Cambridge handbook of areal linguistics, 204-236. Cambridge: Cambridge University Press.

Kuteva, Tania, Bernd Heine, Bo Hong, Haiping Long, Heiko Narrog \& Seongha Rhee. 2019. World lexicon of grammaticalization, 2nd edn. Cambridge: Cambridge University Press.

La Polla, Randy J. \& Chenglong Huang. 2003. A grammar of Qiang, with annotated texts and glossary. Berlin \& New York: Mouton de Gruyter.

Lai, Yunfan. 2017. Grammaire du khroskyabs de Wobzi. Paris: University Sorbonne Nouvelle Paris 3 dissertation.

Li, Chunfeng 李春风. 2012. Bangduo Lahu-yu cankao yufa 邦朵拉祜语参考语法 [A reference grammar of Bangduo Lahu]. Beijing: Minzu University of China dissertation.

Li, Daoyong 李道勇, Xizhen Nie 聂锡珍 \& Efeng Qiu 邱锷锋. 1986. Bulang-yu jianzhi 布朗语简志 $[A$ concise grammar of the Blang language]. Beijing: Minzu Publishers.

Li, Guilan 李桂兰 \& Fuxiang Wu 吴福祥. 2018. Jiangxi Jishui fangyan 'qu' de duogongneng yongfa jiqi yanbian 江西吉水方言 “去” 的多功能用法及其演变 [On the multifunctionality of 'go' in Jishui Gan in Jiangxi]. Fangyan 方言 [Dialects] 2. 201-209.

Li, Qiqun. 2002. Jishou fangyan yanjiu 吉首方言研究 [Research on the Jishou dialect]. Beijing: Minzu Publishers.

Li, Xufang 李旭芳. 2014. Bai-yu cunzaiju yanjiu 白语存在句研究 [A study on the existential sentences in Bai]. Kunming: Yunnan Normal University MA thesis.

Li, Xuping. 2018. A grammar of Gan Chinese: The Yichun language. Berlin \& Boston: De Gruyter Mouton.

Li, Yongsui. 2002. Sangkong-yu yanjiu 桑孔语研究 [Research on the Sangkong language]. Beijing: Minzu University Press.

Li, Yunbing 李云兵. 2005. Bugeng-yu yanjiu 布春语研究 [Research on the Bugan language]. Beijing: Minzu Publishers. 
Li, Yundong 李云东. 2011. Yunnan Wenshan Yi-yu Azha-hua diaocha 云南文山彝语阿扎话调查 [An investigation on the language of Azha in Wenshan, Yunnan]. Guangzhou: Jinan University MA thesis.

Liang, Min 梁敏. 1980. Dong-yu jianzhi 侗语简志 [A sketch of Kam]. Beijing: Minzu Publishers.

Liang, Min 梁敏. 1981. Lingao-hua jianjie 临高话简介 [A brief introduction to Lingao]. Yuyan Yanjiu 语言研究 [Studies in language and linguistics] 1. 264-299.

Liang, Yuzhang 梁玉璋. 1990. Fuzhou-hua ‘tuo?' de cixing yu yufa gongneng 福州话 “着” 的词性 与语法功能 [The grammatical function of 'tuo?' in the Fuzhou dialect]. Yuyan Yanjiu 语言研究 [Studies in Language and Linguistics] 1. 126-132.

Lin, Philip T. 2015. Taiwanese grammar: A concise reference. Greenhorn Media. https:// gogreenhorn.com.

Lin, Shaofang 林少芳 \& Yimin Sheng 盛益民. 2018. Cong chusuo dongci dao panduan dongci de yanbian 从处所动词到判断动词的演变 [A case study of $k a P^{5}$ in the Fuqing Min dialect]. Zhongguo Yuwen 中国语文 [Languages in China] 6. 687-697.

Liu, Lu 刘璐. 1984. Jingpozu yuyan jianzhi 景颇族语言简志 [A sketch grammar of Jingpho]. Beijing: Minzu Publishers.

Liu, Jiansan 刘剑三. 2000. Lingao-Han cidian 临高汉词典 [A Lingao-Chinese dictionnary]. Chengdu: Sichuan Minzu Publishers.

Long, Yaohong \& Guoqiao Zheng. 1998. The Dong language in Guizhou Province, China. Texas: SIL \& University of Texas at Austin.

Lord, Carol. 1993. Historical change in serial verb constructions. Amsterdam \& Philadelphia: John Benjamins.

Lu, Tian Qiao. 2008. A grammar of Maonan. Boca Raton, FL: Universal Press.

Lü, Shanshan 吕珊珊 \& Daxingwang Peng 彭大兴旺. 2020. Hunan Pingjiang Gan-yu zhong de 'luo' zi beidongju 湖南平江赣语中的 “落” 字被动句 [On the passive constructions with ‘luo' as the agent marker]. Yuyan Kexue 语言科学 [Linguistic sciences] 19(2). 183-199.

Luo, Anyuan 罗安源. 2005. Songtao Miao-hua miaoxie yufaxue 松桃苗话描写语法学 [A descriptive grammar of Songtao Xong]. Beijing: Minzu University Press.

Luo, Kangning 罗康宁. 1987. Xinyi fangyanzhi 信宜方言志 [A survey of the Xinyi dialect]. Guangzhou: Sun Yat-Sen University Press.

Luo, Yongxian. 2008. Zhuang. In Anthony V. N. Diller, Jerold A. Edmondson \& Yongxian Luo (eds.), The Tai-Kadai languages, 317-377. London \& New York: Routledge.

Lyons, John. 1967. A note on possessive, existential and locative sentences. Foundations of Language 3. 390-396.

Lyons, John. 1968. Existence, location, possession and transitivity. In B. Van Rootselaar \& J. F. Staal (eds.), Logic, Methodology and Philosophy of Science III: Proceeding of the third international Congress for logic, Methodology and Philosophy of Science, Amsterdam, 1967 (Studies in logic and the foundations of mathematics 52), 495-504. Amsterdam: North Holland.

Ma, Beijia 马贝佳 \& Rong Cai 蔡嵘. 2006a. Wenzhou fangyan cunzai dongci ‘shi' de Laiyuan 温州 方言存在动词是的来源 [The origin of the verb 'shi' in the Wenzhou dialect]. Fangyan 方言 [Dialects] 3. 222-227.

Ma, Beijia 马贝佳 \& Rong Cai 蔡嵘. 2006b. Xici ‘shi' de yufahua 系词 “是” 的语法化 [On the grammaticalization of the copula 'shi']. Guhanyu Yanjiu 古汉语研究 [Research in Ancient Chinese] 3. 57-61.

Ma, Xueliang 马学良. 1951. Sani-yu yanjiu 撒尼语研究 [Research on the Sani language]. Beijing: The Commercial Press. 
Malchukov, Andrej \& Bernard Comrie (eds.). 2015. Valency classes in the world's languages. Berlin \& Boston: De Gruyter Mouton.

Matisoff, James A. 1991. Areal and universal dimensions of grammatization in Lahu. In Elizabeth C. Traugott \& Bernd Heine (eds.), Approaches to grammaticalization, Vol. 2, 383-453. Amsterdam \& Philadelphia: John Benjamins.

Matthews, Stephen \& Virginia Yip. 2011. Cantonese: A comprehensive grammar, 2nd edn. Abingdon: Routledge.

Mao, Zongwu 毛宗武 \& Yunbing Li 李云兵. 1997. Baheng-yu yanjiu 巴哼语研究 [Research on the Baheng language]. Shanghai: Far Eastern Press.

Mao, Zongwu 毛宗武 \& Yunbing Li 李云兵. 2002. Jiongnai-yu yanjiu 畑奈语研究 [Research on Jiongnai]. Beijing: Minzu University Press.

Mao, Zongwu 毛宗武 \& Yunbing Li 李云兵. 2007. Younuo-yu yanjiu 优诺语研究 [Research on the Younuo language]. Beijing: Minzu Publishers.

Mao, Zongwu 毛宗武 \& Chaoji Meng 蒙朝吉. 1986. She-yu jianzhi 峹语简志 [A sketch grammar of She]. Beijing: Minzu Publishers.

Mao, Zongwu 毛宗武, Chaoji Meng 蒙朝吉 \& Zongze Zheng 郑宗泽. 1982. Yaozu yuyan jianzhi 瑶族语言简志 [A sketch grammar of Mien]. Beijing: Minzu Publishers.

Mazzitelli, Lidia. 2015. The expression of predicative possession: A comparative study of Belarusian and Lithuanian. Berlin \& Boston: De Gruyter Mouton.

Meillet, Antoine. 1923. Le développement du verbe 'avoir'. In Antidoron: Festschrift Jacob Wackernagel zur Vollendung des 70. Lebensjahres am 11. Dezember 1923, gewidmet von Schülern, Freunden und Kollegen, 9-13. Göttingen: Vandenhoeck \& Ruprecht.

Mo, Tingting 莫廷婷. 2017. Buyi-yu fangweici ‘shang, xia', 'li, wai’ de yuyi tezheng he yufa gongneng 布依语方位词 “上、下” “里、外” 的语义特征和语法功能 [On the semantic features and the grammatical functions of the localizers 'upside, downside' and 'inside, outside' in Buyi]. Baise Xueyuan Bao 百色学院报 [Journal of Baise University] 3. 52-59.

Morev, Lev N. 1994. Possessive constructions in Tai. In Hajime Kitamura, Tatsuo Nishida \& Yasuhiko Nagano (eds.), Current Issues in Sino-Tibetan Linguistics (26th International Conference on Sino-Tibetan Languages and Linguistics, 13-17 September 1993), 890-905. Osaka: National Museum of Ethnology.

Morey, Stephen. 2010. Turung - A variety of Singpho language spoken in Assam. Canberra: Pacific Linguistics.

Myler, Neil. 2016. Building and interpreting possession sentences. Cambridge, MA: The MIT Press. Mu, Shihua 木仕华. 2002. Kazhuo-yu yanjiu 卡卓语研究 [Research on the Khatso language]. Beijing: Minzu Publishers.

Ngai, Sing Sing. 2021. A grammar of Shaowu: A Sinitic language of Northwestern Fujian. Berlin \& Boston: De Gruyter Mouton.

$\mathrm{Ni}$, Na 倪娜. 2007. De'ang-yu Guangka-hua yiwenju yudiao yanjiu 德昂语广卡话疑问句语调研究 [An investigation of the prosody in questions in Guangka Palaung]. Beijing: Minzu University of China MA thesis.

Norman, Jerry. 1988. Chinese. Cambridge: Cambridge University Press.

Ostipirat, Weera. 2000. Proto-Kra. Linguistics of the Tibeto-Burman Area 23(1). 1-251.

Ouyang, Jueya 欧阳觉亚, Fang Cheng 程方 \& Cuirong Yu 喻翠容. 1984. Jing-yu jianzhi 京语简志 [A sketch grammar of the Jing language]. Beijing: Minzu Publishers.

Peng, Fengshu 彭逢澍. 1998. Loudi fangyan de jieci 娄底方言的介词 [Prepositions in the Loudi dialect]. In Yunji Wu (ed.), Hunan fangyan de jieci 湖南方言的介词 [Prepositions in the Hunan dialects], 146-164. Changsha: Hunan Normal University Press. 
Peng, Fengshu 彭逢澍. 2000. Loudi fangyan de daici 娄底方言的代词 [Pronouns in the Loudi dialect]. In Yunji Wu (ed.), Hunan fangyan de daici 湖南方言的代词 [Pronouns in the Hunan dialects], 145-161. Changsha: Hunan Normal University Press.

Peng, Fengshu 彭逢澍. 2006. Loudi fangyan de yuqi zhuci 娄底方言的语气助词 [Modal particles of the Loudi dialect]. In Yunji Wu (ed.), Hunan fangyan de yuqici 湖南方言的语气词 [Modal particles in the Hunan dialects], 126-140. Changsha: Hunan Normal University Press.

Peyraube, Alain. 1981. Les constructions locatives en chinois moderne. Paris: Langages croisés. Phan, Vu Tuan Anh 潘武俊英. 2010. Yue-yu cankao yufa 越语参考语法 [A reference grammar of Vietnamese]. Beijing: Minzu University of China dissertation.

Post, Mark. 2008. Verbs of posture, existence, location and possession and their grammaticalization pathways in the Tani languages. In Steven Morey \& Mark Post (eds.), North East Indian linguistics, 127-150. New Delhi: Cambridge University Press.

Pu, Zhongliang 普忠良. 2016. Nasu Yi-yu yufa yanjiu 纳苏彞语语法研究 [Research on Nasu grammar]. Shanghai: Shanghai Normal University dissertation.

Ratliff, Martha. 1992. Meaningful tone: A study of tonal morphology in compounds, form classes, and expressive phrases in White Hmong. Dekalb, IL: Center for Southeast Asian Studies.

Ratliff, Martha. 1994. Topicalized NPs with expansion pronouns in Hmong. In Karen L Adams \& Thomas J. Hudak (eds.), Papers from the Second Annual Meeting of the Southeast Asian Linguistics Society, 251-261. Arizona State University, Program for Southeast Asian Studies.

Ratliff, Martha. 2010. Hmong-Mien language history (Pacific linguistics 613). Canberra: Australian National University, College of Asia and the Pacific.

Rao, Min. 2015. Description du guiqiong, langue tibéto-birmane. Paris: EHESS dissertation.

Rao, Min 饶敏. 2017. Guiqiongyu de cunzai dongci yanjiu. 贵琼的语存在动词研究 [Existential verbs of Guiqiong]. Journal of Chongqing Technology and Business University (Social Sciences edition) 34(2). 86-92.

Ruan, Guijun 阮桂君. 2009. Ningbo fangyan yufa yanjiu 宁波方言语法研究 [Grammatical studies on the Ningbo dialect]. Wuhan: Huazhong Normal University Press.

Saeliao 刘玉兰 (Liu Yulan), Thanyalak. 2012. Taiguo Mian-yu cankao yufa 泰国勉语参考语法 [A reference grammar of Mien in Thailand]. Beijing: Minzu University of China dissertion.

Sagart, Laurent. 1999. Notes on the Nanchang dialect (Sketch grammar and transcriptions). Melbourne: Department of Linguistics, La Trobe University Unpublished manuscript.

Sagart, Laurent, Roger Blench \& Alicia Sanchez-Mazas. 2005. The peopling of East Asia: Putting together archaeology, linguistics and genetics. London \& New York: Routledge Curzon.

Sapir, Edward. 1921. Language: An introduction to the study of speech. New York: Harcourt, Brace.

Saul, Janice E. \& Nancy Freiberger Wilson. 1980. Nùng grammar. Summer Institute of Linguistics \& University of Texas at Arlington.

Schuessler, Axel. 1988. A dictionary of early Zhou Chinese. Honolulu, HI: University of Hawai Press.

Shee, Naw Hsar. 2008. A descriptive grammar of Geba Karen. Chiang Mai: Payap University MA thesis.

Shi, Jian 时建. 2009. Lianghe Achang-yu cankao yufa 梁河阿昌语参考语法 [A reference grammar of Lianghe Achang]. Beijing: China Social Sciences Press.

Shi, Shuo. 2018. Ethnic flows in the Tibetan-Yi corridor throughout history. International Journal of Anthropology and Ethnolnology 2. 2.

Sidwell, Paul. 2014. Austroasiatic classification. In Mathias Jenny \& Sidwell Paul (eds.), The handbook of Austroasiatic languages, Vol. 1, 144-220. Leiden: Brill.

Smyth, David. 2002. Thai: An essential grammar, 2nd edn. London \& New York: Routledge. 
So-Hartmann, Helga. 2009. A descriptive grammar of Daai Chin. Berkeley, CA: STEDT, University of California.

Solnit, David B. 1997. Eastern Kayah Li grammar, texts glossary. Honolulu, HI: University of Hawai'i Press.

Sposato, Adam. 2014. Word order in Miao-Yao (Hmong-Mien). Linguistic Typology 18(1). 83-140. Sposato, Adam. 2015. A grammar of Xong. Buffalo, NY: University at Buffalo dissertation.

Starosta, Stanley. 2005. Proto-East Asian and the origin and dispersal of the languages of East and Southeast Asia and the Pacific. In Laurent Sagart, Roger Blench \& Alicia Sanchez-Mazas (eds.), The peopling of East Asia: Putting together archaeology, linguistics and genetics, 182-197. London \& New York: Routledge Curzon.

Stassen, Leon. 1997. Intransitive predication. Oxford: Oxford University Press.

Stassen, Leon. 2009. Predicative possession. Oxford: Oxford University Press.

Stassen, Leon. 2013. Predicative possession. In Matthew S. Dryer \& Martin Haspelmath (eds.), The world atlas of language structures online. Leipzig: Max Planck Institute for Evolutionary Anthropology. http://wals.info/chapter/117 (Accessed 5 May 2019).

Su, Xiaoqing 苏晓青 \& Yongwei Lü 吕永卫. 1996. Xuzhou fangyan zidian 徐州方言字典 [A dictionary of the Xuzhou dialect]. Nanjing: Jiangsu Jiaoyu Press.

Sun, Chaofen. 1996. Word order change and grammaticalization in the history of Chinese. Stanford, CA: Stanford University Press.

Sun, Hongkai 孙宏开. 1982. Dulong-yu jianzhi 独龙语简志 [A sketch grammar of Dulong]. Beijing: Minzu Publishers.

Sun, Hongkai 孙宏开. 1983. Chuanxi minzu zoulang diqu de yuyan 川西民族走廊地区的语言 [Languages of the ethnic corridor of Western Sichuan]. In Association of Studies on China Southwest Nationalities (ed.), Xinan Minzu Yanjiu 西南民族研究 [Studies on the Southwest Nationalities], 429-454. Chengdu: Sichuan Nationalities Publishing House.

Sun, Wenfang 孙文访. 2015. Jiyu ‘shi, you, zai’ de yuyan gongxing yu leixing “基于是、有、在” 的 语言共性与类型 [Language universals and typology of copular, existential/possessive and locative verbs]. Zhongguo Yuwen 中国语文 [Languages in China] 1. 50-63.

Sun, Hongkai 孙宏开, Chenglong Huang 黄成龙 \& Maocao Zhou 周毛草. 2002. Rouruo-yu yanjiu 柔若语研究 [Research on the Zauzou language]. Beijing: Minzu University Press.

Sun, Hongkai 孙宏开 \& Lu Liu 刘璐. 1983. Nuzu-yu jianzhi 怒族语简志 [A sketch grammar of Nusu]. Beijing: Minzu Publishers.

Takashima, Ken-ichi. 1996. Language and palaeography. In Gary F. Arbuckle (ed.), Studies in early Chinese civilization: Religion, society, language and palaeography, Vol. 1, 179-505. Osaka: Kansai Gaidai University.

Tian, Desheng 田德生, Tianzhen He 何天贞, Kang Chen 陈康, Jingzhong Li 李敬忠, Zhimin Xie 谢志民 \& Xiumo Peng 彭秀模. 1986. Tujia-yu jianzhi 土家语简志 [A sketch grammar of Tujia]. Beijing: Minzu Publishers.

Vittrant, Alice \& Justin Watkins (eds.). 2019. The Mainland Southeast Asia linguistic area. Berlin \& Boston: De Gruyter Mouton.

Wang, Li 王力. 1958. Hanyu shigao 汉语史稿 [History of the Chinese language], 3 vols. Beijing: Kexue Press.

Wang, Fushi 王辅世. 1985. Miao-yu jianzhi 苗语简志 [A sketch grammar of Hmong]. Beijing: Minzu Publishers.

Wang, Yuhong 王育弘. 1994. Wa-yu de Jieci 低语的介词 [Prepositions in Wa]. In Jingliu Wang 王敬骝 (ed.), Wa-yu yanjiu 唒语研究 [Research on the Wa language], 136-145. Kunming: Yunnan Minzu Press. 
Wang, Wenqing 王文卿. 2007. Jinyuan fangyan yanjiu 晋源方言研究 [Research on the Jianyuan dialect]. Beijing: Yuwen Press.

Wang, Feng 王锋. 2012. Kunming Xishan Shalang Bai-yu yanjiu 昆明西山沙朗白语研究 [Research on the Bai language of Xishan Shalang in Kunming]. Beijing: Zhongguo Kexue Press.

Wang, Fushi 王辅世 \& Deguang Wang 王德光. 1982. Guizhou Weining Miao-yu de fangweici 贵州 威宁苗语的方位词 [Localizers in Weining Hmong]. Minzu Yuwen 民族语文 [Minority Languages of China] 4. 20-34.

Wei, Xuechun 韦学纯. 2011. Shui-yu miaoxie yanjiu 水语描写研究 [A descriptive study on the Shui language]. Shanghai: Shanghai Normal University dissertation.

Wei, Maofan 韦茂繁. 2012. Xia'ao Zhuang-yu cankao yufa 下坳壮语参考语法 [A reference grammar of the Zhuang language of Xia'ao]. Shanghai: Shanghai Normal University dissertation.

Wei, Maofan 韦茂繁 \& Shuguan Wei 韦树关. 2011. Wuse-hua yanjiu 五色话研究 [Research on the Wuse language]. Beijing: Minzu Publishers.

Wu, Yunji. 2005. A synchronic and diachronic study of the grammar of the Chinese Xiang dialects. Berlin \& New York: Mouton de Gruyter.

Xiang, Mengbing 项梦冰. 1997. Liancheng Kejia-hua yufa yanjiu 连城客家话语法研究 [Grammatical studies on Liancheng Hakka]. Beijing: Yuwen Press.

Xie, Qiyong 谢奇勇. 2014. Xintian fangyan de jieci 新田方言的介词 [Prepositions in the Xintian dialect]. In Yunji Wu (ed.), Hunan fangyan de jieci [Prepositions in the Hunan dialects], 2nd edn., 115-130. Changsha: Hunan Normal University Press.

$\mathrm{Xu}$, Huiling. 2007. Aspects of Chaozhou grammar: A synchronic description of the Jieyang variety. (Journal of Chinese Linguistics Monograph Series 22). Hong Kong: Chinese University Press.

Xu, Ying 徐颖. 2009. Fuzhou fangyan yuqici [si $\left.{ }^{11}\right]$ yanjiu 抚州方言语气词“是 $\left[\mathrm{si}^{11}\right]$ ”研究 [A study of the discourse marker [si $\left.{ }^{11}\right]$ in the Fuzhou dialect]. Wenjiao Ziliao 31. 38-40.

Xu, Baohu 许宝华 \& Huan 陶寰 Tao. 1997. Shanghai fangyan zidian 上海方言字典 [A dictionnary of the Shanghai dialect]. Nanjing: Jiangsu Jiaoyu Press.

Xu, Lin 徐琳 \& Yanxun Zhao 赵衍称. 1984. Baiyu jianzhi 白语简志 [A sketch grammar of Bai]. Beijing: Minzu Publishers.

Yang, Tongyin 杨通银. 2000. Mo-yu yanjiu 莫语研究 [Research on Mak]. Beijing: Minzu University Press.

Yang, Yan 杨艳. 2016. Hani-yu Woni-hua yanjiu 哈尼语窝尼话研究 [Research on the Woni language]. Shanghai: Shanghai Normal University dissertation.

Yin, Shage 银莎格. 2012. Yincun mulao-yu cankao yufa 银村仟佬语参考语法 [A reference grammar of Yincun Mulao]. Beijing: Minzu University of China dissertation.

Yu, Cuirong 喻翠容. 1980. Buyi-yu jianzhi 布依语简志 [A sketch grammar of Bouyei]. Beijing: Minzu Publishers.

Yu, Jinzhi 余金枝. 2010. Aizhai Miao-yu cankao yufa 矮寨苗语参考语法 [A reference grammar of Aizhai Xong]. Beijing: Minzu University of China dissertation.

Yu, Cuirong 喻翠容 \& Meizhen Luo 罗美珍. 1980. Dai-yu jianzhi 傣语简志 [A sketch grammar of Dai]. Beijing: Minzu Publishers.

Yuan, Zhongshu 苑中树. 1994. Li-yu yufa gangyao 黎语语法纲要 [An outline of Hlai grammar]. Beijing: Minzu University Press.

Zhai, Huifeng 翟会锋. 2011. Sanguanzhai Yi-yu cankao yufa 三官寨彝语参考语法 [A reference grammar of Nisu (Sanguanzhai)]. Beijing: Minzu University of China dissertation. 
Zhang, Xiuzhen 张秀珍. 2005. Guibei Pinghua yu tuiguang Putonghua yanjiu 桂北平话与推广普 通话研究 [Studies on Guibei Pinghua and the promotion of Putonghua - Research on Hezhou Jiudusheng]. Nanning: Guangxi Minzu Publishers.

Zhang, Shuya. 2018. Stem alternations in the Brag-bar dialect of Situ Rgyalrong. Linguistics of the Tibeto-Burman Area 41(2). 294-330.

Zhang, Junru 张均如, Yiqing Zheng 郑贻青, Xulian Li 李旭练 \& Jianyou 谢建猷 Xie. 1999. Zhuangyu fangyan yanjiu 壮语方言研究 [Research on the Zhuang dialects]. Chengdu: Sichuan Minzu Press.

Zhao, Min 赵敏 \& Maoyun Zhu 朱茂云. 2011. Mojiang Hanizu Kaduo-hua cankao yufa 墨江哈尼族 卡多话参考语法 [A reference grammar of the Kaduo variety of the Hani language]. Beijing: China Social Sciences Press.

Zheng, Yide 郑懿德. 1985. Fuzhou fangyan de ‘you’ zi ju 福州方言 “有” 字句 [On the sentences with 'have' in Fuzhou]. Fangyan 方言 [Dialects] 4. 309-313.

Zheng, Wuxi. 2016. A grammar of Longxi Qiang. Singapore: National University of Singapore dissertation.

Zhou, Zhizhi 周植志 \& Qixiang Yan 颜其香. 1984. Wa-yu yanjiu 唒语简志 [A concise grammar of the Wa language]. Beijing: Minzu Publishers.

Zhu, Xiaonong. 2006. A grammar of Shanghai Wu. Munich: Lincom Europa. 